Illinois State University

ISU ReD: Research and eData

Theses and Dissertations

3-4-2021

\title{
Peering At The Mirror Of Reflection: Agency And Design Thinking In The Development Of Writerly Identities
}

Elizabeth Louise Jones

Illinois State University, mo_writer@yahoo.com

Follow this and additional works at: https://ir.library.illinoisstate.edu/etd

Part of the English Language and Literature Commons, and the Linguistics Commons

\section{Recommended Citation}

Jones, Elizabeth Louise, "Peering At The Mirror Of Reflection: Agency And Design Thinking In The Development Of Writerly Identities" (2021). Theses and Dissertations. 1379.

https://ir.library.illinoisstate.edu/etd/1379

This Dissertation is brought to you for free and open access by ISU ReD: Research and eData. It has been accepted for inclusion in Theses and Dissertations by an authorized administrator of ISU ReD: Research and eData. For more information, please contact ISUReD@ilstu.edu. 


\section{PEERING AT THE MIRROR OF REFLECTION: AGENCY AND DESIGN THINKING}

\section{IN THE DEVELOPMENT OF WRITERLY IDENTITIES}

\section{ELIZABETH LOUISE JONES}

209 Pages

I have always valued reflection highly - as a means of developing as a writer and as a life practice - but I have been disappointed by the lack of thought resembling reflection when asking students to write about their writing practices. This dissertation presents the results of a grounded theory study of student reflective assignments through a direct analysis of the themes which emerged from a set of reflections from a course designed around the topic of games primarily board, card, and video games. This study differs from much of the previous scholarship on reflection in composition in that I analyzed what students say in these reflections rather than to analyze the purpose of reflection in reinforcing writing skills or in transferring writing skills to other contexts. The participants in this study were primarily first-year college students enrolled in a writing course with a curriculum focused on genre study and activity theory. The results of this study suggested that while many students tended to distance themselves from their work, through "I" claims and passive voice, these strategies may be important ways developing a sense of reflection. Other students demonstrated greater engagement with their work, taking ownership of their composing processes and using design thinking in their reflections. However, a tension between design thinking and engagement may have prevented students from fully using both of these in reflective writing.

An important finding in this project is that students must claim agency in order to develop texts that show strong evidence of reflective thought. While they also demonstrated evidence of design thinking, partly due to the nature of the design process as one of making deliberate choices, students were more likely to resort to strategies intended to satisfy the 
instructor when they lacked a sense of control over their work, whether due to the constraints of an assignment or due to their own unwillingness to make the decisions associated with taking ownership of a project. I also advocate for an understanding of reflection that recognizes the desire of students to make social connections through their reflective writing. Although students frequently invoked surface claims that they tailored their work from an audience, their reflections revealed a deeper desire for connections with their classmates and with potential readers.

KEYWORDS: design thinking, engagement, reflection, writing studies 
PEERING AT THE MIRROR OF REFLECTION: AGENCY AND DESIGN THINKING

IN THE DEVELOPMENT OF WRITERLY IDENTITIES

ELIZABETH LOUISE JONES

A Dissertation Submitted in Partial

Fulfillment of the Requirements for the Degree of

DOCTOR OF PHILOSOPHY

Department of English

ILLINOIS STATE UNIVERSITY

2021 
(C) 2021 Elizabeth Louise Jones 
PEERING AT THE MIRROR OF REFLECTION: AGENCY AND DESIGN THINKING IN THE DEVELOPMENT OF WRITERLY IDENTITIES

ELIZABETH LOUISE JONES

COMMITTEE MEMBERS:

James Kalmbach, Chair

Julie M. Jung

Brian Rejack

Bob Broad 


\section{ACKNOWLEDGMENTS}

With the deepest gratitude to Jim Kalmbach for his patience, persistence, and enthusiasm in guiding me through the process of conducting my research and writing the results.

With special thanks to Julie Jung for her support and of her teaching in some of the best classes I have ever taken.

With gratitude for Brian Rejack and Bob Broad for both their teaching and their support for this project.

With appreciation to my brothers Devin and Colin, to my mother Laura Guyer, to my daughter Rachel Beamon, and to Gary Beamon. Also, a great debt to Denise Sherwood for all of the times she reminded me to get my writing done. And thanks to countless other friends - old and new - who encouraged me along the way.

With thanks to Citlalin Xochime and Sandy Harmon for quiet places to sleep and work. To my four-legged friends, Charlie (R.I.P.) and Rosie, who took me for walks in the desert and entertained me with countless rounds of "bite-face" and tug-of-war, and to Miracle and Scout for carrying me on relaxing trail rides.

And finally, the greatest of thank to my father, Dale A. Jones (an alumnus of Illinois State Normal University). While he passed away several years before I started on this adventure, he always believed in me and assured me I could do anything I wanted. In the year before his passing, he encouraged me to work on a doctorate degree and said he always wanted a doctor in the family. I told him I wouldn't be a "real” doctor (as in a medical doctor), but he assured me that a doctorate in English studies would count.

\section{E.L.J.}




\section{CONTENTS}

\section{Page}

ACKNOWLEDGMENTS

$\begin{array}{ll}\text { CONTENTS } & \text { ii }\end{array}$

TABLES

CHAPTER I: INTRODUCTION

Defining Reflection $\quad 4$

Designing the Research Project $\quad 6$

$\begin{array}{ll}\text { Overview of Chapters } & 7\end{array}$

CHAPTER II: TRAVELING CONCEPTS: REFLECTION, DESIGN, AND EMBODIMENT 11

Enigmas of Reflection $\quad 12$

History of Reflection in Composition $\quad 14$

Reflection and Assessment $\quad 16$

Reflection and Multimodal Composition $\quad 19$

Reflection and Design $\quad 22$

Defining Design Thinking $\quad 27$

Design thinking, Reflection, and Embodiment 33

Metacognition and Reflection $\quad 35$

Pausing to Look Ahead $\quad 38$

CHAPTER III: PARADOXICAL ROOTS: USING GROUNDED THEORY

TO READ STUDENT REFLECTIONS $\quad 39$

The Course and the Students $\quad 40$

The Student Participants $\quad 51$

What I Wanted to Learn - Engagement and Design in Reflection 53

Grounded Theory Chooses Me $\quad 56$

Digging into Specific Codes $\quad 62$ 
Coding for "I" Claims $\quad 64$

Coding for Audience $\quad 66$

$\begin{array}{ll}\text { Coding for Engagement and Creativity } & 68\end{array}$

$\begin{array}{ll}\text { Coding for Satisfaction } & 70\end{array}$

$\begin{array}{ll}\text { Conclusion } & 71\end{array}$

CHAPTER IV: STORIES OF SELF, CREATIVITY, AND DESIGN THINKING 73

In Which Students Distance Themselves from their Work 75

"I" Claims and Audience $\quad 75$

"I" Claims and Improvement $\quad 76$

Use of Impersonal Language $\quad 82$

Audience and Engagement $\quad 86$

The Hero's Journey as Commonplace $\quad 89$

In Which Students Begin to Reflect in More Recognizable Ways 94

Agency and Creativity $\quad 95$

Satisfaction and Creativity $\quad 99$

$\begin{array}{lr}\text { Creativity, Enjoyment, and Engagement } & 102\end{array}$

$\begin{array}{ll}\text { Student Interest in Topics } & 104\end{array}$

In Which Students Engage and Take Ownership through Design Thinking 106

$\begin{array}{ll}\text { Conclusion } & 114\end{array}$

CHAPTER V: DESIGN THINKING AND CULTURAL NARRATIVES:

FOCUSING ON THE SOCIAL $\quad 116$

Reflection as a Social Process $\quad 117$

Audience and Social Connections $\quad 119$

$\begin{array}{ll}\text { Engagement and Embodiment } & 128\end{array}$

Challenges in Redesigning Reflective Assignments 132

Should We Teach Reflection? 137 
$\begin{array}{ll}\text { APPENDIX A: COURSE SYLLABUS } & 150\end{array}$

APPENDIX B: UNIT 1 ASSIGNMENT SHEET 162

APPENDIX C: EXAMPLE NARRATIVE FOR UNIT 1 166

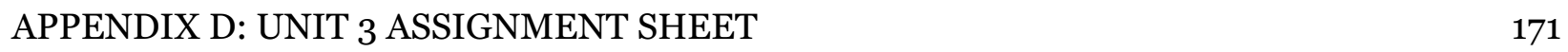

APPENDIX E: EXAMPLE OF UNIT 3

APPENDIX F: ASSIGNMENT SHEET FOR FINAL REFLECTION 177

APPENDIX G: COMPREHENSIVE LIST OF CODES $\quad 180$

APPENDIX H: IMAGES FROM ORGANIZING THE CODES 185 


\section{TABLES}

Table

Page

1. "I" Claims and Relationships to Other Codes $\quad 65$

2. Codes Representing Audience $\quad 66$

3. Uses of Audience Codes $\quad 67$

4. Central Codes with Related Codes $\quad 69$

5. Codes Associated With "Satisfaction" $\quad 71$

6. Level of Enthusiasm about Satisfaction Correlated with Associated Codes $\quad 101$

7. Relationship between Design Concepts and Audience 107 


\section{CHAPTER I: INTRODUCTION}

Mieke Bal (2002) argues that when concepts - an "abstract representation" - travel between disciplines, "their meaning, reach and operational value" must be reassessed (p. 24). The concept of reflection is in need of such a reassessment in its travel between various academic disciplines, including nursing, design, and engineering, and in its travel between scholars within English studies.

While reflection seems to be a natural fit with writing studies and a "natural" process in a writing classroom, much of the scholarship on reflection in this field has been focused on the purpose and outcomes of reflection, particularly the transfer of writing skills from one context to another. Since some of my first experiences with reflection in a composition course were negative, however, I have attempted to better understand reflection and to develop strategies to help students write reflective texts. Too often, the assignments students submit as reflections seem to lack any evidence of thought that is recognizable as reflection. Therefore, the purpose of this project has been to focus not on looking past the reflections to support their use in composition but to look directly at reflections written by students to determine what these texts reveal about their approach to writing them. I also wanted to examine the role of design thinking, which I used to develop the reflective assignments, looking for evidence that students had taken up design thinking in their own writing.

My personal experiences with reflection began with my own journaling, and this practice was directly associated with my own development as a writer; it was not only a means of reflecting on experiences on the page but to also gain experience with writing. Inspired by stories of famous authors, I began to keep a journal when I was about 13 years old, and in this notebook, I reflected on music, spirituality, the difficult relationship I had with my mother, and other concerns that evolved over many years of journaling. During a significant chunk of time in my 20s, my journals were filled with notes on the Bible and questions that I was unable to ask at the conventional churches I attended. In the years that followed, I also struggled with 
depression, marriage, and career choices in these pages, and the process of reflecting on these challenges made it easier for me to deal with them and to move forward in life.

In contrast, my professional interest in reflection began with my first full-time college teaching position at a public liberal arts university in the Midwest. My teaching and writing experience seemed to be suited to the first-year writing program at this university since the program required students to complete portfolios, and I had previously used portfolios and studied some of the scholarship on portfolios, including the reflective cover letter that typically accompanies student writing portfolios. Unlike the very personal reflections I had recorded in my journals, most of which I would be embarrassed to share with anyone today, students in this writing program were asked to write reflections to account for their writing processes and revisions of major projects throughout the semester.

In my first couple of semesters teaching in this program, I used the assignments that had been written by the Writing Program Administrator for instructors to use, if they chose to do so. However, the reflective documents students produced were difficult to read, not because of the way in which students wrote but because of the intense emotions in their texts. Students used these reflections as a way of complaining about the assignment, sometimes directing their anger and frustration directly at me. Their "reflections" were directed outward instead of engaging in the examination I expected them to make of their own drafts and processes. My own positive experiences with reflection as a keeper of journals made these student submissions even more perplexing and painful.

In my disappointment at the negative reflections students submitted, I re-wrote the reflective assignments in order to encourage students to look more at their own work for the course, and while this reduced the accusatory tones, the end results were often uninspiring. That was until about three years later, when I focused one of my courses entirely around multimodal projects. The students in this particular class seemed to produce more engaging reflective cover letters for their final portfolios than the students in my classes focusing more on alphabetic 
composing. I thought at first that I might have been imagining the difference, but I went back into the gradebooks for each of my classes and found that the average score I gave on the reflections at the end of the semester were indeed higher in the multimodal class than in my other classes. Ultimately, this class provided the opportunity for me to develop the pilot project that would later lead to the research for this dissertation.

I also began to question the connections between multimodal composition and reflection, which I will further discuss in the next chapter. Like many instructors in their early experiences with multimodal composition, I was concerned that multimedia projects would reduce the experience students would have in alphabetic writing. However, when I interviewed the students from that fall multimodal course, they repeatedly discussed their writing, and even when I encouraged them to tell me more about the multimodal projects, they did not discuss these as much as I had hoped. One of the things that was most consistent in these interviews was the importance of writing about topics that mattered to them. I had thought that the use of various media was a potential way to motivate and engage students, but what I found was that it was the flexibility in choosing their topics that most interested them.

A year after I transitioned from a full-time position at the liberal arts university to teaching as a graduate assistant in the doctoral program at Illinois State University, I developed a composition course around the theme of games, particularly board and card games. Although I knew that students preferred to write about topics that interested them, I wanted to use a theme that I thought would interest students while also providing them with some choices in their writing. I was invested in games myself, and I reasoned that virtually everyone had played board and card games with families while growing up. My assumption proved to be correct. I experienced some anxiety with the choice of a theme that seemed relatively "light" and lacking the exigency of topics more closely associated with national or worldwide problems. However, I was encouraged by the work of James Paul Gee, who has invested a great deal of scholarship into identifying the characteristics of video gaming that also apply to education. Ultimately, 
most students were interested in the topic, and the students I interviewed were enthusiastic about the opportunity they had to be creative with their projects.

\section{Defining Reflection}

Reflection is perhaps most frequently viewed as a thought process and sometimes associated with an image of meditation and contemplation, whether about past or future experiences. The use of "reflection" in the title of a work usually refers to a series of thoughts on a particular topic or on the experiences of an individual. The term - or practice of reflection seems to have also gained popularity in the latter half of the $20^{\text {th }}$ century, though it was certainly not unknown prior to that. A direct line exists from the work of Donald Schön through Kathleen Blake Yancey's scholarship on reflection within the discipline of composition, and reflective writing has increasingly become a crucial element of composition programs. This reflective turn, however, should arguably be considered in the context of design in large part the result of Schön's (1983) argument that design is implicated in the creative activities in a variety of disparate disciplines.

The concept of design, however, seems to have entered composition separately from reflection, primarily with the practice of multimodal composition. Like reflection, design has also been presented as a sort of solution to problems in composition instruction. In Jody Shipka's Toward a Composition Made Whole (2011) is the sense of a promise - one of completion, perhaps not of the discipline but of a practice that marries the intellectual work of writing with the physicality of multimodal composition. While Shipka's work comes after that of several of prominent scholars in composition and rhetoric, her pedagogy encourages students to explore the materiality of composing to a greater extent than previous books on multimodal composition have suggested. Yet even in the suggestion of an "ultimate" solution is the word "toward," Composition is not finally completed or made "whole" but is still looking "toward" completion, toward a "better" approach or understanding of writing/composing and how to best teach the process of making and conveying meaning through a variety of texts. 
My examination and untangling of these interwoven strands of reflection, design, and multimodal composition began when I asked how a reflective genre might be defined. I thought that if I could teach reflection as a genre, students would be able to better approach the process of reflection. At the same time, however, I thought that if reflection were to be taught as a genre, the activity of reflection might be diminished. Yancey has argued for reflection as a means of helping students to recognize their processes of writing so that they may transfer their knowledge of writing to different writing situations beyond the composition classroom. But if reflection is merely another genre in which students will learn to write, then it seems to be less useful in accomplishing this goal of transfer. On the other hand, some of the other pedagogical tools we use in composition, such as revising and editing, are not activities students inherently know how to do, yet we use these to help them produce what we expect to be "better" work. I eventually concluded that reflection is a skill that must be taught, and I theorized, based on my reading of Schön's work, that design thinking and multimodal composing - closely related concepts, to be sure - could be powerful tools in generating reflective thinking and writing by students.

While the link between multimodal composing and design seems obvious, the link between reflection and design did not begin to coalesce for me until I read Donald Schön's pair of books, The Reflective Practitioner and Educating the Reflective Practitioner. These books focus on reflective practitioners in professions such as nursing, teaching, environmentalism, and business, suggesting the broad impact of theories, and I wanted to better understand the source of not only the terminology Yancey imported into composition pedagogy but also of the wider implications of reflection. I was surprised at how prominent a role design played in the various case studies in Schön's books, but I also found myself struggling to understand his models of reflection. I noticed that while Schön describes classrooms and mentoring situations, his discussions of reflections centered not on the students or mentees but on the professors and mentors, and reflection-in-action occurs during the interactions between the more experienced 
professional and the apprentices. This contrasted with my previous understanding of reflection in composition pedagogy and its emphasis on student reflection. Nevertheless, my previous experience with reflection in the classroom influenced me to consider how I could incorporate design into reflective assignments and to also look for the use of design thinking by students.

\section{Designing the Research Project}

Over two semesters, I collected the work of students who agreed to participate in this study. I also interviewed several students in the semester following their enrollment in my class to discuss their thoughts on their work, especially their multimodal projects and reflections. In the second of these two semesters, I also used assignments that called for students to use design thinking to a greater extent, particularly in a project in which I asked them to develop the scenario, or premise, for a new or existing game (board, card, video, etc.) and to write reflections about the process. Due to this shift in my course as well as the number of texts I had collected, I ultimately limited my project to the reflections submitted by participants in the Fall of 2017. I then used a grounded theory approach to analyze the reflections and interviews from these study participants to develop conclusions about the relationships among multimodal composition, reflection, and design thinking.

Although I initially thought of this study as a means of showing the value of incorporating design thinking, the design of the project did not provide me with comparative data. As the project unfolded, I began to realize that what I wanted to learn was how students responded to these reflective assignments. Although I was interested in seeing if the design process students used in their multimodal projects would have a significant impact on their reflective writing, I also wanted to determine what students would reveal about their approaches to this type of writing.

After coding and analyzing several dozen assignments, the results of which I will present in Chapter 4 of this dissertation, I came to the following conclusions: 
- Students recognized and articulated the benefit of interaction in learning. They also demonstrated the social nature of learning in reflections, shaping them according to commonplaces/narratives that reflected their identity as students, active learners, and writers.

- Students also frequently used phrases and wording that placed distance between themselves and their composing processes. Although these strategies seem to represent an avoidance of responsibility for their work, they may also be examples of reflection.

- Although students are highly social and value the time and needs of audience more than we may realize, they also valued individual creativity and originality, and they were more engaged when they had the opportunity to participate in creative activities. Their discussions of creativity were often marked by design thinking.

- Students who responded to reflective writing assignments in engaging ways also appeared to "design" an identity of themselves as writers. They also tended to present their experiences with more direct language.

Ultimately, students seemed to resist assignments that asked them to reflect on their individual work in isolation. Instead, they tended to depict themselves as socially situated writers speaking to and working alongside other student writers and paying attention to the audiences to which they addressed their texts.

\section{Overview of Chapters}

In Chapter II, I explore reflection as a characteristic particularly of the essay genre in order to ascertain the type of thinking that is typically associated with reflection. I also discuss the development of reflection within the discipline of composition, beginning with the observations of students reflecting as they compose and continuing with the work of Yancey and her model of reflection based on the work of Donald Schön. Due to Schön's emphasis on design, I also focus on intersections between design and reflection, particularly in design education. 
Schön's work seems to have been taken up primarily in the area of reflective practice in a variety of disciplines, which is natural considering the range of professions he discusses in his pair of books, The Reflective Practitioner and Educating the Reflective Practitioner.

More recently, scholars in design have developed models of design thinking, the most popular of which may be the Stanford model, which focuses on the process of design. Other models of design thinking focus more on the cognitive process of design or on an alternative model of reasoning known as abduction. In addition to examining these models of design thinking, I examine studies on the role of reflection in design education, which mirror Schön's work to some extent. Schön's case studies might be described as focusing on the role of design in reflection while the more recent studies focus on the role of reflection in design.

Although the concept of design in composition predates the rise of multimodal composition, it is arguably multimodal composition that sparked a wider interest in design as a component of writing studies. Scholars, such as Jason Palmeri (2012 have argued that multimodal composition is not a new phenomenon in writing studies but that writing has always been multimodal. Some of the scholarship in drawing design and composition together compares these processes and finds resonance between the major steps in each process. Other work, such as that of New London Group, envisions multimodality as a means of redesigning education itself.

Chapter III might best be described as the "nuts and bolts" of my project, but this does not mean that it is not also informed by scholarship. In this chapter I introduce the course I taught as part of this project, and I describe the university, particularly its history as a teacher's college. As part of a discussion of the course curriculum, I also describe the units I planned for the course, the reflective assignments, and the writing program within which the course was located. I also describe the method by which students were recruited for this project, and I provide a general overview of the students who agreed to participate in the study. I then introduce the grounded theory methodologies and the scholarship supporting these methods as 
appropriate for making qualitative claims about texts in a dataset. In addition to identifying my methodology, I also describe my process of analyzing, and in some cases completing additional coding, after I completed the tagging of reflective assignments using software for qualitative research. Along with this description of analysis, I present tables to illustrate the relationships between selected codes. In this section of Chapter Three, I focus on the codes that figured most prominently in my analysis of the reflections in my dataset, and I present several tables to enumerate these codes and to show the relationships between codes in the dataset.

Chapter IV is centered on my analysis of student reflections, drawing on the codes described in Chapter III as well as the intersections between codes and the larger themes that the codes revealed. I discuss linguistic features that resulted in the distancing of students from their work and then identify reflective texts in which students demonstrated design thinking and reflective thought. Even though I argue that students constructed their identities as writers through their reflections, it has been difficult to avoid using the term "authentic" to describe my impression of more engaged texts, especially since I used the term "authenticity" in my coding. I also discuss the heroic narratives that students often worked into their reflections and argue for an understanding of social connections in reflections that are characterized as much by the influence on reflections as on seeking these connections. The organization of the chapter moves from reflections that demonstrated strategies students used to distance themselves from their writing to students whose work represented greater engagement and thoughtful assessment of both their work and their writing processes. I will also discuss the presence of design thinking in the reflections I examine in the later sections of this chapter.

Finally, in Chapter V, I will account for the differences between students who tended to use distancing language and those whose texts demonstrated a greater degree of reflective thought. The differences between these texts can be explained by a greater sense of agency and more prominent use of design thinking in the latter texts. While I discuss design thinking in depth in Chapter Two, I focus on the link between agency and design thinking in student texts 
that provide evidence of reflective thought. In addition, I discuss the value and role of reflection within writing studies and how it might be better incorporated into composition pedagogy and why I believe it is still important to teach reflection. 


\section{CHAPTER II: TRAVELING CONCEPTS: REFLECTION, DESIGN, AND EMBODIMENT}

As Mieke Bal has argued, concepts that have traveled between disciplines, particularly in the humanities, are in need of further examination at the conclusion of these travels. Reflection has not only moved across disciplinary boundaries between design and composition, but it has also traveled from the writings of eminent education scholars such as John Dewey (1910), who envisioned reflection as a sort of a pause in a hypothetical anecdote of a traveler who has reached a fork in a road. This embodiment of reflection is not unlike some of the earliest appearances in composition, such as in Pianko's (1979) studies of reflection. Pianko describes reflection as an activity, or rather a pause in activity, as students stop writing to reread what they have written or look up to gaze about while considering the words to record next. These students seem to have been contemplating a fork in their thought before they return to inscribing them onto the page.

Dewey (1910) further explains that "Any attempt to decide the matter [of which road to take] by thinking will involve inquiry into other facts, whether brought out by memory or by further observation, or by both" (p. 11). He further explains that "As long as our activity glides smoothly along from one thing to another, or as long as we permit our imagination to entertain fancies at pleasure, there is no call for reflection. Difficulty or obstruction in the way of reaching a belief brings us, however, to a pause" (p. 12). Activity and a pause in activity also characterize Belanoff's (2001) work on reflection. She emphasizes the action of reflection in noting early meanings of the word - a turning back, as in a mirror, and the "fixing," or capture, of an idea or image. Belanoff argues for the existence of "a path from reflection to meditation," a word that, like reflection, contains the elements of both stillness and movement (p. 405-6). Like Dewey and his analogy of a road, Belanoff's discussion also suggests a journey, with reflection now carrying the opposing practices of activity and pause.

Although Belanoff's descriptions of ecstasy of medieval monastic women may seem unrelated to contemporary students, her aim is at understanding of a group of related (and still 
relevant) concepts that include silence and contemplation along with reflection and meditation. Of meditation, she says, "What particularly interests me are 'revolving' and 'exercise,' as both provide a sense of activity. When one meditates, there is fixity, but there is also a form of movement” (p. 406). This fixity within movement seems similar to the thoughts, emotions, and understanding potentially revealed through reflection. At the same time, however, scholars in writing studies also speak of reflection as the discursive means of visualizing the text as it is and as it could be. Reflection is also a means of transmitting a student's knowledge of a text to an instructor in order to provide a context for assessment (Sommers, 1988; Camp, 1992). In its travels, then, reflection has taken on not simply a pause but is now associated with the fixity of writing, of capturing more permanently what was previously a passing moment. Consequently, reflection within writing studies is characterized by a static moment in which one peers at the text as it exists but then attempts to capture the process leading to this moment and the possibilities for progression beyond it.

In this chapter, I further explore the concept of reflection and its dynamic relationship with composition. In addition, I examine the concepts and practices of design thinking, assessment, and metacognition and their travels between other disciplines and composition. I also put these concepts into conversation with one another in order to better understand how they interact with each other in the context of reflection.

\section{Enigmas of Reflection}

"Reflection" is often used by scholars in writing studies to refer to the actual document being produced, which suggests the status of reflection as a genre. However, writers use a variety of genres to produce reflective writing, including essays, letters, and memos, which are often chosen and assigned by an instructor, as with Sommer's (1988) reflective memos. Of course, the use of "reflection" as a way to distinguish a document is used widely beyond writing classrooms, as the myriad uses of "reflections" in titles demonstrates. Noam Chomsky (1975), in his 
Reflections on Language, for example, represents a tentative, perhaps contingent, moment in his thinking about language.

The essay tradition, as evolved from Montaigne, may be the quintessential example of an actual reflective genre, characterized by a tentative exploration of a topic. Paul Heilker (1996) captures this characteristic of the essay in his discussion of the work by several essayists of the 2oth century. He uses Joan Didion's essays as examples to represent an "evolution of an author's understanding over time, how the essay embodies an author's skeptical groping toward an uncertain truth" (p. 67). He notes the way in which her essay "On Keeping a Notebook" poses questions that resonate with the purpose of a reflection in composition - to ask questions about what a student might have done differently or plans to do in the future. Another characteristic Heilker discusses is the "inwardly directed skepticism of essayists, an authorial self-critique, also evident in Didion's essays" (p. 67).

In spite of Heilker's pedagogy of the essay as a reflective genre, the evolution of reflection in the composition classroom depends less on a sense of genre and more on its typical purpose of introducing a project or portfolio. While the use of reflection diverges from the trajectory of the traditional essay in composition instruction, an understanding of the essay as a genre may help to illuminate the expectations instructors have of reflection. Drawing on Heilker, Davis and Shadle (2000) describe the research essay in a way that resonates with this sense of refection: "[allowing] for multiple viewpoints, [putting them] into dialogue with one another, and arriv[ing]...at a provisional conclusion to be questioned in the dialectic's next round, or a recasting of the question" (p. 430). This work of questioning resonates with Yancey's (2016) conception of "constructive reflection" as "the process of developing a cumulative, multi-selved, multi-voiced identity, which takes place between and among composing events" (p. 4). In an earlier work, Yancey (1996) tells the story of an executive who has been laid off and struggles to maintain hope of finding a similar position before his severance package has been used up. What strikes her about this narrative is the inability of the author to see himself as part of any 
other community besides that of executives and ultimately is unable to "generate multiple versions of his own (life) text” (p. 65). This inability seems to represent a lack of questioning - a lack of consideration or recognition of possibilities.

Thus, the concept and practice of reflection in composition is not simply akin to looking in a mirror but is a practice in which we can conceive of the image in that mirror peering back at ourselves. When we ask students to reflect on their work, we ask them to look back on their process of arriving at their final submission. However, this type of reflection is not as easy to accomplish as looking into a mirror since it requires the use of memory and perceptions, which creates an uncertain view of a composing process that is partially invisible to all but the writer, and sometimes to the writer as well. Camp and Levine (1991) present refection as a means of "[making] visible much in learning that is otherwise hidden, even from the student writers themselves" (p. 197). Their definition of reflection is perhaps typical: "the practice of students looking back at their work" (p. 197).

\section{History of Reflection in Composition}

In the nearly thirty years since reflection was introduced as a significant practice in composition pedagogy, it has been widely adopted as a means of helping students to develop metacognition of writing. Yancey (2016) provides a brief overview of the history of reflection in her introduction to $A$ Rhetoric of Reflection, identifying the topics with which reflection has been engaged in three distinct periods of composition history over the last few decades. As with any history in composition, perhaps, the scholarship on reflection has branched out from what Yancey characterizes as a simple beginning, the reading in this area being "short and quick" (p.

3). As Yancey describes the current work in composition, though, she demonstrates the ways in which these branches of reflection in composition are tangled with those of other disciplines, and the roots for these branches stretch back further than the articles on reflection she cites by Pianko (1979) and Perl (1980). Likewise, the trajectory of reflection in composition appears more complex when considered next to some of the other major developments in the field, but 
in general, the development of reflection within the discipline of composition is one of progression from embodied practices in early studies to alphabetic texts that accompany portfolios and even multimodal reflections.

Through interviews conducted after her observations, Pianko finds that students who identified as stronger writers used reflective pauses more frequently than other students did. Similarly, Perl (1980) identifies the rereading of previously written portions of a text and recalling the topic of the project as key activities in the composing process, although she does not refer to these practices of reflection. Even more significant than the recognition of reflective activities, however, is the practice of inviting students as informants when investigating the significance of these processes. This recognition of student agency was arguably necessary before reflective assignments could develop since these texts also allow students to be informants on their own writing instead of instructors being the sole arbiters of knowledge about their students' writing.

Multiple forces seem to have driven both the genesis and further development of the practice of reflection in composition. To some degree, the pedagogies labeled as "expressivist" by James Berlin (1987) have played a role in reflection through the trust of a student writer's intuition and experiences as a source of "truth" to be captured through the process of recording them on paper. Therefore, the use of reflection today might be viewed as a vestige of "expressivist" instruction in composition with a need for more scholarship directed toward the tension between the social foundations of rhetoric and the focus on individual reflection. Some of this scholarship has already been undertaken, such as in Jung's (2011) argument that reflective writing leads to "liberal constructions of the writer as a single unified self" (p. 629). Yancey acknowledges this and other concerns about reflection, but much of the research in reflection has focused on individual students and their attention on their own work, including the use of case studies in the research of Yancey, Robertson, and Taczak (2014) on the use of reflection in their "Teaching for Transfer" curriculum. In each of the models of instruction 
examined in this study, only a few students were selected for study, reinforcing the experiences of individual students seemingly unconnected to each other. While rhetoric has shifted the instruction of writing as a process imbued with social awareness - of audiences, of current events, of contexts - reflection seems to have remained an individual endeavor, written by individual students focusing on their own work. Perhaps the most influential influences on reflection within writing studies have been an emphasis on assessment, the development of multimodal composition, and the recognition of a need for transferability of writing skills.

\section{Reflection and Assessment}

During the late 1980 s and into the 1990s, attention to assessment seems to have paved a path for Yancey's work in reconfiguring Schön’s model of reflection for composition classes. Composition instructors designed projects to elicit reflection in the form of texts, as in Jeff Sommer's (1989) "Writer's Memo" and the use of cover letters with portfolios for the purposes of assessment. Other scholars from this period, as acknowledged in Yancey (2016), include Chris Anson (1989) and his use of reflection in dialogue with "the primary texts of a portfolio," Roberta Camp (1991) and the use of reflection to open up a student text, and Bill Thelin (1994) with the effect of student reflection on the response of instructors to student writing. In a presentation at the 1995 Writing Program Administrator's conference, Yancey (1996) emphasized the role of reflection as the key feature that "distinguished [portfolios] from folders" (p. 56). The folder is merely a container for student work while a portfolio is shaped in part by the reflection students write to introduce their work.

In basing her model on Schön's work, Yancey's (2016) contribution to portfolio assessment was "a...practice-based theory of reflection in writing keyed to three related forms of reflective practice - reflection-in-action, constructive reflection, and reflection-in-presentation" (p. 4). Yancey (1998) describes reflection-in-action as the awareness of the writer of her relationship with the text and the "relationship between the reader and the text" during the process of composing (p. 23-25). This practice of reflection may be captured in various 
assignments during and after the student finishes composing a text. She identifies four kinds of "knowledges [reflection] fosters" (p. 46):

- knowledge of the text a student produces

- appreciation of his or her texts

- the ability to critique one's own texts,

- the ability to apply a plan to a writing project.

Constructive reflection differs from reflection-in-action in that it refers to the cumulation of experience developed from multiple reflective assignments; Yancey describes her realization that reflection needed to take place throughout the semester - "woven into the curriculum" in order to be effective (p. 67). Finally, Yancey explains that reflection-in-presentation is like cumulative reflection in that it focuses on writing over a period of time, such as in a cover letter for a portfolio completed at the end of a course. It is, she says, "a description that must satisfy both the writer and the reader," consequently making it a rhetorical, or social, act (p. 70, 72). Yancey (2016) identifies a variety of uses even within this model of reflection - "as a narrative of writerly development,...an account of process or self-assessment, and...an introduction to the portfolio itself" (p. 5). The other "uses" of reflection texts are not so much in how they are employed but in the recognition of the roles of reflection. A significant development in the understanding of reflection is that it is not subordinate to but is parallel with the other work students produce in composition classes. Yancey (2016) "theorized that reflective texts are primary texts in their own right" and that the relationship between reflection of the other major projects in a composition class is "dialogic and multi-contextual, not hierarchical" (p. 5).

Schön's (1983) emphasis on professionals may be particularly relevant to a reconsideration of reflection in composition since the discipline of composition itself developed and confronted professional challenges such as the increased weight of assessment. Schön points to the complexity of expectations, sometimes contradictory, that prompted his study of 
reflective practice among professionals. Composition scholars have experienced such expectations as much as any of the other professions Schön examines in his books on reflection. He suggests that practitioners, who he places in opposition to theorists, fear a form of paralysis, or an inability to act effectively, if they pause to reflect on or to analyze their own actions. He observes that "when leading professionals write or speak about their own crisis of confidence, they tend to focus on the mismatch of traditional patterns of practice and knowledge to features of the practice situation - complexity, uncertainty, instability, uniqueness, and value conflict...." (p. 18). Yet he also observes that "some practitioners do manage to make a thoughtful choice, or even a partial synthesis, from the babble of voices in their professions," a process that even those within their fields have not been able to describe (p. 19). Ultimately, Schön identifies reflection as the process that allows professionals to take effective action in the face of the “indeterminacies and value conflicts of practice" (p. 19).

Work on assessment may then reflect a similar lack of confidence within the field of composition about our ability to teach writing. In a 1991 foreword, Peter Elbow says that assessment, "what I cannot help calling a preoccupation with testing - may in fact by the biggest development in education in the last fifty years" (p. ix). This preoccupation has manifested in an increasing lack of trust in educational institutions due to the No Child Left Behind Act of 2002 placing increased scrutiny on public schools through high stakes testing requirements that impact school funding and create greater anxiety among students as schools emphasized the importance of standardized testing.

Likewise, Yancey (2016) suggests a wavering confidence in the use of reflection in or as assessment when she argues that to use reflection "only or exclusively as a mechanism for evaluation is to waste its potential" (p. 11). In 1996 Yancey complicates the assessment of reflection:

I'd like to know what I'm supposed to do with reflection. Read it? Respond to it? Evaluate in in a gentle way so that it "improves"? And how would I know what that 
improvement looked like? (What is, after all, "good" reflection? Is there such a thing as bad reflection?) What's the relationship between the improvement and a person's learning? A person's multi-vocality? A person's sense of self-knowledge? What happens to our assessment when we include such reflection? (p. 66)

The inverse to this last question is equally relevant: what happens to reflection when we assess it?

Reflection is used in lower stakes assessment in a variety of ways in composition, ranging from process descriptions to exit slips, all of which a teacher uses to determine which tactics may be working in the classroom and which may need to be adjusted. However, Yancey's term "reflection-in-presentation" suggests that students may submit a performance of reflection instead of a text that captures the thoughts, emotions, and feelings they experienced while composing assignments. The concepts of validity and reliability, commonly recognized as key requirements of successful assessment, therefore, underscore a potential paradox for reflection in composition. If students are unable or unwilling to account for their actual experiences, the reflection texts they produce presumably also lack the ability (validity) to reveal thinking processes to the instructor who reads the reflections and then designs instruction based on these texts.

\section{Reflection and Multimodal Composition}

These linkages between assessment and reflection are highlighted by Horner's (2016) challenge to the notion "of language, as ideally, the efficient and neutral conduit of thought rather than the occasion for action-reflection" (p. 120). At the same time, Horner seems to return to an embodied sense of reflection when he describes reflection as a means of slowing the process of writing in order to make it visible, multimodality being a key practice of producing such visibility in composition. Yancey (2016) points out that a contemporary understanding of reflection must also include attention to "electronically mediated reflection and the affordances it can offer students" (p. 12). Faris, et al, (2017) point out that Yancey has also been a leader in 
multimodality in addition to reflection, delivering what "may be the first...printed [CCCC] Chair's Address to constitute Anne Frances Wysocki's (2004) conception of new media as media that call attention to their own materiality and construction" (n.p.) While these examples emphasize multimodality as a recent development, other scholars have presented a much longer history of multimodality in composition, including Palmeri's (2012) recognition "that compositionists have attempted, at least since the 1960 , to articulate alphabetic writing as a multimodal process that shares affinities with other artistic forms of composing” (p. 3). Similarly, Shipka (2011) points to publications that highlight non-alphabetic modes of composing in the 1960 s and 1970 in her critique of the frequent assumption that multimodal composition is synonymous with digital texts (p. 4-5).

However, multimodal composition has also been a significant driver of reflective writing assignments, with books such as Selfe's (2007) Multimodal Composition and Arola and Wysocki's (2012) composing (media) = composing (embodiment) recommending such assignments, partly to supplement the often-difficult task of grading multimodal projects. Shipka's (2011) discussion of the processes involved in the type of projects her students were doing perhaps best explains the relevance of reflection in capturing this rich process:

I was positioned - by having created the assignment, the course itself, and having worked closely with the student over the month she spent working on the [ballet] shoes — in ways that allowed me to see, and so to understand, the final product in relation to the complex and highly rigorous decision-making processes the student employed while producing this text. (p. 3)

While working on a more traditional academic project in alphabetic form is arguably as complex as the projects Shipka describes from her classes, they lack the three-dimensional element that may allow both the student and the teacher to better visualize the project as it takes shape.

Selfe's (2007) collection of teacher experiences with multimodal composition extends the conception of multimodal projects as worthy of a central place in composition classes. Her 
volume is not only a practical primer on how to develop, teach, and assess multimodal projects but also includes reflection on the role of multimodal composition within rhetoric and composition as well as the wider discipline of English studies. Mickey Hess argues in this volume that "one of the greatest benefits of experimenting with multimodal composing...is the opportunity [for teachers] to re-think what they know about composition: to test, evaluate, and expand the theories of composing that have developed when teaching alphabetic writing and get students to do so as well” (p. 30).

Hess (2007) further argues that "Multimodal composition can expand the range of choices students make," and suggests a pedagogy that engages "students in reflection about not only the processes, but the products of composing" (p. 29). She describes reflection as a means of incorporating critical thinking and an awareness of learning: "reflection allows students the opportunity to articulate the personal connections they establish with their work and their subject matter" (p. 33). Writing in the same volume, Kara Poe Alexander (2007) calls on reflection following a peer review session and presents several affordances of this assignment:

Taking the time to reflect on their compositions in draft form allows students the time and focus they need to synthesize the suggestions they have received from others, formulate some effective plans for revising, and connect their experiences as readers of such compositions with their experiences as authors. (p. 130)

Alexander also presents the benefits for teachers, to include monitoring the revision process, to consider revisions to their own pedagogy, and to understand the thought process of their students: "what students are trying to accomplish, what components of the composition authors consider effective, what aspects they think continue to need work, and how authors interpreted the peer-review suggestions of others” (p. 130).

The exigence for Yancey's (2016) edited collection on reflection was both practical and theoretical: Yancey refers to a seminar in reflection she taught two years earlier but also points to a recognition that "scholarship on reflection is in a third phase" in which scholars seek to 
understand and revise earlier reflective practice while also subjecting reflection to criticism and "theorizing reflection in new ways and for future use" (p. 5). In setting the scene for recent scholarship on reflection in composition, she cites Dewey's influence, saying that "we must also think, or reflect, on ... learning for it to make sense, and when we do, our performance improves" (p. 8). Consequently, "transfer" - the transport of "knowledge and practice" from the context of the writing classroom to courses in other disciplines - is not only one of the most important concepts currently associated with composition, but it is also associated with reflection (p. 12). Yancey calls for students to identify what is happening in their composing processes and to carry these processes forward into other projects beyond composition classrooms. The process of transfer, or what Yancey calls reflective transfer, is associated with the "generalizing and identity-formation processes that accumulate over time, with specific reference to writing and learning” (p. 13).

\section{Reflection and Design}

However, composition is not alone in its attention to transfer or to reflection, with a significant amount of scholarship with both of these concepts also occurring in design education. In an article on the engagement of design students, for example, Chamorro-Koc, et al (2015) describe a relatively quick classroom activity called "design bombs" which "promotes reflective design process and consideration for future development as design pedagogy in the midst of current university education trends" (p. 18). Watkins (2014) links design thinking with reflection in a study of students in design workshops focused on sustainability with an additional focus on "deep learning." This type of learning is characterized by engaging the interests of students and by the use of assessment activities such as reflection rather than tests. While students in this study were not tasked with a design project, they were all students of product design who were being asked to consider the relationships between social problems and the designs that led to these problems or that might improve conditions through sustainable solutions. Students submitted reflective journals after the three workshop sessions included in 
this study, and Watkins ultimately observed that in these journals, students "demonstrate[ed] reflection, critical reflection, and a grasp of design thinking in their individual reflective diaries" (p. 44).

Although not teaching in the field of design, Etkina, et al (2010) describe a study in which physics students were divided into two groups, one of which was required to design their own experiments and one in which the experiment design was provided to the students. The authors of this study repeatedly link reflection with this process of design, arguing that the students in the design labs "need[ed] to be highly meta-cognitive to complete their design tasks" (p. 62). Although all students were assigned the same material, this study found the students in the design labs developed a stronger set of skills needed by apprentice scientists, a development attributed to the "designing and undertaking of their own experiments and by the embedded reflection during the semester" (p. 87).

In spite of the influence of Schön's work, the relationship he drew between reflection and design seems to have been lost in carrying his models of reflection to composition. A significant concern for Schön is that the professions developed in the last century and a half, including his own teaching discipline of urban planning, have failed to solve the problems - through the design of solutions - that these professions were intended to solve. Schön explains this partly through his observation that most problems faced by professionals fail to adhere to standards. They are almost always unique and ultimately require invented solutions, and the process of finding these solutions relies on establishing the parameters of the problem before potential solutions can be designed. These problems have become more widely known as "wicked problems," a term originally explained in a 1973 article by Horst Rittel, a professor in design, and Melvin Webber, professor of urban planning. Although Schön does not use this term in The Reflective Practitioner, his description of problems that have been difficult or even impossible for professionals to solve (including "urban blight") is consistent with that of "wicked problems." 
Consequently, Schön (1983) proposed reflection as a means of describing the way professionals use a form of design to successfully solve problems that they encounter on a regular basis, and then the recognition of this process of problem solving as a way to approach more difficult problems. The central idea in his work, "reflection-in-action," relies as much on intuition as on scientific and technical knowledge to solve problems and is explained through case studies from a disparate set of disciplines: design, landscape architecture, counseling, and music. He writes that "others have suggested that all occupations engaged in converting actual to preferred situations are engaged with design. Increasingly, there has been a tendency to think of policies, institutions, and behavior itself, as objects of design" (p. 77). One of the professions Schön explores from the perspective of reflection and design is that of management, particularly in the way businesses are taken by surprise when their products are taken up by consumers in ways other than intended. Schön cites the example of $3 \mathrm{M}$ producing a type of tape intended for the repair of books but which was used by consumers in a variety of other ways. Managers of marketing at $3 \mathrm{M}$ "reflected on unanticipated signals from the marketplace, interpreted them, and then tested their interpretations by adapting the product to the uses that consumers had already discovered.... Their marketing process was a reflective conversation with consumers" (p. 245).

The importance Schön places on artistry in a century marked with unprecedented technological advances is perhaps the greatest appeal of his theories on reflection. While the argument that artistry has a place in problem solving during an era of space exploration and its need for mathematical precision may seem like a backward step, the "looking back" associated with many uses of reflection, reflection-in-action draws the knowledge from the practitioner out into its immediate application. Although Schön applies the concept of design to many different disciplines, he does so to show how reflection also applies to the problems faced in each of these professions. 
The general concept of design also resonates with a practice of reflection rooted in Dewey's characteristics of uncertainty and perplexity due to the type of problems both designers and writers encounter and must solve. The opening lines of Margolin's Design Discourse (1989) suggest a universal quality of design as a concept and a practice: "Design is all around us: it infuses every object in the material work and gives form to immaterial process such as factory production and services" (p. 3). Buchanan (1989), writing in the same volume says "Design is what all forms of production for use have in common. It provides the intelligence, the thought or idea - of course, one of the meanings of the term design is a thought or plan - that organizes all levels of production, whether in graphic design, engineering and industrial design, architecture, or the largest integrated systems found in urban planning” (p. 108). While Schön (1983) says of the approaches to problems by various disciplines is not identical, "we may also discover, at a deeper level, a generic design process which underlies these differences" (p. 77). The New London Group, whose work infuses multimodal work in composition, for example, uses the language of design to imagine changes in education and communication with 21st century technologies in mind (Cope and Kalantzis, 2000).

In the decades since Yancey transported Schön’s model of reflection into composition, scholars in rhetoric and composition have also made a home for design in composition, even if the concept of design was not entirely new to the field. A 1978 composition textbook, Invention and Design: A Rhetorical Reader (Burt and Want, 1978), says of the two processes that make up the title that they are "key rhetorical skills...vital to the writing process" (p. xi). The authors of this textbook define both invention and design as complex processes, with design involved in "selecting, ordering, and structuring the results of invention into a coherent and effective finished product" (p. xi). Although the textbook then proceeds in the manner of the traditional texts of that time, focusing on the modes of description, comparison/contrast, classification, process analysis, cause/effect, and finally argument, some of the activities are predictive of the attention to materials that would take place with multimodal composition. One suggested 
activity, for example, asks students to classify "the materials used in some craft or pastime other than wood carving [the subject of the essay preceding the activity]" (p. 144). Another activity instructs students to focus on an analysis of physical activities or to classify people on physical appearance or their hobbies, legitimizing embodied experiences as a means of developing analytical skills (p. 162).

The increase in articles on design thinking in recent years shows some evidence that the field of composition is still very interested in thinking and cognition, as evidenced by Purdy's (2014) article on design thinking and the dramatic increase in College Composition and Communication articles discussing cognition in 2016. ${ }^{1}$ If we work from the proposition that writing is the process of capturing thought on paper or some other medium, then an understanding of cognition is an appropriate place from which to theorize reflection as it is associated with writing provided that it is balanced with the social underpinnings in composition scholarship. Such an approach preserves the essence of complexity theories, such as activity theory, that consider the full range of writing activities.

Schön's influence on reflective practices in composition suggest that design thinking may present a more viable model for creating reflective assignments than the models I had originally used in my previous full-time teaching position. ${ }^{2}$ These assignments were arguably linear and intellectual in nature and failed to account for the materiality of writing processes. However, while composition has already embraced the concepts of design and design thinking (George, 2002/2011; Marback, 2009; Leverenz, 2014; Purdy, 2014), research in design thinking by scholars in disciplines beyond composition suggests a different thought process than the

\footnotetext{
${ }^{1}$ Six articles on cognition appeared in CCC in that year, and no other year has seen more than two articles with the keyword of "cognition."

2 In those assignments, the questions I developed for students to use in writing their reflections were focused on the writing process, such as asking students to describe their process of composing a paper and to discuss difficulties.
} 
rhetorical perspective that composition scholars use when they emphasize the needs of an audience and how to effectively present information in a variety of formats, including audiovisual, kinesthetic, and alphabetic texts.

Cross (2006), for example, argues that design thinking is a third form of thinking that is distinct from the scientific and humanistic thought that dominates the general education curriculum for college students. Cross emphasizes that design thinking involves thinking about concrete forms and engages "concrete/iconic modes of cognition" (p. 28). This model challenges the theories of Piaget, for example, which identify abstract thinking as a more complex form of cognition. Mezirow (2011) also suggests that while reflection is often used to refer to "higherorder mental process," this view of reflection as a process synonymous with "thinking or learning" reduces the efficacy of reflection. He also argues for a distinction between reflection and critical reflection, the former allowing one to work within accepted constructs while the latter requires "challenging the established definition of a problem being addressed, perhaps by finding a new metaphor than reorients problem-solving efforts in a more effective way" (n.p.).

\section{Defining Design Thinking}

Over a period of several weeks, I repeatedly heard a sponsorship spot on NPR for a local design firm that announced their use of design thinking to meet the needs of their customers, and I couldn't help thinking to myself that it seemed redundant for designers to advertise that they use design thinking. After all, I asked myself, how else would a designer think? Upon further reflection, however, I realized that a key theme in Schön's work is that reflective practice is a means of bringing the process of thinking to consciousness, that through reflection, designers become aware of their thinking as they develop solutions to a problem. Design thinking has most commonly been associated with a series of steps that were originally laid out by Stanford University's d.school:

- Empathize

- Define 
- Ideate

- Prototype

- Test

Although the d.school is a recent program founded in 2005, this model of thinking has become widely known with many variations, such as additional steps or alternate arrangements of these five modes, as the d.school refers to them (Doorley, et al, 2018).

In transporting design thinking into composition, though, some scholars, such as Purdy (2014), have relied on a comparison between design thinking and composing processes: "Like the writing process, the process of design thinking conventionally involves several recursive steps. Just as steps in the writing process have evolved, so have steps in the design thinking process" (p. 627). He then includes a table in which the steps of the writing process "Research, Analyze audience, Brainstorm, Write rough draft, Share and revise" - are illustrated next to the parallel design steps (p. 628). Purdy concludes that "there is a good deal of overlap between design thinking and the writing process" and cites Buchanan's observations that design is a rhetorical process (p. 629).

However, in his chart and later in his article, Purdy (2014) draws distinctions between the traditional writing process and this model of design thinking. I found myself troubled for several months by the use of the label "design thinking" since it describes a series of steps that can be marked in tangible ways rather than a thought process, but I eventually realized that the type of thinking laid out by design scholars still underlies the process promoted by the Stanford d.school. Purdy modifies the traditional start of the writing process with a step similar to that of the process described by the d.school. Instead of beginning with brainstorming, he begins with research and audience analysis and points out that while design thinking calls for generating many ideas in search of solutions to problems, the technique of brainstorming in composition "does not usually focus on generating as many options as possible" (p. 629). In my own teaching, I typically use brainstorming as a process to help students focus on a narrower perspective in order to make a project manageable. Purdy, however, argues that the 
openness [of design thinking] can usefully be applied to the writing process in helping to guide students away from settling on one thesis statement too early and excluding evidence that does not support their position. It can also encourage writers at all levels to make choices attentive to the affordances and constraints of different texts and technologies rather than merely convention, to consider multimodal and multimedia textual forms in addition to the standard print essay" (p. 629-30).

This need to be open to possibilities in research is echoed in Wierszewski's (2017) argument against beginning research projects with a thesis statement, which she observes has been a common practice across composition textbooks and online research guides posted by many academic libraries (p. 231). She writes "genuine inquiry-the kind of research that often leads to new ideas and important choices-tends to begin with unsettled problems and questions" (p. 232). While this description of research does not necessarily equal the level of "wicked problems," it does reinforce the open-ended nature of design thinking. Thus, design thinking, like the writing process, is not merely a set of steps through which one can work through in a linear fashion to reach a satisfactory solution.

In fact, writing in Landscape Journal, Shearer (2015) challenges the concept of a stepwise model of design by describing design as a process of abductive reasoning. Shearer explains that abductive reasoning is rooted in possibilities that are determined by the way a problem is framed, which is similar to Schön's observation that reflection-in-action is marked by the practice of a professional framing a problem. Because much of design thinking is associated with tangible results, such as in architecture or product design, the application of design thinking to reflection in composition suggests that an embodiment of thinking and knowing is a requirement. It is perhaps not coincidental, then, that the first studies of reflection in composition focused on actions of the body - the gazing about and rescanning Pianko (1979) describes in her work. 
Orthel (2015) likewise constructs design thinking through cognition and abductive reasoning, a type of thinking that he argues allows designers to construct solutions to wicked problems, which he points out are not merely difficult to solve but which are characterized by a lack of access to complete knowledge. The key feature of abduction, the process of making "best guess explanations' about available data" (Shearer, p. 129), makes it particularly well suited to match the characteristics of wicked problems. Marback (2009) lists some of the most important of these characteristics as contingent, ambiguous, unique, and dynamic, all of which contribute to the complexity of these problems. Shum, et al. (1997) offers another list of the characteristics of wicked problems:

- cannot be easily defined so that all stakeholders agree on the problem to solve;

- have no clear stopping rules;

- have better or worse solutions, not right and wrong ones;

- have no objective measure of success;

- require iteration-every trial counts;

- have no given alternative solutions-they must be discovered;

- require complex judgements about the level of abstraction at which to define the problem;

- often have strong moral, political or professional dimensions which cannot be easily formalized. (p. 6).

Rittel and Webber (1973) introduced the term "wicked problem" to refer not to a problem that is simply difficult, but which lacks a clearly defined solution. Math problems or chess moves, in contrast, may be difficult to solve, but Rittel and Webber still describe them as "tame" problems because the answer is discoverable. It is also possible to determine definitively if a tame problem has been solved.

Perhaps the most crucial point in Rittel and Webber is that wicked problems are associated with "social problems," a term that resonates with the view of composition as a social 
process. Like the composition of a paper, wicked problems cannot be solved in the same way as a calculation problem, such as the trajectory of a spaceship (p. 160). In fact, planning professionals, as Rittel and Webber explain, originally adopted the "systems approach of the military and the space programs," an approach that is made up of a series of steps that assume that a solution can be found. These steps are not unlike other series of steps that proceed from the assumption that a solution will inevitably be found, which has not been the case for a vast number of social problems. However, Rittel and Webber argue that the solution to wicked problems will actually come before an understanding of the problem and its context (p. 161). The implications of this understanding in composition are that as a document enumerating or describing causes and effects - the agency of the writer followed by the resulting text reflection inverts the process of solving wicked problems, a category in composition scholars such as Marback (2009) place writing tasks.

The scholarship of Shearer (2015) resonates with the recognition of composition as a social process in his assertion that in "the second half of the twentieth century, theories and practices of abduction became increasingly important as a way to understand human cognition across activities," including design (p. 129). Scholars in composition have also emphasized the social nature of writing and rhetoric, not only through an attention to audience and the widespread use of peer review but also through activity theories that account for both cognitive and material aspects of writing. Shearer distinguishes abductive reasoning from deduction and induction reasoning by showing the differences between the ways science and design construct truth. While science seeks "impartial truth," design seeks "satisfaction of the designer, the client, of stakeholders, or of a negotiated settlement of all parties (p. 129). In identifying the various starting points of the design thinking process - forms, objectives, vision, challenges/opportunities, and an image of the world - Shearer suggests a similarity between design thinking and the principles Purdy (2014) develops through the use of cultural-historical 
activity theory to remediate the classical canons. ${ }^{3}$ Like Shearer, Purdy points out that these concepts are not intended as steps to follow in producing text but are a "map of literate activity" (n.p.).

Shearer's intention is not that the designer will start with one of the starting points he has identified and then proceed through the other four but that the starting point determines the unique shape of both the process and product within that project. He acknowledges that one approach is indeed to work through each of these propositions, but the initial proposition chosen as the starting point leads to thinking and solutions that are shaped by the initial answers to those questions - thinking about the width of doors in a proposed building (forms) leads to different solutions than questions about land use (image of the world), for example (p. 133). Shearer explains that an argument that results from abductive reasoning is rooted in possibilities while the traditional view of argument is based on "a claim supported by evidence and reasons of cause and effect" (p. 133). He goes on to say that "design arguments are constructed from highly contingent relationships. The attempt to generate the generative proposition to other levels of abstraction provides a way to consider how effectively or robustly it frames the problem. In the proposed framework, a well-made design argument is one with consistency of thought across all levels of abstraction" (p. 133).

Cross (2006) has argued for the inclusion of design thinking as a third form of thinking in general education curricula, which has historically favored scientific and humanistic thought. He argues that design is not just a skill but also the awareness of how to use the skill and the knowledge gained in "concrete/iconic modes of cognition" (p. 28). Cross observes that thinking about concrete forms has been limited to lower order thinking, as in Piaget's model, but that design thinking offers a way to revise our understanding of earlier theories of cognitive

3 These concepts are production, representation, distribution, reception, socialization, activity, and ecology. 
development. Goswani (2011), for example, found that when children were presented with analogy problems, they were able to understand more complex relationships through a familiarity with the concrete objects and situations that made up those problems.

In summary, design thinking should be thought of as more than a way to enact creative thinking. Purdy (2014) builds on an understanding of design thinking as being a "forward orientation," with a focus on "combination and connection instead of critique," and an emphasis on finding multiple possible solutions (p. 620, 626). Although Leverenz (2014) tends to use “design thinking” and "design process" interchangeably, she also highlights some of the distinguishing characteristics of design thinking that are relevant to composition, including “divergent thinking," “constructive reasoning” (or abduction), and exploration (p. 6).

\section{Design thinking, Reflection, and Embodiment}

Although Belanoff (2001) explores activities of the mind - contemplation, reflection as "a kind of nourishment of the mind" - her observations of the activities of scholars are all of embodied experiences. She says that reflection has been associated with "the stillness of prayer," but for the "modern scholar," the equivalent of prayer might lie in reading and research, conversing with other scholars, and simply "staring into space” (p. 407). In this section, then, I redefine reflection as an application and awareness of both abstract and concrete processes and skills as well as an activity that not only engages the mind but also the body. Consequently, it is a dynamic process, much as Dewey emphasizes the importance of uncertainty and confusion in generating thought processes synonymous with reflection.

Multimodal composition has been recognized as a means of embodying composition processes. One of the difficulties I have observed when assigning reflective writing is that students are rarely able to provide a detailed explanation of their process, perhaps because they attempt to rely on intuitive processes instead of thinking through problems as they write papers. Often, they describe how a paper is organized, which is something that they can visualize and handle after the project is complete. Marback (2009) focuses on design as a means of "enlisting 
our affective sensitivity to engage in the persuasive interconnections of signs, things, actions, and thoughts," but points out that it is only after the project has proceeded far enough to embody these relationships that we can see and recognize them (p 407). Indeed, Marback explains that

Visualizations of arguments, while grounded in words, are also something other than words and have an impact on our perceptions that words cannot adequately replicate. In the end, students cannot comprehensibly interrogate either their design choices or the final successes of their designs because they are so immersed in the discoveries of their designs, the designs themselves, and responses to those designs (p 411).

Responding to Schön's concept of “knowing-in-action,” Jung (2011) also points out the limitations in attempting to describe the "tacit knowledge" employed in composing: "[it] cannot be fully represented in language, because any attempt to describe that knowledge would inevitably distance the practitioner from the immediacy of her own knowing-in-action” (p. 631).

Since multimodal composition is frequently a visual and material process, an embodied process, whether using physical or digital materials, it represents what may be the most obvious example of design in composition. ${ }^{4}$ Cross argues that the "designerly way of knowing" includes reasoning about objects and the ways they can be used in design.

A significant branch of designerly ways of knowing, then, is the knowledge that resides in objects. Designers are immersed in this material culture and draw upon it as the primary source of their thinking. Designers have the ability both to 'read' and 'write' in this culture: they understand what messages objects communicate, and they can create new objects which embody new messages (p. 26).

\footnotetext{
4 Writing as design also includes the construction of linguistic features, such as sentences, so I do not mean that multimodal composition is the only use of design in composition.
} 
The resonance between this passage and the work of composition - both multimodal and alphabetic - suggests that the work of design education is already being explored in composition in both digital and material projects. More important, perhaps, is the need to emphasize the similarity in design and writing processes as exploratory, the outcome indeterminant at the beginning of the process, ideally at all levels of education. Too often students assume that they should write correctly, especially in a first draft, instead of exploring different possibilities, or that if they are asked for revision, it must be because they completed an assignment "wrong" the first time.

\section{Metacognition and Reflection}

The fingerprints of design thinking are evident within composition and rhetoric even when multimodality is not specifically addressed. In describing a revised strategy for instructors and professors to read reflections, Jung (2011) demonstrates one of the tenets of design thinking - the consideration of multiple possibilities. Instead of dismissing reflective writing altogether, Jung advocates for a different methodology for interpreting student reflection, "inquiring into how student writers experience and understand the work of writing” (p. 636). In an analysis of a reflection focusing on the use of categories to organize ideas, Jung says of a particular student that "instead of simply encouraging Sarah to develop and make connections among and across her ideas and paragraphs, we must first persuade her to believe that the epistemology of the outline is only one way to understand and approach the work of writing” (p. 639). This suggestion demonstrates what is perhaps the prime element of design thinking in considering all options over the belief that a "correct" solution exists.

The importance of awareness in design resonates with the expectation of metacognition in reflection, which makes multimodal composition not just a tool for innovative projects but also a form of reflection. Since multimedia projects are designed, this type of project is also inherently reflective when students actually employ the design thinking strategies such as considering multiple options. 
When Pianko (1979) identifies pauses in the process - gazing about and re-reading the text - as evidence of reflection as students compose, she also reiterates the need for metacognitive awareness: "It is reflection which stimulates the growth of consciousness in students about the numerous mental and linguistic strategies they command and about the many lexical, syntactical, organizations choices they make - many of which occur simultaneously - during the act of composing” (p. 277). Likewise, Walker's (2012) title for a chapter describing a historical observation project - "Pausing to Reflect" - underscores this need for time and space in order to reflect. In this chapter, Walker emphasizes the power of the media provided to working-class volunteers who recorded their embodied experiences of day-today life in "day diaries.”

The sense of reflection as a pause also appears in much more contemporary work, such as Bruce Horner's (2016) chapter in Yancey's collection on reflection. He argues for the value of reflection as resurfacing, as in coming out of a surface such as water, in contrast to "writers [who] may prefer to slide beneath the surface of consciousness" (p. 119) and lack awareness of their composing choices. ${ }^{5}$ In his argument for slowing the process of composition for reflection, more specifically "action reflection," a concept borrowed from Freire. Horner calls for teachers to resist the tendency to "reproduce and reinforce representations of language, as ideally, the efficient and neutral conduit of thought rather than the occasion for action-reflection," and unlike much of today's work in reflection, he does not call for a separate text documenting the reflective practices of students (p. 120). He observes instead that "action-reflection is a feature of all language practice” (p. 120). Likewise, Perl (1980) also cited by Yancey, represents reflection not as a separate part of the writing process, such as in an accompanying text, but as

5 This may explain the student affinity for a sense of "flow" as they write, an approach that suggests an abdication of responsibility for choices in favor of just allowing the writing to happen. 
part of the process itself, arguably as a "felt sense that prompts the writer to begin or to continue" (p. 366).

Invoking the word "sense" resonates with Wysocki's (2012) argument that writing teachers "need, then, to consider media that use the alphabet and to ask how such media engage with our senses and contribute to our embodiment" (p. 4). In calling for the use of media that is able to engage more of our senses, she asks "what other sorts of arguments are possible when we broaden our senses of the texts we can make for each other through the possibilities of the digital?” (p. 7).

The articles in Yancey's volume explore various forms of multimodal composing that challenge the conception of writing as an activity centered in the mind. Interestingly, while Jung's (2011) article does not directly address either design or multimodal composition, she uses language about making processes visible, which resonates with these arguments by Perl and Wysocki. Due to the visual elements in many multimodal compositions, they may be the optimal vehicle to inculcate a design frame of mind in composition students. Although Wysocki criticizes the primacy of the visual, the use of images has been a significant starting point for design, to which many of the projects described in Arola and Wysocki's collection attest. Diana George (2002/2011) says that while the "pictorial turn" typically focused on interpretation of images, especially advertising, the image is most significant because of its association with design as well as the increasing use of composition technologies, primarily the desktop computer and the Internet, which allow students ready access to and use of images. ${ }^{6}$

Therefore, as a practice that is often visible and potentially slower, multimodal composition is particularly valuable in composition because it is an ideal site for reflection, whether in the use of multimedia to construct arguments or to document the composing of

${ }^{6}$ I do not ignore the use of copyrighted images in student work but make sure they are aware of both fairuse in their own writing for academic purposes as well as and the need for permission when using such images in published work. 
alphabetic or multimodal projects. The use of tools that make a process visible, audible, and material may help to activate and reinforce reflective thought. The type of cognition that forms design thinking might be evident in a multimodal project without a separate reflective document, and while these reflective documents are useful, they are not the sole means of engaging students in the practice of reflection.

\section{Pausing to Look Ahead}

At the beginning of this project, I chose to use design thinking as a model for reflection, distilling the concepts from design scholars such as Schearer (2015), Orthel (2015), and Cross (2006) to develop a set of reflection questions that might prompt students to reflect on their writing in more care and with more depth in their insights. Among my goals, as a teacher, was a desire for students to reflect about their work in a way that was not only more satisfying for me (or anyone) to read but also for the students to have a better understanding of their own work, their processes as well as their products, and for students to also apply design thinking. I sought this alternative approach to reflection for its potential to help students to approach reflection as something more valuable than another box to check in their academic journey.

In the following chapter, I describe the research project that emerged from a combination of my interest in reflection and my understanding of design. I describe the way I incorporated design thinking into the assignments for the reflections students wrote at the end of units and at the end of the semester. I include the questions I developed to elicit design thinking and the multimodal reflection I developed for the final project of the course, a project meant to reinforce the reflective thought in students through design thinking and design processes. In addition, I describe my use of grounded theory to analyze the reflective work student participants submitted over the course of the semester. I outline not only my process of coding this work but also the methods I used to analyze the resulting codes and to re-read students texts from the perspective I gained during this process. 


\section{CHAPTER III: PARADOXICAL ROOTS: USING GROUNDED THEORY TO}

\section{READ STUDENT REFLECTIONS}

In the previous chapter I focused on the concepts of reflection, multimodality, and design thinking to trace the interrelationships between these concepts and to explain my approach to reflection in the classes in which I conducted this study. I wanted to determine whether an approach to reflection rooted in design thinking would help students to engage with the process of reflection. Although design thinking has been defined in different ways by scholars in design, these models agree on the inherent nature of design as both an abstract and concrete process. Prior to this study, I theorized that because multimodal composition, like design thinking, includes both abstract and concrete elements, developing reflective assignments around this type of thinking could help students to build an ethos of reflection in my classes. I intentionally developed some projects that would take advantage of visual and spatial affordances, in particular, which meant that students were ideally using design thinking throughout the course rather than limiting its use to either projects or reflections on their projects.

Since I did not set out to definitively prove the effectiveness of design thinking, I designed a qualitative study that would allow students to show what was important in their reflections and their processes of composing both class projects and reflective documents. My choice of grounded theory methodology was also driven by a need to reconcile the complex net of concepts I wove in the previous chapter within the context of the complexity presented in the texts written by students. While the first part of this chapter focuses on the more concrete details of my class and the students, it also mirrors the abductive thought introduced in the previous chapter, a process of marrying concrete and abstract in a relationship that is both rooted in and transcends its components. Even the term "grounded theory" maintains this seemingly paradoxical construction - "grounded" as in a base element, like dirt under one's shoes, combined with "theory," a word that conjures both broad-scale understandings and 
mysteries about the universe, yet a universe that is made up of particles so small as to be insignificant until massed together.

In this chapter, then, I will describe the ways I developed a course that would draw on both of these elements in at least some of the major assignments of the course. The writing program within which I was teaching is an important context. Guest writing scholars who have spoken to faculty and students in the writing program have included Jody Shipka, who led instructors and professors in a workshop in the use of materials to create compositions to explore the agency of both composers and objects with which we worked. In fact, after displaying my own project in my office for a couple of years, I sensed that it wanted to be recycled, and I was at peace when I carried it to the appropriate blue bin.

As I explain the units in my class, then, I will also place them at least nominally into the philosophy of the program and show how I developed reflective assignments for each unit. Following this, I will describe the students who participated in the study as well as the method by which they were recruited. I will also provide details about the gender, programs of study, class standing, and what I know about their ethnicity. In the next section, I will describe my experience with grounded theory methods and explore the underpinnings of this methodology. I will also draw some comparisons but also acknowledge the distinctions between grounded theory and feminist methodologies in order to clarify my research stance. Finally, I will describe some of the most significant codes from my dataset to lay the groundwork for the analysis of major themes in Chapter Four.

\section{The Course and the Students}

In the fall of 2016, I began teaching in the writing program at Illinois State University, a school with a strong tradition as a teacher's college. I continued to teach in this program through the academic year 2017-2018 and recruited participants for my study during the spring 2017 and fall 2017 semesters. This writing program was characterized by its emphasis on genre study, transfer, and cultural-historical activity theory as well as on fostering students to become 
writing researchers, or more specifically researchers of writing practices. The goal of the program can probably best be described as equipping students with the means of teaching themselves how to write in the various genres they will encounter in other courses and in their professional lives. Because this process of learning does not require students to focus entirely on academic genres, instructors often choose to study non-traditional genres, some of them making use of the university library's special collections, which include circus materials. Other examples of non-traditional genres instructors made use of during the time I taught there were listicles and slam poetry.

A key feature of the writing program was a locally published journal of writing research with articles submitted primarily by undergraduate and graduate students from various majors (most graduate students were in English). Articles were characterized by a light-hearted tone intended to appeal to the freshman students who make up the majority of the audience. Many instructors of the program assigned for their final project of the course an article in this style. The articles are generally rooted in the study of genres and writing practices using seven concepts laid out in "Re-situating and re-mediating the canons: A cultural-historical remapping of rhetorical activity," by Paul Prior, et al (2007). These seven concepts - production, representation, distribution, reception, socialization, activity, and ecology - are presented as a contemporary means of "remapping" the classical canons of invention, arrangement, style, memory, and delivery. While both of the sets of concepts map literate activity, Prior, et al, argue that a "cultural-historical approach suggests that, rather than revising and reinterpreting the classical canons, it is time to begin remapping the territory of rhetorical activity" (n.p.).

The program also called on students to "document knowledge in new writing situations by clearly articulating how existing knowledge and skills have adapted and changed over the course of a new writing experience" ("Learning Outcomes for [English] 101.," 2015). This was typically referred to as "uptake," a process Bawarshi and Reiff (2010) define as "knowledge of when and why to use a genre," particularly for the purpose of allowing "users to perform 
consequential social actions" (p. 86-87). Within the program, students were tasked with producing "uptake genres," to include uptake journals, writer's notes/memos, exit slips, and self/peer assessment, to demonstrate not only their knowledge of one or more genres but also to document their use of these genres. For my classes, I used the term reflection for this type of work when it occurred at the end of a unit even though the term "reflection" was otherwise rarely used in the program. Yancey, Robertson, and Taczak (2014), however, employ the concept of reflection in order to achieve the transfer of writing skills from composition courses to other writing situations. The primary vehicle for transfer in their Teaching for Transfer approach is reflective writing, such as a "2-3 page reflection piece in which you begin to develop your theory of writing, considering the concepts of genre, audience, and rhetoric situation and how they connect” (p. 74). It is this form of uptake with which I was more familiar when I entered the writing program in which I taught the course I describe below.

One of the other learning outcomes in this writing program also focused on multimodal composition and embraced not only composing in digital environments but also with materials, and the program maintained several cabinets full of arts and crafts supplies for instructors to use in their classes. One semester, I included an extra credit project calling on students to work in groups to create a chalk manifesto on a sidewalk located on campus. Several students also created posters and drew comics by hand while one student created a booklet the semester before I gathered the data for this project.

Consequently, I wanted to take advantage of the flexibility in this program to create a class focused on games, including card games, board games, and video games.7 I had been looking for an opportunity to teach a class in which students would design complete games, but because I thought this would take away from the emphasis on writing, I limited the scope of the course to genres and topics associated with games. While part of my motivation in choosing a

7 The syllabus for this course is in Appendix A. 
focus on games was due to my own interest, I also reasoned that it might generate interest and engagement with students. I assumed that every student would have played a board or card game in their lifetime, which proved to be a valid assumption, even if their games were limited to children's games, such as Candyland and Chutes and Ladders. My own preference for games has been European-style games, starting with classics in this category of games, Settlers of Catan (now known as simply Catan) and Ticket to Ride, and I wanted to use these games to challenge students to consider a variety of levels of complexity for their own projects. Euro-style games are characterized by complex strategy, multiple pathways toward winning, and continued engagement for all players throughout the game. The mechanics of Seven Wonders, for example, involve all players receiving, playing, and passing cards simultaneously, and players can win in three different ways: by accumulating points through the production of resources, through the collection of scientific cards, or by overwhelming neighboring players with military force.

At two or three points in the semester, I reserved space in the writing program's noncomputer classrooms for students to explore some of the games in my own collection. I wanted students to add the tactile sensations of playing games to their memories of games, paralleling, to some extent, the interplay between the material and intellectual activities associated with writing. The rooms I reserved were more conducive to these activities since the tables were flat instead of equipped with laptop computers, as the regular classrooms were. During the first of these sessions, I provided games that were unfamiliar to most students and asked them to explore the components of the games, to look over the rules, and to start a game with the information they were able to collect in the ten or fifteen minutes I provided. I selected board and card games, such as Mysterium, Dragonwood, and Bang!, to mimic the blend of abstract and concrete thought involved in design thinking, as described by Shearer (2015) and Orthel (2015).

Later in the semester, I devised a simplified version of Mysterium that would involve the entire class by assigning them to play in groups. In the game, players are given clues by the 
player designated as the "ghost," and they use these clues to deduce the identity of the murderer, the location of the murder, and the weapon. The game has been compared to the much older game of Clue, but the players take on the role of mediums attempting to solve a murder with a separate set of suspects, who are unnamed - only pictures are provided of the suspects. Because the images on the clue cards are intended to be dream-like, coming from a ghost who has been weakened by the number of years since his murder, I selected cards from the entire deck in order to give each group of student-players the best chance for success instead of selecting cards from a randomly drawn set, as the game is normally played. Ultimately, the game is won or lost on a cooperative level. In the final round, players with more points gained during the previous rounds receive a greater number of clues to determine the murderer, the location, and the weapon, but ultimately, the game is won or lost cooperatively by a vote of players. Any ties are broken by the choice of the "player who progressed furthest" in the earlier rounds of the game (Nevskiy and Sidorenko, Mysterium Game Rules, 2015, p. 12). My selections of clues ultimately allowed my classes to win my simplified version of the game.

From these experiences, I hoped students would recall some of their earlier experiences playing board and card games, which I asked them to write about in the first unit. The assignment sheet for this project and its reflection are in Appendix B, and a paper I wrote as an example is in Appendix C. For the main project in the first unit, I asked students to write narratives about their experiences playing a specific game or multiple games with family members or friends, either recently or as a child. This assignment eventually revealed the range of experiences students had with games, from playing just an occasional game to regular game play, including on weekend visits with extended families. A few students wrote about playing video games with family members, but most wrote about board games and card games. One shy student wrote about being invited by fellow dorm residents to play a game, which led her to develop new friendships. Two students wrote about playing "spoons" with family members, both of them capturing the frantic pace of the game in their narratives. Other students wrote about 
the bonds they developed with immediate family members by playing a favorite game frequently. I found their narratives to be interesting and engaging.

After students completed their rough draft, I then asked them to remediate their narrative rather than to revise it. As I mentioned earlier, students had employed a variety of media to complete these projects, such as producing comics by hand or by using websites and creating posters or artwork. The final stage of this unit was to write a reflection on both writing the draft of their narrative and remediating it. In creating the reflection assignments for this semester, I incorporated principles from design thinking, particularly attention to stakeholders (audience) and to the choices students made. In order to help students develop and organize their reflective assignments, I provided the following list of questions:

1. What are the different approaches/topics you considered before writing your initial draft?

2. What choices of media did you consider for the multimodal version of your narrative?

3. What influenced your ultimate choice?

4. What problems did you face throughout this unit?

5. What resources did you use for answering your questions?

6. How satisfied were you with your projects for this unit?

7. How well do you think you met the needs of your audience?

Since an important aspect of design thinking is considering possible approaches to a project, the first three questions focus on the choices students considered with regard to both their topics and their choice of media for the second stage of the project. I also wanted to know about the problems students encountered while working on their projects and the means by which they had their questions answered. Finally, I wanted to know how their own satisfaction with their projects balanced with their potential audience.

For the second unit, I assigned a research project that included both library research and primary research in the form of interviews, surveys, and questionnaires. One of my goals for this 
unit was to introduce students to a variety of genres they might encounter or need to produce in future research projects. These genres included annotated bibliographies and surveys, in addition to their final write-up of the project. For this project, they needed to choose a topic associated with games of any type, but I had not foreseen some of the problems this topic would create. For example, several students wanted to make the argument that video games do not make players of these games more violent than non-players; however, after a considerable amount of academic research in this area, there is little conclusive evidence to prove or disprove this argument. In addition, it would be difficult for students to conduct enough interviews or receive enough responses to surveys to make a case either way. But these students were not that different from students in other semesters prior to or since then. Many of them have been trained, whether on purpose or inadvertently, to think of a research project as an opportunity to argue an opinion they already hold instead of as a means of exploring an issue or answering a question.

Students also chose other topics that related to their major, especially students in teacher education, who tended to research the use of games in classrooms. Some of the approaches these students took to their primarily research were to interview practicing teachers and to survey college students on their experiences with games in education. My purpose in asking students to conduct this primary research was to foster more engagement with their project and to help them to understand that research is a broader process than just looking up information on websites and in articles and books. I wanted them to approach their projects with curiosity, a desire to not just regurgitate material from their sources onto the page but to ask questions to which they did not yet know the answers.

Another key aspect of this project was that I asked students to take a meta-cognitive approach in presenting their projects and to include reflection within their final product, which was to be written in the form of an extended memo. This memo was to present the information students gathered on their topic as well as how they would use this research experience in future 
classes. I expected students to explain what they learned from both their sources and primary research and then asked them to conclude their memo with a reflective section. I included a list of questions but explained that these were "intended to guide your thoughts and may be used to develop the outline of your memo." I also emphasized that the final product should not "real like a set of answers to questions.” The questions I provided for their thought process, and which are similar to those for unit 1, were as follows:

1. What are the different topics you considered before completing your annotated bibliography?

2. What influenced your ultimate choice?

3. What did you learn from your sources? This should be a substantial part of your memo.

4. Which sources from other students were also related to your project?

5. What did you learn from the surveys? How did they connect to your sources?

6. What problems did you face throughout this unit?

7. What resources did you use for answering your questions?

8. How satisfied were you with your projects for this unit?

9. How well do you think you met the needs of your audience?

Students were to focus most of their attention on presenting their research and then to conclude their memo with a reflection section that was shorter than the stand-alone reflections from the first and third units.

For the third unit of the semester, I assigned the task of creating a game description for a new or existing game that lacked such a description. The assignment description for this unit is in Appendix D. I imagined students using the knowledge they gained during the research project to develop this project. Many students found this unit somewhat difficult since they were not as familiar with the types of games that use an extensive description to set up the scenario.

However, I brought in several booklets from these games for students to study, and I created an example of a description for an original game I had conceived (see Appendix E). Their final 
results seemed to indicate that they had a good understanding of what I expected in this unit, and the most creative projects tended to introduce original games although students did not need to explain all of the rules of the game. I also expected the final draft of these projects to use media other than a Word document with only alphabetic text, and students used a variety of media - primarily digital - to produce their final projects. Projects included tri-fold brochures, a design for a video game box, infographics, posters/flyers, and a movie trailer. Their willingness to try out different formats and designs seems to indicate an increasing comfort with openended projects, i.e., projects in which the organization and the media are not strictly defined.

As with Unit 1, I assigned a reflection in addition to an endorsement letter for another student's game design or a letter introducing their own design. Most students used the former option to introduce a game created or re-envisioned by a classmate. The set of questions I provided for this reflection were similar to those of Unit 1 while some of the questions were adjusted for this specific project:

1. What influenced you in developing your description?

2. What are some of the different possibilities you considered in both the type of game (board, video, card, etc.) and the topic?

3. How did your previous projects - your games narrative and your research project help you with this project?

4. How does your game description relate to culture or to ethnicity? Does it appeal to a wide range of people or narrow? Who are those people? Neither option is preferred for this assignment - I just want you to be aware of the implications of your choices.

5. What problems did you face in this unit?

6. What additional resources did you use beyond your research sources and assigned readings?

7. How satisfied were you with your projects for this unit?

8. How well do you think you met the expectations of your audience? 
Once again, I focused the questions on themes of decision making and audience, and to these I added a question about how their previous projects influenced their decisions in this project. Ironically, some students claimed their previous projects did not impact this project, but then they went on to explain how those projects were a factor in developing this one. Students had the most trouble with the question in which I asked them to think about how their games and games, in general - were connected to cultural expectations, whether in the types of players they attract or in the artwork and characters featured in games. However, I was not effective in cultivating a discussion about the link between culture and games, leaving students uncertain about how to answer my question about how their games intersected with culture and ethnicity.

I wanted students to be aware of when games were drawing on images or practices of particular cultures or histories. All of the character cards in the game, Dragonwood (Kisgen, 2016), for example, depict white or light-skinned characters: a lightly tanned warrior, a fairskinned wizard with blonde hair, an elf with blonde hair, a female warrior with red hair, and a light-skinned woman with black hair who appears to study a glowing orb. On the box for Ticket to Ride (Moon, Alan, 2004), a game in which players build railroads across a map of the United States, every character in the artwork appears to be of white European ancestry even though, as Theodore Kornweibel (2010) shows in his photographic history, American railroads - both freight and passenger - have been an important part of African American history. While Mysterium offers more diversity in its collection of psychics as avatars, it does so in problematic ways. While the two white male psychics, McDowell and Belcour, acquire their gifts through academic study, the Spanish Alma Salvador and the Ottoman Ardhashir inherit their gifts. While these different nationalities appear to represent diversity, they also reinforce stereotypes of the "exotic" other. Also contrasting the rational approach of the white males are the Chinese Madam Wang, who is part of a secret society studying the I-Ching, and the wealthy American Jessalyn Smith, who accidentally discovers her gift. Another example of culture I hoped students would recognize was in the names the Mysterium game booklet gives a hypothetical set of players, 
names of European ancestry: Laura, Stephanie, Paul, Carl, and Alex. Overall, however, students did not make many connections between their own game descriptions and cultural representations.

After students completed this unit, the final assignment for the semester was to create a multimodal reflection over the entire semester, and the description of this project is in Appendix F. As with the first and third units, I provided an assignment sheet that listed questions for students to use in developing their reflections. I included both required and optional questions, and the two required questions (or rather, sets of questions) were as follows:

1. How has your writing process evolved during the semester? How do you envision your approach to writing projects in the future, whether for other classes or in your career? Don't assume you won't write - many nurses and engineers, for example, are surprised by the amount of writing they do in their careers.

2. How did you approach projects in which you had a choice of media or format? What media did you use when you had the opportunity to use someone other than paper and ink or its digital representation (word processing document)?

I wanted students to have a sense of agency and to give them the freedom to structure their reflections, so I provided an additional list of eight questions from which they could choose at least five to answer:

1. What resources did I use through the semester, and which ones were the most effective?

2. How did I make sure I understood the expectations for each deliverable?

3. What strategies and technologies allowed me to communicate my ideas most effectively?

4. What procedures and processes (or steps) helped me to complete assignments successfully?

5. How did I organize my ideas about both genre and topic as well as my time for each project? 
6. How did I make sure I could relate to the subject of the different projects? How did I keep myself engaged and motivated to do my best work?

7. What purposes did I have in mind when working on my projects?

8. How did I use antecedent (prior) knowledge of both genres and my topics? How was this knowledge helpful, and how did it interfere?

I used concepts of design thinking, to some extent, to develop these questions, as I did for previous units, but I also wanted this list of potential questions to reflect the learning objectives for the course. Although I did not include direct questions about audience and audience expectations, the theme of audience was present in at least two of these questions. The expectations for assessment of deliverables, for example, were tied to the expectations of an audience. Communicating ideas, as in the third bulleted point above, and the purpose, in the second to last question, also imply ways of connecting with the audience.

\section{The Student Participants}

I recruited students from two sections of English 101 in the spring of 2017 and again in the fall of 2017. Dr. James Kalmbach visited all four of these classes to explain my project and the consent forms to my students. All those who consented to participate in the project were required to sign the consent forms. An additional consent was required for permission to use any multimodal work in published documents that may result from this research. Because I had made substantial changes to my course between the spring and fall, I chose to use only the fall students in this study. These classes were predominantly White, and the group of students who agreed to participate was also primarily White. Between both classes, 26 students elected to participate, and of these, 16 participants were female, and 10 were male. After the end of the semester, I excluded two students who did not complete the course requirements, leaving 15 female and 9 male participants. Of these remaining 24 students, three identified as Latino or Hispanic, and one student immigrated from Bosnia-Herzegovina as a child. At least one student had grandparents who spoke a different language (Polish). These 24 students were generally 
representative of my overall classes except that two African American students were enrolled in my classes but did not choose to participate.

The primary majors for this group of participants were education and business, but other majors included theatre, art, and math. These students were divided almost evenly between two different sections, but I grouped all students together in my dataset.

During the spring of 2018, I invited all participants to meet with me for an interview about their projects and their reflective assignments, and five students completed an interview that lasted about 30 minutes each. These interviews were semi-structured in that I had prepared a list of questions, but I did not follow the order of these questions strictly. I also asked followup questions where it was relevant to do so, and before I concluded each interview, I checked to ensure that our conversation had addressed each of my questions. These included the following:

1. What processes, methods, or knowledge from English 101 have you used in other classes?

2. Which experience from English 101 has been the most helpful in other classes?

3. Describe an experience from English 101 that has not yet been helpful to you.

4. Please describe a specific assignment in which you consciously used processes, methods, or knowledge from English 101 to complete the work. How helpful were these English 101 skills?

5. Please describe multimedia projects you have completed or will complete in the semester after you took English 101. Have or will these projects involve reflection? What tools from English 101 did you use to complete these projects?

6. Discuss an assignment from this semester in which your work in English 101 may not have helped you.

7. If you have completed any writing in the workplace, identify and describe any of the ways English 101 has helped. 
To transcribe the interviews, I used an online transcription service (Temi) that used encryption methods to secure confidential materials for IRB-approved research projects. Because this service used voice recognition instead of live transcription, I needed to listen to and correct each file. For this project, I transcribed every word spoken by a student, including utterances such as "um," "uh,” and "yeah.” Some students frequently used "like” instead of "um," and since I transcribed every use of "um," I also transcribed all uses of "like" in order to maintain consistency. I also marked pauses with an ellipse. While I also transcribed my own questions or comments from the interviews, I did not transcribe them as thoroughly as I did those of students, leaving out many incidental utterances since I was more interested in the differences between responses to my questions.

\section{What I Wanted to Learn - Engagement and Design in Reflection}

As indicated in the introduction to my dissertation, I have always valued reflection highly — as a means of developing as a writer and as a life practice - but I have been disappointed by the lack of thought resembling reflection when asking students to write about their writing practices. In this project I wanted to study student reflections not for their efficacy in reinforcing their learning but for what students revealed about their writing processes. I also wanted to know if (and how) students would use design thinking as a method of reflecting on their projects.

Although the literature on writing studies strongly supports the use of reflective practice in writing courses, I found little research on how to encourage students to practice reflection. My fear was that the lack of reflective thought in student assignments was due to a shortcoming in my own teaching. However, I also reasoned that a close study of what students were writing in their reflection assignments might suggest more effective strategies for developing reflective assignments. Due to the ways students wrote about their experiences with assignments, I also wanted to examine potential relationships between reflection and engagement. Since students usually write their reflections after they completed their projects, a reflective assignment itself is 
not necessarily a means of producing engagement during their writing process, but it might help to reinforce engagement with the overall process of composing a project. Furthermore, research has indicated that reflection is valuable as a means of reinforcing knowledge and practices of writing for the purposes of transferring writing skills to other contexts (Yancey, Robertson, and Taczak, 2015; J. Sommers, 2011). In order to encourage this transfer, scholars say students need to be able to identify their process not only in the steps they practice but also at the cognitive level, requiring the practice of metacognitive skills that reflection can help to develop.

However, I had already observed that it seemed difficult for students to identify how they go about writing a paper. When asked about this, students often describe the organization of their paper, recounting how they started with the introduction and thesis statement, proceeded through supporting the thesis in their body paragraphs, and then wrote a conclusion. Only after I prompted students to think more broadly about their practices, such as how they arrived at their topic and where they procured support, would they begin to explain their process of writing their paper distinct from the organization of their assignment. In fact, in past semesters, I found it more effective to ask students indirect questions about their writing. For example, I found that they were better able to identify why they chose a particular topic, and this often shed some light on their actual writing. When I first began to assign reflective writing - prior to my teaching as a Ph.D. student - I used questions that were provided in assignments developed by the director of the writing program. Eventually, I replaced the provided questions with those of my own and felt that in responding to these questions, students had taken steps toward what I thought of as genuine reflective thinking.

Admittedly, words such as "genuine" and "authentic" are contested terms, whether in the area of writing studies or in other social science research, and so I use these terms to refer to representations of thought as evidenced in the writing rather than as empirical evidence of student thought. Yancey (1998) has argued that students construct a "multivoiced" identity through reflections (p. 200). Therefore, evidence of "genuine" or "authentic" reflection 
necessarily only refers to the evidence of reflection within a text rather than within the minds of students. As a researcher, however, I want to respect the students who agreed to participate in my study and to represent them as honestly as I can. Students who participated in an interview with me had a greater opportunity to voice their own opinions and thoughts through a loosely constructed conversation, yet their statements within these interviews were still arguably constructions of selves who emerge in a particular academic context.

Because of the earlier experience with a multimodal course that I discussed in my introduction, a course in which students seemed to write more thoughtful and engaging reflections, I also became interested in the relationship between reflection and design thinking, beginning with the work of Donald Schön and continuing through more recent studies focusing on the use of reflection in design education. The strong connection between reflection and design, particularly in design pedagogy, led me to consider the use of design thinking to construct a different type of question for students to use in reflection. The model of design thinking I followed is identified in literature from designers as "abductive thinking" (Orthel, 2015; Shearer, 2015), a fusion of both concrete and abstract thought, which prompted me to assign a multimodal reflection project at the end of the semester. In order to understand the results of these reflections, I needed to analyze the reflections and allow students to tell me their thoughts on their projects and on reflection itself. In order to analyze these to the extent I desired, qualitative research, specifically grounded theory, seemed to offer the best methodology to construct a theory about what students value when they respond to reflective assignments.

To better illustrate this connection between the concepts of multimodality, design, and reflection, I propose a conventional three-part argument:

1. Multimodal composition requires attention to design elements.

2. Education in design and design thinking has focused on reflection.

3. Therefore, composition could also make use of the connection between design thinking and reflection 
Because multimodal composition is as much a design process as a writing process, I theorized that design thinking could be effective in building an ethos of reflection in my classes. Like design thinking, multimodal composition requires attention to both abstract and concrete elements. However, the practice of composition - without the addition of the modifier "multimodal" composition - also consists of both abstract and concrete practices. To some extent, these relationships bump into each other messily, with no clear starting point at which to examine them, but I thought that reading the reflections of students who were also creating multimodal projects would reveal more about these muddied connections.

\section{Grounded Theory Chooses Me}

When I took a course in qualitative research, focused more specifically on grounded theory, my classmates and I were somewhat surprised that it was not a required class for all Ph.D. students in our program. I can't speak for my classmates, but I appreciated this research method because it represented what I think of as a more concrete and systematic approach to research. The title of this section is meant to capture the sense that rather than choosing grounded theory, it was a methodology that seemed as if it had been waiting for me to discover it. While this suggests that the choice of grounded theory was not rational, Broad (2012) argues that "choices among research methods are not as purely rationalistic and strategic as we might wish, believe, or pretend” (p. 200). It was after I had already completed my analysis and labeled this section that I realized that it came from Broad's question "in what ways and contexts do our methods choose us?” (p. 202). The coding process in grounded theory still requires the same type of analytical skills required across the breadth of methodologies in composition, but whether through the use of specialized software or through manual methods, coding provides a structure for observations and a way to extend those observations across multiple texts. The first time I encountered grounded theory methodology in a previous class, I had asked why this was not used more widely in English studies because of its emphasis on the use of words as data. The professor explained that the coding process is actually very similar to, if not synonymous with, 
the textual analysis used even in literature. She went on to explain that it is typically used intuitively in literary studies instead of through the systematic approach I would learn later in the qualitative research course.

Although the terms qualitative research and grounded theory methods are sometimes used interchangeably, qualitative research refers to a wider range of research that offers an approach to problems that cannot be resolved through quantitative methods. In addition to grounded theory methodology, qualitative research also includes case studies and ethnographic studies, for example. Lauer and Asher point out advantages of qualitative research as ...attempts to give a rich account of the complexity of writing behavior, a complexity that controlled experience generally cannot capture. It tries to show the interrelationships among multifaceted dimensions of the writing process by looking closely at writing from a new point of view in order to recognize important variables and to suggest new hypotheses for further study. (p. 45)

However, Lauer and Asher present several disadvantages to the use of qualitative research in composition studies and do not include the application of grounded theory methods in their book focusing on empirical research.

Broad (2012), citing from the work of Miles and Huberman, in explains "that qualitative methods take as their main type of data 'words rather than numbers"' (p. 197), but he goes on to explain that this distinction between quantitative and qualitative data is not enough to identify what a qualitative researcher does, particularly in the area of writing studies, since the use of words as data is shared by the majority of researchers not only in writing studies but across the English disciplines. Consequently, Broad defines himself as "an empirical-qualitative researcher" who is interested primarily in "things people do, say, and write in day-to-day life" (p. 199) He says the "primary focus of the empirical-qualitative research is relationships and interactions among people, not published texts" (199). These qualities, however, are not quite 
enough to characterize grounded-theory methodology, "a system for developing and validating findings based on analysis of empirical, discursive data" (Broad, 2012, p. 204).

Corbin and Strauss (2008) begin their primer on grounded theory methods by defining the process as the "specific methodology developed by Glaser and Strauss (1967) for the purpose of building theory from data. In this book the term grounded theory is used in a more generic sense to denote theoretical constructs derived from qualitative analysis of data" (p. 1). Although the most basic sense of grounded theory is that it derives from an analysis of words in the context of interactions between humans, Corbin and Strauss emphasize that the significance of grounded theory is in its attempts to account for complex situations. They caution against "simple explanations for things. Rather, events are the result of multiple factors coming together and interacting in complex and often unanticipated ways.... We believe that it is important to capture as much of this complexity in our research as possible, at the same time knowing that capturing it at all is virtually impossible" (p. 8).

Flower (1989) recognizes the need for research that captures the complexity of the activity of writing when she calls for methodologies that avoid "theoretical positions that try to polarize (or moralize) cognitive and contextual perspectives" (p. 282). Although today's writing studies research seems to have avoided these oppositions, Flower's call is still relevant in defining the purpose of grounded theory within writing studies research. She cites grounded theory, as developed by Glaser and Strauss, as a means of realizing "a vision that is grounded in specific knowledge about real people writing in significant personal, social, or political situations" (p. 285). Working within the cognitive/social dichotomy in which the field was immersed at the moment, Flower acknowledges that her own earlier work with Hayes in cognitive theory does not exist outside of a cultural context in that it "did little more than specify that the 'task environment' was an important element in the process; it failed to account for how the situation in which the writer operates might shape composing” (p. 283). In the present, 
Teston, et al (2019) illustrate the complexity multimodal composition adds in their study of a professional writing course in which students produce work for a community partner:

We offer up a data-based feedback model for helping students respond (via multimodal design) to spaces and places that, because of changing socioeconomic, geographic, environmental, political (and so on) conditions, are constantly evolving (and devolving, for that matter). We argue that multimodal pedagogies that foreground materialdiscursive conditions require dynamic feedback models that create conversations with students about the contingent nature of 'available means.' (p. 197)

While the study by Teston, et al, begins from a perspective of assessment through the use of grounded theory methods, the research team employed the intuition that characterizes grounded theory as they worked through a rigorous process of open coding followed but further coding through a limited set of 13 codes. Furthermore, they used this process to investigate the conditions in which students made composing decisions, such as the failure to use captions, which they traced to "problems in our computer classrooms with the MovieCaptioning software we typically used" (204). In their search for a "unifying theory," the researchers find that "multimodal work is constantly contingent on a wide range of material-discursive conditions" (p. 204).

Contingency characterizes not only the results of this study but of grounded theory methodology in general in that the process and the results are shaped by not only the human relationships represented by the data but also by the relationship of the researcher with the data. Deborah Dillon (Alvermann, O’Brien, and Dillon, 1996) interrogates the contexts that shape a researcher's work with respect to factors that have an impact on the outcome of the research process. She says of the report that emerges from a grounded theory project,

I am also interested in knowing how daily events and interactions with participants shape the lenses used by researchers as they engage in ongoing data collection, analysis, and interpretation. Incorporating this information in a written report is critical to a 
reader's understanding of the research, yet I have found it is difficult to accomplish. (p. 116).

For my own project, I used texts that I had previously graded, which made it more difficult to position myself as a researcher instead of as the instructor of the course. At the same time, though, I do not believe my status as the former instructor of the participants can be ignored. On one hand, my role as the former instructor often prevented me from approaching the texts absent my disappointment that my assignments (e.g., questions) for reflection did not yield the result I hoped. On the other hand, the same conditions pushed me to analyze with more care to determine what these student texts reveal about their constructions of reflection and of their constructions of themselves as reflective writers.

Although my project is not situated within the primary concerns of feminist research, I wanted to position myself within the ethics of feminist methodologies. Eileen Schell (2010) argues that a primary characteristic of feminist research is attention "to the significance of gender and gender asymmetry as a basic feature of all social life, including the conduct of research” (p. 8). She goes on to cite as first among Gesa Kirsch's set of commitments feminist researchers make in their methodologies, to "ask research questions which acknowledge and validate women's experiences" (8). While the majority of the participants in my study were women, I did not set out to specifically focus on reflection from their perspective alone although my own personal experiences with reflective writing are certainly grounded in feminist leanings. While grounded theory does share some characteristics with feminist methodologies, chiefly a reflexive stance and a sense of care for the participants in a study, grounded theory values a process of allowing themes to "bubble up" during the coding process rather than to begin with a stance on gender that might have prevented certain themes from emerging.

However, I wanted to take on some of the other commitments of a feminist researcher to the extent the approval process of the Institutional Review Board would allow. Advocates of grounded theory describe the process of collecting data as reflexive, meaning that ideally, data 
collection, coding, and then further data collection occurs in close proximity or even simultaneously (Corbin and Strauss, 2008, p. 31). Because the participants in my study were also students in my class, though, I would not know their identities until after the semester was concluded and final grades assigned. To start coding files of all students on the possibility of their participation would have violated the expectations of the IRB and would have introduced observations leading to skewed results. Even if I had removed the files and coding produced by non-participants, it would have been much more difficult, if not impossible, to ignore observations and conclusions I formed from coding of the non-participants. In order to account for contingencies, then, I collected all of the work students submitted during the semester, including drafts and homework assignments. During the semester I scanned assignments that students submitted on paper, and after I received the consent forms signed by participants, I collected the work participants had submitted online and organized them into digital folders based on the type of assignments.

My practice of reflexivity, then, occurred primarily during my coding process as I struggled to distance myself from the role of grader in order to focus more on what students were expressing in their texts. In revisiting their reflections in more depth, I made discoveries that frustrated me from the perspective of a teacher but that may provide important student perspectives on the process and value of reflection. While I realize that I am performing my own construction, or interpretation, of these texts, my desire has been to allow the stories and voices of students to emerge from my accounting of their work. I wanted to emulate the ethos of Bob Broad (2012), who refers to his own work as "deeply rooted in the interpretive framework(s) of research participants (p. 204). Ultimately, my research stance might be best described as humanistic rather than specifically feminist - humanistic in that I employ an empirical approach within a humanities discipline but also because of a drive to understand a process mediated by human beings with complex needs and drives. 
In spite of the time since Paul Anderson (1998) wrote about ethics in "person-based research," his emphasis on the "simple gifts" from students remains relevant today:

We should remember, instead, that in person-based research we are the recipients of gifts. The volunteers in our formal studies hand us the gift of their time and cooperation. The persons whose unpublished words we quote have shared their experiences, ideas, and feelings with us. In comparison with the discomforts and dangers that participants in some biomedical research volunteer to endure, these are very simple gifts. But they are not trivial. No matter how we proceed in our discussion of research ethics, no matter what outcome we devise, let it be our goal to assure that both individually and as a discipline we treat these gifts_and their givers-justly, respectfully, and gratefully. (p. 83).

One of my primary goals during this project, therefore, was to appreciate these gifts as well as the givers.

\section{Digging into Specific Codes}

In this section I describe my process of coding files for analysis and then my initial analysis of some of the most significant codes that emerged from this process. The analysis I describe here was a process of quantifying codes, identifying similar codes, and determining intersections between codes. In Chapter Four I will turn from enumerating codes and identifying correlations to discussing the themes that emerged during my process of coding the reflections.

The software I used for analysis, NVivo, is a popular software package that is used for the coding, or tagging, both alphabetic text and images, that characterizes qualitative research. Qualitative researchers use this software to find associations between different codes and to create charts in order to better visualize the data. After organizing files by assignment type, I uploaded all of the reflections as well as the transcripts of interviews into NVivo and then 
labeled each file with its appropriate category: Reflections-Unit 1, Reflections-Unit 3, Final Reflections, and Interviews.

I started my process with open coding, which refers to the use of phrases that the researcher develops in order to account for a meaningful word or phrase in a sentence. "Meaningful" in this sense refers to the connection between the text and the topic of reflection rather than intrinsic meaning. I also used in-vivo coding, which refers to the use of the text itself as a code, usually in the form of a single work. While NVivo allows researchers to import a codebook - a list of pre-existing codes - I did not seek out or create such a list in order to pay close attention to the specific texts in my dataset.

As I proceeded through my coding process, I reused codes as often as possible, but without keeping a close watch on which codes I had previously used, I created many similar codes that could have been replaced with existing codes. Consequently, this process led to the creation of over 400 codes, even after I began to focus more on the use of existing codes (or "nodes" in NVivo) and on the codes that appeared to have the most impact on my interpretation. Appendix $\mathrm{G}$ includes the entire list of these codes. Before undergoing extensive analysis of my dataset, then, I found it necessary to take an extra step to organize my codes since my list of codes exceeded 40o. I could have gone through my dataset to consolidate many of these codes, but since it took several steps to copy each code and its tags to another code, I was concerned I would accidently lose some of my work and chose instead to manually group the codes together.

To manage the number of codes, I began to place them on Post-it notes that I organized on the front of my refrigerator. Rather than having more than 400 Post-in notes, however, I placed multiple related codes on many of the post-in notes. I worked through this process by starting with codes I used most frequently, and by the time I reached the codes that were limited to just a few, or often just one, occurrence, I had already organized many of those codes into groups. I then transferred these groups onto sheets of paper and then wrote the less-frequently 
used codes not already classified onto the pages that contained related codes. Images of these pages are in Appendix $\mathrm{H}$.

\section{Coding for "I" Claims}

An "I" claim in the context of this project refers to the use of the following three examples in student reflections:

I think

I believe

I feel

When I began coding for these claims, I had used just one code for all three examples, but after realizing that I coded "I" claims inconsistently, missing many of them, I revisited the reflections in which students used these phrases and found that they used them for two primary purposes - as well as a few others that were difficult to classify - to discuss improvement and to discuss audience. I used Nvivo to conduct a comprehensive search for "I think," "I feel," and "I believe," and coded each present tense use of an I-claim as "Improvement," "Audience," and "Other." The numbers of instances for each use are shown in Table 1 below. I usually did not code "I" claims when they were used to indicate an action in the past or as part of an infinitive (usually also a past action) since these uses were not examples of qualifying their thoughts about their projects. In many cases, the past action represented their thought processes in developing topics and making choices about the media they would choose for their multimodal projects, choices that resulted in more concrete evidence than their opinions - represented by the "I" claim - about improvement and about audience. 
Table 1

"I" Claims and Relationships to Other Codes

\begin{tabular}{lllll}
\hline \multicolumn{1}{c}{ Associated } & \multicolumn{3}{c}{ Types of "I" claims } & \multirow{2}{*}{ Total } \\
\cline { 2 - 4 } & I think & I feel & I believe \\
\cline { 2 - 4 } Improvement & $26(0.27)$ & $21(0.27)$ & $9(0.16)$ & $56(0.24)$ \\
Audience & $40(0.40)$ & $26(0.33)$ & $21(0.38)$ & $87(0.37)$ \\
Other & $32(0.33)$ & $32(0.40)$ & $26(0.46)$ & $90(0.39)$ \\
\hline Total & $98(1.00)$ & $79(1.00)$ & $56(1.00)$ & $233(1.00)$ \\
\hline
\end{tabular}

Before conducting a closer analysis of the "I" claims associated with improvement, I chose to limit the files for further study to those that used more than one type of these statements. Because Nvivo only allows queries in which codes intersect or occur near each other, I had to manually develop the list of reflections by saving the list of files for each code into an Excel sheet (through Word) and then labeling each file in the list with the code. After sorting the files by name, I was able to determine which files were listed more than once. Each type of file that I coded was represented in these results - reflections for units 1 and 2, final reflections, and transcripts of interviews. The only files that used different types of "I" claims more than once were final reflections and transcripts. Of the final reflections, three students (Helen, Felecia, and Quinn) used two of the "I" claims for improvement, and one student (Stacey) used all three of them. Among the students I interviewed, only Margie used more than one type of these codes ("I feel" and "I think") to discuss improvement in the course. I also conducted a query of all of the codes associated the "I" claims discussed in this paragraph, and many of the codes in the resulting list were also associated with improvement. 


\section{Coding for Audience}

I approached the analysis of student use of audience through both coding and text queries within Nvivo. In the coding process, I tagged references to audience which included other terms, such as "readers," and accounts of asking others to read their work. The terminology students used was less important than evidence that the text referred to audience. Consequently, my codes varied depending on how the text referred to the audience since I was not certain during the process how detailed my coding needed to be. Table 2 below lists the codes associated with audience in order of frequency, from the most occurrences to the least. Codes that begin with a lower-case letter represent in vivo coding (in which the wording in the text is used as the code).

\section{Table 2}

Codes Representing Audience

\begin{tabular}{lc}
\hline \multicolumn{1}{c}{ Codes } & Number of uses \\
\hline Audience concern & 80 \\
Audience appeal & 61 \\
audience & 28 \\
Audience interest & 20 \\
Audience benefit & 8 \\
audience expectations & 5 \\
Audience - lack of concern & 3 \\
Audience awareness & 2 \\
\hline Total & 207 \\
\hline
\end{tabular}

In order to account for all the references to audience, I set up a query to find all uses of the word "audience," and the number of results returned - 204 -matched the number of codes in the chart above almost exactly, which suggested that my coding was an accurate representation of the use of "audience" throughout the dataset. Using the file classifications in NVivo, I was also able to determine the number of times "audience" was used in the set of reflections for each unit as well as how many times each student used the term. This was particularly significant since the Unit 1 and Unit 3 reflection questions asked students to discuss 
the way their projects responded to the audience while I did not include a question about audience in the set of questions for the final reflection. The results in Table 3 below show that even without a question about audience in the final reflection, the students who chose to discuss audiences in their final reflections did so with even more frequency than students had in the unit reflections.

\section{Table 3}

\begin{tabular}{llll} 
Uses of Audience Codes & & \\
\hline Unit & $\begin{array}{l}\text { Number of times } \\
\text { "audience" was used }\end{array}$ & $\begin{array}{l}\text { Number of students } \\
\text { who used “audience" }\end{array}$ & $\begin{array}{l}\text { Average number of } \\
\text { times students used } \\
\text { "audience" }\end{array}$ \\
\hline Unit 1 & 67 & 21 & 3.2 \\
Unit 3 & 51 & 18 & 2.8 \\
Final Reflection & 53 & 10 & $5 \cdot 3$ \\
\hline
\end{tabular}

Table 3 suggests that as the class, progressed, fewer and fewer students talked about audience but those that did talked more about it. I then also created a list of the top uses of "audience" by student for each unit in order to select the files from which to initially draw material for discussion in the next chapter and to compare the language students used in discussing audience. The greatest number of times "audience" was used in a single document was a final reflection in which the student used the term 18 times, which skews the average for that unit; however, the average of the uses of audience by the other students was 3.9, still higher than in Units 1 and 3. In these lists, I included only the top seven (or about 1/3) of the number of times "audience" appeared. To limit the number of files in my list, I counted duplicate number of uses to make up the top seven. In other words, in Unit 1, the top seven numbers for the use of “audience" were 11, 7, 6, 5, 5, 4, and 3. For the final unit, since only ten students used "audience," I included all of them in that list. This allowed me to determine which students addressed audience most consistently, and I found that only four students - Margie, Stacey, Adam, and Jamie - appeared in each list, and I will discuss their use of "audience" in the next 
chapter. These four students accounted for 98 of the 207 times the word audience was used throughout the dataset.

\section{Coding for Engagement and Creativity}

As I was sorting through the codes, I found that a few, such as "creativity" and "enjoyment," seemed to belong at the center of the spatial array of codes, partly because they appeared so frequently. I also sensed that their position as central codes was the result of them not fitting neatly into other categories. Creativity and enjoyment, for example, were not among the codes with the top numbers of references, but they seemed to be potential bridges between other codes and themes. I also included reflection and engagement in my core concepts; the inclusion of engagement was due to my interest in potential connections between engagement and reflection. Engagement has also been an important concept since the inception of this project, making it important to account for it in my coding. All four of these central concepts also included several related codes (listed by frequency), as indicated in Table 4 on the next page. 
Table 4

Central Codes with Related Codes

\begin{tabular}{|c|c|c|}
\hline Grouping & Code & $\begin{array}{l}\text { Number of } \\
\text { references }\end{array}$ \\
\hline \multirow{7}{*}{ Creativity } & Creativity & 49 \\
\hline & Creative & 16 \\
\hline & Unique & 16 \\
\hline & Imagination & 8 \\
\hline & Different & 6 \\
\hline & Creative style & 6 \\
\hline & Originality & 3 \\
\hline \multirow{3}{*}{ Enjoyment } & Enjoyment & 27 \\
\hline & Fun & 12 \\
\hline & Flow & 6 \\
\hline \multirow{10}{*}{ Reflection } & Reflection & 11 \\
\hline & Reflection - Benefit of & 9 \\
\hline & Refection - Other classes & 7 \\
\hline & Self-knowledge & 2 \\
\hline & Self-evaluation & 2 \\
\hline & Reflection - Multimodal & 2 \\
\hline & Choices and Reflection & 1 \\
\hline & Reflection Process & 1 \\
\hline & Reflection as Invention & 1 \\
\hline & Reflection - lack of & 1 \\
\hline \multirow{8}{*}{ Engagement } & Engagement & 9 \\
\hline & Interest & 13 \\
\hline & Motivation & 10 \\
\hline & $\begin{array}{c}\text { Interest in Writing - Life } \\
\text { experiences }\end{array}$ & 9 \\
\hline & Interesting & 3 \\
\hline & Interested & 2 \\
\hline & Lack of Interest & 1 \\
\hline & Lack of Motivation & 1 \\
\hline
\end{tabular}

Although Creativity was not at the very top of the list of codes by frequency of use, I had noticed during my coding that it appeared more often than I had expected. In conducting a 
search for each reference to creativity throughout the dataset, I discovered that all of the participants in this study used a form of the word "create" or a term associated with creativity, such as "unique" or "original." Furthermore, the fact that I had coded for creativity in more reflections than the codes associated with the questions I had actually asked of students made me consider creativity a central concept. This puzzled me somewhat since I had taught a composition course rather than a creative writing course, but I initially credited the emphasis on creativity on the focus on the course on games. These creativity codes are discussed in the second section of Chapter 4 .

\section{Coding for Satisfaction}

Because so many students reported satisfaction with their work, I also wanted to analyze the "Satisfaction" code in more detail, particularly as it related to audience. Unlike the sets of codes I have discussed in this chapter, I primary used just one code when students discussed their satisfaction with their projects, and I coded for this feeling 62 times. As I was organizing my codes, I also included eight instances that I coded as "Pride." I did not pay as much attention to these codes at first because they were typically part of the answers to one of the reflection questions that I had included with both the Unit 1 and Unit 3 reflections. I considered the possibility that students affirmed their satisfaction in order to ingrate themselves to me. However, I was stunned that every student reported satisfaction with their work, and more than half of them reported this feeling in both Units 1 and 3 reflections.

Although it was the number of instances of satisfaction codes that drew my attention, I wanted to find correlations between "Satisfaction" and other codes in order to determine what this satisfaction meant in the context of the work students had completed in the course. However, a query to determine which codes intersected with "Satisfaction" returned 45 codes, and I was unable to detect a pattern among these codes. After I identified all of the codes that were associated with "Satisfaction," I discovered that the query had returned all instances of each of the associated codes instead of just those nodes that intersected with "Satisfaction." 
While I wanted to use the software to help me with this analysis, I decided to move forward in my analysis by creating a spreadsheet that included both the file name and each reference to this code in the text. I was then able to read through each of the quotations from the reflections and to identify which of the intersecting codes were the most relevant to the concept of satisfaction, and these are shown below in Table 5 . I include the most relevant codes that resulted from this analysis in the chart below. I excluded two references that appeared in a final reflection since only one student addressed this idea in that assignment. After I completed these steps, I continued my analysis to identify the enthusiasm students seemed to display in discussing their enthusiasm, and I will discuss this further in the second section of the next chapter.

\section{Table 5}

\begin{tabular}{lc} 
Codes Associated With "Satisfaction" \\
\hline Intersecting Codes & $\begin{array}{c}\text { References to } \\
\text { "Satisfaction" } \\
\text { n=60 }\end{array}$ \\
\hline Creativity & 26 \\
Audience & 18 \\
Help from others & 10 \\
Interest in topic & 9 \\
Effort & 8 \\
Personal experiences & 4 \\
Processes & 4 \\
Fun & 2 \\
Interesting idea & 2 \\
Research & 2 \\
Expanded thinking & 1 \\
Motivation & 1 \\
Met criteria & 1 \\
New project & 1 \\
Prior learning in & 1 \\
course & \\
\hline Includes "Change in process" and "New \\
writing experiences"
\end{tabular}

\section{Conclusion}

In the next chapter, I will turn from enumerating codes and identifying correlations to identify and discuss prominent themes that emerged during my process of coding the reflections of the participants in my study in the fall of 2017. These themes include the use of I-claims, the 
importance and meaning of creativity, and relationships between audience and satisfaction. I will discuss the extent to which students value creativity, attention to audience, and their satisfaction with their own work. In my analysis of the I-claims, I discuss and attempt to account for troubling and incoherent sentences which often follow these claims. Along with discussing the relationships between specific codes, I will also discuss over-arching narratives that are associated with these codes. These narratives - as depicted in the reflections within this dataset - include stories of improvement, hard work, and heroism (based on Joseph Campbell's model of the hero's journey). I conclude the chapter with a focus on the reflections of students whose texts included evidence of reflective thought as well as design thinking. ${ }^{8}$ An important point revealed throughout the dataset was the significance of social connections in their writing practices, which may reveal a significant flaw in the premise of reflection as evidence of or even emphasis on the cognition of individual students.

${ }^{8}$ I have not enumerated codes for design thinking in this chapter since I did not use any codes for design thinking in my data. However, as will be discussed in Chapter 4, codes for audience and creativity are related to design thinking. 


\section{CHAPTER IV: STORIES OF SELF, CREATIVITY, AND DESIGN THINKING}

In the previous chapter, I laid out the rationale for the use of grounded theory in this project and explained the general principles of this process as well my process of coding and analyzing files. These details included the identification of specific codes based on their frequency and relationship with other codes. In this chapter, I will engage in a higher order discussion of the meanings that these codes suggest. My approach to coding the files in this project was open-ended since I wanted all the central themes from student reflections to emerge in order to gain a sense of what students chose to express in their reflections. Some past studies have relied on just a selection of reflections from a larger group, using a case studies approach to support claims about the purpose and effectiveness of reflection as a means of affecting transfer from a writing class to other contexts for writing. My own goal was to approach my analysis from as neutral a position as possible, a process that was complicated by my role as the instructor for the classes in which these reflections were submitted for a portion of student grades.

However, as I discussed in my previous chapter, part of my methodology was to reflect on my own process of reading and analyzing these reflections. I was often disheartened at what seemed to be a lack of reflective thought, even though I approached the coding with the goal of seeing what these reflections suggested about the challenges students face when asked to write reflections, particularly reflective assignments that would be evaluated as part of their course grade. In the early stages of my project, I hoped that I could identify the characteristics of reflection, as practiced by both student writers and published writers, as if it constituted a genre that students could emulate. I envisioned making the teaching of reflective writing more straightforward, asking students to analyze reflective writing as they would any other genre. Instead, I often found myself mystified at the repetition of phrases and narratives that seemed to undermine the purpose that has been the foundation of assigning reflection in first-year writing classes: to help students to become aware of their writing processes and to reinforce successes 
for future use.

The reflections I analyzed for this project revealed instead a sense of ambiguity and uncertainty even when students made claims about improvement as writers. The claims in student reflections were often qualified by "I think" and "I believe" statements, which seemed to indicate a lack of confidence in or doubt about the statements that followed. The extent to which students focused on audience also seemed more likely to be driven by a desire to please the instructor (of the course), who had emphasized the importance of being aware of an audience, rather than expressing real concern for the needs of an audience. For my own part, I began to suspect that this emphasis on the needs of the audience may have caused students to experience a weaker sense of agency, the audience acting as more of a constraint on their word choice, style, and genre choice than may be necessary at this stage of their writing development. Rather than use the word "agency" in their reflections, however, students appeared to link a sense of agency with creativity, using this term to denote the freedom in my course to choose a topic or genre. While I have always associated "creativity" with the use of style or language to design a project for aesthetic purposes, students seemed to use this term to emphasize autonomy and difference.

As I describe the themes that emerged from these reflections, I quote frequently from students in an attempt to allow their individual voices to emerge from the overall dataset. In some cases, I have retained their personal pronouns within the quotation even when that perspective differs from that of the rest of the sentence. I chose to do this to avoid imposing bracketed pronouns on the quotations but, more importantly, to also keep the focus of this chapter on the experiences of the students. In some cases, I have also included incidental uses of "like" and "um" while in other cases I have edited the text to remove these. I note immediately following the text if I have removed these from quotations from student texts and explain my reasoning. 


\section{In Which Students Distance Themselves from their Work}

In the first part of this analysis, I focus on uses of language and narratives that appear to indicate attempts by students to distance themselves from their work and potentially limit their engagement with their reflective assignments. This distancing often results in sentences that are incoherent, perhaps evidence of a disordered thought process or just a difficulty in controlling sentences that are made more complex through the distancing strategies. I initially thought of the examples in this section as failures of students to reflect on their work in spite of my efforts to provide questions that would lead to reflective thought. However, their uncertainty may actually represent important steps toward reflection, the ability to "stand apart" being a necessary component of metacognition (Grossman, 2009, p. 17).

\section{"I" Claims and Audience}

One of the most prevalent types of phrases in the in the reflections in this study was what I have labeled the "I" claim, which includes "I think," "I feel," and "I believe." I had coded these inconsistently at first, not realizing how significant these might be at that point, but when I searched for and located all uses of these claims, I discovered that they appeared a total of 233 times across my dataset. Furthermore, I found that these statements could be categorized by their purpose and were often associated with audience and with improvement of writing throughout the semester, and although students used these constructions with audience about $25 \%$ more than they did in referring to improvement (i.e. "I feel that my writing has improved...”), the use of these "I" claims seemed to reveal an uncertainty about the statements students made both about audience awareness and about their own writing improvement.

These claims frequently lacked details, weakening students' claims about their writing. For example, one student writes "I definitely think that my audience's needs have been met with each of the different mediums." The use of "definitely" seems to be an attempt to bolster the weakness suggested by the word “think.” Another student's statement contains redundant words 
and phrases: "I think overall in the end I did a good job at providing enough information and ecology to make the game sound interesting and informational at the same time.” The confusion suggested by the use of both "information" and "informational” within the sentence, as well as both "overall" and "in the end," suggest that the student is not completely comfortable making this statement. One student seems to justify his choice of media by claiming that it appeals more to the audience: "In my opinion, I think that the poster is a better medium because it gives people both visual and textual representations. Making the poster was very fun...”

Audience concerns were the topic of 84 "I" claims (24\% of all "I" claims), suggesting that students lack confidence in their claims of paying attention to audience concerns. In addition, the word "audience" was among the most frequently used words in my dataset, and 204 references were associated with the concept of audience. As I continued to read through these references, though, I frequently wondered if students were focused on audience because of honest concerns or if it was a topic they addressed because they were expected to do so. Lyndsey, for example, uses an "I" claim to make a general statement about the importance of audience: "I believe that writing for your audience is one of the most important details within a paper." While she sets this up as a belief, this claim seems to simply echo instruction in the course, particularly since writing for an audience is an aspect of the process of writing a paper rather than a detail "within a paper."

\section{“I" Claims and Improvement}

While I always hope students improve their skills during the semester, I sensed that the claims of improvement students made came more from the reasonable expectation that instruction would improve their writing and that they would complete their projects with greater ease. When students claimed that they had improved as writers but lacked examples to prove their claim, I wondered if their emphasis on improvement came from their own impression that projects became easier as the semester progressed or from an expectation that a writing course will naturally improve their writing skills. This is not to suggest that students did not 
demonstrate any improvement over the course of the semester, but without support for their claims, their potential overstatement of their improvement suggests the importance they place on improvement.

In addition to the ambiguity posed by the use of "I" claims in statements about improvement, it was the potential redundancy that I had originally noticed. A student could simply write "I improved in X areas during the semester" instead of "I think I improved in X areas during the semester." Overall, students tended to use these claims of improvement more frequently in Unit 3 than in Unit 1. Perhaps because Stacey uses all three of the "I" statements think, feel, and believe - in her final reflection for the course, her document contained more assertions of self-improvement than most of the reflections by other students. While she speaks about her process, particularly when using "believe" and "feel," she does so in general ways. She says, "My writing process has come a long way between the beginning of the semester and the end....also, I feel like I know how to construct my writing a lot better than I have before.” After this she discusses the value of brainstorming before drafting a paper, and later in the reflection, she re-emphasizes brainstorming when she says that without it, "I feel as though my writing wouldn't meet the necessary standards." The last time she uses "I feel" in her reflection to describe improvement, she emphasizes how prepared she is for writing in other contexts. Her follow-up statement, however, provides few details: "I know exactly what needs to be done and how I can get there." She uses "believe" when speaking of her "future with writing," which she says, "will be a lot easier than where I started." In this case, the use of "believe" seems appropriate since she is speaking of the future but could also indicate an uncertainty about the writing she will encounter after this course. Finally, she uses "I think" in a section in which she addresses the way her "writing quality improved a lot after receiving comments from other people. I was able to delete a lot of my old work and add more detailed ideas." This is the only place in the final reflection in which she describes specific actions she took to improve her writing; however, the use of "I think" still suggests uncertainty with this claim as well. 
While Helen has fewer statements about improvement in her final reflection, they echo and perhaps suggest even more uncertainty than in Stacey's reflection. In addition to the use of an "I" claim, she adds adverbs to intensify the statement, but at the same time, this intensity suggests uncertainty since the first adverb emphasizes her belief in her improvement rather than the improvement itself: "I definitely believe that my writing has improved significantly over the course of the fall semester, from the first narrative essay to my last unit reflection." The "fromto" construction here seems either to emphasis the scope of the course or to distract from the uncertainty in the beginning of the sentence. In another sentence associated with improvement and using an "I" claim, Helen says "I think that, even though I enjoyed the projects versus the papers, I think that the writing assignments helped me get my ideas across much clearer than the projects.” Although she does not reference improvement directly in this sentence, she suggests a method of improvement of the ways she communicates to her audience. In other sections of her final reflection, she discusses her difficulty in trying to overcome procrastination, and one statement that suggests improvement in that area is when she says of her project for Unit 3 that it was "honestly the only project I didn't rush through because I was so excited to create it." She does not indicate how she might try to avoid procrastination in the future, however.

A few students (Mandie, Michael, Micky, and Quinn) focused on the connection between improvement and ease in Unit 3 and largely avoided "I" claims, but a sense of anxiety about their writing is still present. Although Quinn does use "I think" and "I believe" to qualify statements about improvement, his final reflection contains statements that indicate more confidence, such as when he says, "I knew that I would be able to improve my score if I practiced more." His use of "I" claims differs from other students in that he sometimes emphasizes the improvement in a dependent clause at the beginning of each sentence rather than in the main clause, as in this sentence: "Since my writing skills have improved, I believe this will be important for projects in the future" (italics added to indicate the dependent clause). He also 
tends to write some of his claims in the passive voice, which has the effect of distancing himself from the process. For example, he says "Learning new ways to write... and how to genre research I feel self-assured that my writing projects in the future...will be well done" (emphasis added). In the last paragraph he returns to a more confident voice and writes, "I knew it was possible for me to improve my writing skills as long as I practiced writing.” In the same document he expresses this confidence, his uses of "I think" and "I believe" combined with passive voice suggest that he is actually concerned about his improvement.

Another way students showed a lack of confidence was in the use of adverbs to emphasize their claims about improvement and learning. Quinn, for example, identifies the way he fulfilled his predictions about improvement in his writing, but he often undermines his claims, similar to the way Helen did in her reflections. He writes: "The amount of writing I did in this class has definitely helped me to improve my writing skills and become a stronger writer." He ends this section with a "I am very content with the material I learned and my performance in the class." He seems to manifest confidence "with the material I learned and my performance in the class," but prefacing the word "content" with "very" suggests an insistence that may weaken his claim.

The uncertainty created by "I" claims seemed to intensify when a student used only one of the three claims (think, feel, or believe) in a reflection. In addition, the use of "I believe" statements exclusively tends to result in students writing incoherent sentences. Michael uses "I believe" statements four times early in his final reflection, and two of these sentences are structurally unsound. He starts his reflection with "I believe this class really helped me with that writing for my future as I can take different angles at an assignment and believe as I learn more and more about writing and literature the more and more my writing will get better." Although it is likely that "I" at the beginning of the sentence is intended to be the subject for both uses of "believe," he seems to struggle to articulate how his writing has actually improved. He finishes his paragraph with another incoherent thought: "I believe will be good writer for the rest of my 
college career and where I end up working.” Interestingly, however, he does not claim improvement of his writing skills specifically but rather an improvement of his approach to assignments. In his next paragraph, for example, he says "I believe starting assignments early and writing down my ideas before writing helped me during this course.” Like Quinn, Michael also uses passive voice to refer to the completion of his projects, and his responses to the reflection questions I provided do not stand on their own and are sometimes limited to just two sentences.

In addition to the use of adverbs, some students used perspective as a means of creating distance from their writing and even from their own sense of confidence. In her final reflection, Mandie uses phrases that seem to indicate confidence: "after this class, I know I will be better off on those than I would have been before." Although she does not use the word "improve" in her final reflection, this sentence as well as others point to the experience or concept of improvement. In the same paragraph as the above quotation, she also says "I discovered my true ability of creating pieces that would better engage my audience and try to connect them to me." In the sentence just prior to this quote she had described how cautious she had been in her writing assignments before taking this class. She also emphasizes her success in the course through the use of the word "always": "One thing that I always did before starting each one was coming up with as many ideas as I could think of for the project so that I had more choices. I always chose the topic that I thought would be most successful in means of detail and creativity.” However, when Mandie writes about her purpose in writing and identifies her purpose as connecting with the audience, this is the only place in her final reflection that she uses second person pronouns. She writes that

"If you can get the audience to connect with the text in some way, in most cases they will want to keep reading it.... For any writer, you want to feel that sense of accomplishment, and know you have achieved that when the readers are looking at your work in a positive way." 
Shifting to the second person perspective seems to be a way for Mandie to also shift attention from her own work, distancing herself from her own experience.

Even when students appeared to be more confident about their writing, a hint of uncertainty emerged from their approach. Like Quinn and Mandie, Micky also uses the phrase "I know" in her final reflection to describe how the "class has expanded my writing skills in ways that I know have made me a much more well written student." Unlike many other students, however, she describes some of the specific ways she benefited from the class, including different approaches to assignments, improved research skills, and knowledge of business letters. She seems to reassure herself about her writing ability, though, when she describes previous experiences, such as winning essay contests and having "never struggled when it has come to writing assignments." In contrast to Mandie, who said her main purpose was to connect with the audience, Micky says that her purpose is to succeed: "I know what I am capable of and turning in work that doesn't live up to those capabilities makes me incredibly disappointed in myself." Micky is one of the most confident students in her final reflection, but the last slide in her final reflection turns into a sort of pep talk to herself when she says, "All I have to do is put the time and effort in and I can achieve anything I put my mind to." Even at the edge of her confidence is at least a small portion of doubt.

Scholarship supports an interpretation of "I" claims as expressions of doubt. Nes (2016) points out that "Using 'I believe' to guardedly affirm a proposition is commonplace" (p. 84). Nes adds that the use of such claims violates the linguistic norm that the speaker expresses a truthful statement, yet the use of "I believe" does not sound as odd to a listener as the use of "I assert" to state a claim. Indeed, as I indicated above, I had not paid close attention to these claims at first. Nes argues that linguistic norms make it preferable for speakers to make assertions without qualification when they are certain of the veracity of their statements. However, Nes explains that when "I believe" is used as a parenthetical expression, it often represents a lack of confidence in the statement and may be intended to convey only an approximation, or 
weakening, of this statement. Nes calls these statements "I believe" - guarded assertions, or IBGA, and says that through "simple reasoning, then, it seems that speakers can infer that anyone who IBGAs violates either a central norm of belief, or corollaries of central maxims of conversation" (p. 71). Although Nes says that statements may be intended to show that the speaker who uses these IBGA are expected to believe the statements that they are making, in my reading of these reflections, these claims seemed to indicate a lack of confidence (p. 68).

In addition, the use of these "I" claims creates a distance between the writer and the statements that follow the initial claims of thinking, feeling, and believing. Making these statements about audience and about improvement without prefacing them with an "I" claim would make them more immediate and concrete, a move that students seem unwilling to make. Moreover, in using these "I" claims, they seem to get lost in the complexity that this phrase requires, and their sentences are more likely to be garbled or incoherent.

\section{Use of Impersonal Language}

Beyond "I" claims, some students also seemed to distance themselves from their work by using passive voice to qualify claims about creativity. Although I coded for passive voice, I did not catch all of the examples in student texts during the coding process, and it was not until I was examining codes associated with impersonal language that I noticed the number of times these students had used passive voice. I ultimately realized that although only five students used passive constructions, four of these students had described themselves as lacking creativity, suggesting a reluctance to claim ownership of creativity.

Mandie described the way the class helped her to become more creative, but when she discussed her work, her use of passive voice suggests a lack of agency when she says "a lot of thinking and creativity went into this project." Likewise, Adam claimed that "Most of the work and structure of the paper were already thought out before I even started the rough draft," again limiting his role in developing the paper before he began to write. Matthew also employs passive voice, as indicated by this sentence: "My game description, letter of endorsement, and my 
reflection ended up being created to my liking." This sentence makes it seem as if another person was responsible for his projects, but I thought it was more likely a reflection on his view of his own work than it was for him to have actually had another individual complete his projects.

A lack of agency can also be seen in the impersonal language that several of these students adopted when referring to projects or their work in the course. Adam, for example, describes the requirements of the projects in terms of the overall class rather than establishing any personal connection or investment: "For example we wrote an endorsement letter.... First we had to create a project to create a game description for a new game.” In my coding, I labeled this type of language "student reporting voice" or "student explaining voice" to indicate text in which students reinforce their role as students rather than as writers. Although I had requested students not add this type of detail to their reflections since I was the audience and already knew what the assignments were, I also realized that using this voice was another way for students to distance themselves from their texts.

In my analysis of these codes, I observed that the use of this student voice fell into three categories:

- Narration of individual or class activities

- Definition or identification of terms or assignments

- Explanation of cause-effect relationships.

I had coded text with the "student reporting voice" earlier in the process than I had the "explaining" codes, and these references were primarily narrative with just a few definition or cause-effect references. The references I coded as "student explaining voice" were mixed evenly between narration and a combination of definition and cause and effect. These numbers indicate that I perceived of narration as a form of reporting and the more complex definitions and causeeffect as explanation. In all of these cases, though, when students used these strategies, they 
were describing the general activities and assignments from the class rather than the specific processes students took in their composing.

The next most frequent use of explaining was manifest in definitions of terms or identification of terms or assignments. These examples interested me because they were generally as impersonal as the narrative sentences, and they sometimes resulted in incoherent thoughts: "Transmedia opens up a whole new way of allowing more of a population to vital information.” Explanations such as this one suggest that the student had retained this knowledge, but like the claims about audience, this one is also a parroted version of what I had shared with the class.

Although only seven of the references for "student reporting/explaining voice" were statements of cause and effect, these seemed to reveal the priorities of students, which were often not writing improvement. The clearest example a cause-effect relationship is this statement by Tony: "Understanding the expectations and requirements on assignments are very important because if you do not comprehend something on the rubric and do not ask about it, it can affect your grade." While his statement is certainly not false, the use of "you" makes it unclear if Tony is making this statement out of his own experience, from observation of other students, or from a general knowledge about how the grading of assignments takes place. The use of "you" also seems to be a generic construction since he is not describing his own actual experience and is most likely not using "you” to refer to his direct audience of the instructor (myself).

Most of the examples of cause-effect are less obvious, such as this claim by Margie: "Through description, the writer is able to create a scenario; she can put her audience in a different place and time based on the words she chooses." Cause and effect here refer to the use of description and word choice and their effect on an audience, and this statement is appropriate from Margie since putting an audience into a different setting is at the core of what she does as a theatre major. What is interesting about the way Margie uses this, however, is that she starts the 
paragraph in which this statement appears with very specific observations about her theatre class. She argues that she has gained knowledge about herself as a writer and has been able "to expand my thoughts and ideas" through the activities of the class, but when she reaches the sentence above, she is reporting something that a writer (student or otherwise) can do and does not indicate whether or not she has actually done this. She has also shifted from personal pronouns to third person pronouns, which increases the impersonal nature of the statement. She follows this with an additional statement that I also coded as "student explaining voice" “To be able to move one with a piece of text takes patience, creativity, and an open mind.” - and then she begins to shift back to first-person pronouns, finally shifting from the generic student voice to her personal goal of "not only [producing] work I see as adequate, but something that will move my audience."

Adam also uses cause and effect in an indirect way when he says: "I made sure to choose a font, layout, and multiple images using what I think the audience would enjoy.” The cause is found in the phrase "font, layout, and multiple images" with the effect being the audience reception, which is not dissimilar to Margie's comments above. What is different in Adam's case, and a large part of the reason I coded it as I did, is that this sentence follows an earlier statement in the document using very similar wording in reverse - "Different images, layouts, and fonts" - to explain how to convey an idea to an audience without using words exclusively. After he talks about the specific media he chose, an infographic, he then returns to the general statements about audience without explaining the specific choices he made in creating his infographic.

Although students usually employed declarative sentences when explaining course activities and expectations, providing this information also suggests a lack of agency as well as a lack of engagement with the course material. When students use this "reporting" voice, they are primarily filling space with this information, and like the examples of passive voice, this type of language also represents distancing while also limiting their explanation of their own 
experiences.

\section{Audience and Engagement}

As discussed earlier in this chapter, students often discussed audience through the use of ambiguous "I" claims, but the comments four students - Margie, Stacey, Adam, and Jamie made about audience were associated with emotional reactions rather than about other concerns, such as tone and register. Although the use of emotion would seem to place students closer to their audience and contrast the earlier distancing attempts, their reflections reveal a distancing from analytical or critical thought about their topics. These four students expressed concern about making their work interesting for the readers rather than to challenge their readers, and by extension, themselves. Margie and Stacey, for example, both used the word "intrigue" to describe the response they hope their audiences will have. Jamie says that she wanted to provide an interesting storyline in her project for Unit 3, and for the same project, Adam wanted to create "an appealing and entertaining” description. Of her remediation of the narrative in Unit 1, Margie comes closer to having an effect that is more than interest or intrigue: "My intent is for my audience to stop and ponder about what is in front of her eyes and think what can make these people feel this way?"

However, while some of these students indicated that they want to challenge their audience, they also seemed to assume that their audiences want material that is easy to understand. Jamie writes about using "words [that] were not too hard to understand" while Adam's desire is to “make [his project] easy to read and organized.” He also discusses the advantage of using "images, layout, and fonts" to provide an understanding of the material without using words. He adds that "This makes it easier for the audience to understand more quickly about the story making it quicker for them to get to the end and still be interested."

Several passages suggested that in spite of the number of times these students discussed audience, this may have actually been a means of disguising their lack of engagement with the 
audience and the course. Students tended to focus on entertainment rather than conveying ideas and information such as when Adam writes in his final reflection about creating projects that entertained and fulfilled the requirements of the assignment. Some of the phrases used in other sections of their reflections seem to indicate a lack of attention to their work, at least in these assignments. Adam writes about developing "the subtopics and sections of the paper" and then dividing them into "different subcategories that I can fit together and make flow throughout the project."

While the number of times Jamie, Margie, and Stacey referred to audiences was stable across all three reflections with differences of three or fewer uses between units, Adam discusses audience five times in the Unit 1 reflection, seven times in the Unit 3 reflection, but 18 times in his final reflection. He uses "audience" four more times than Jamie does in her final reflection and 10 more times than Margie. His discussions of audience are also focused on the emotional responses of readers. Although this may be partly the result of projects that were more personal in nature than in a traditional composition class, he uses language associated with entertaining the audience 15 times and only mentions the goal of informing the audience one time. The language surrounding the purpose of informing the audience also includes a mention of persuading the audience partly because he had referred to the letter of endorsement: "I explained how the game worked and why it would appeal to customers then later talked about why it would be important for them to buy the game. I hoped to make the first paragraph informative and the second persuasive in order for the letter to be effective.” An interesting move in this first sentence is to refer to an audience external to the audience of the letter, the additional audience being that of the game he is endorsing.

Ultimately, the reflections of the students who referred to "audience" the most frequently seem to reveal only a rudimentary understanding of the concept of an audience. In at least two of the reflections, the writers assumed an audience much like themselves, such as when Jamie refers to an audience comprised of the class and of people with similar interests. Her logic in 
discussing her satisfaction with her work is to argue that she was satisfied because the audience would be satisfied. In one of her reflections, Margie suggests an audience of other students, and in her Unit 3 reflection, she describes her audience as people of her generation. Adam acknowledges other audiences, such as in writing his recommendation letter to a company, but he does not examine the type of company or the type of customers he suggests would be interested in his game concept. He also acknowledges that he will be expected to write to an audience of colleagues in his future career, but I found myself wanting to know more about these potential colleagues and how he might reach them.

A significant problem here, of course, is that these concerns are tied to assessment and the need to develop a way to grade these assignments, and from a teacher perspective, I am likely to interpret the lack of completion or of not meeting expectations as a lack of interest or engagement in these reflective assignments. As a researcher (as well as a teacher), however, I am concerned that expecting students to develop their reflections through the questions I provided reduces the opportunity for students to exercise agency. Likewise, I wonder if an emphasis on the needs of an audience also restricts the degree of agency students think that they can claim. Margie's reflection for Unit 1 veered dramatically from the assignment, perhaps as a result of interference from other genres in which she has written extensively, but it also seemed to demonstrate a strong sense of agency. She also organized her final reflection in an alternate way without answering the required and optional questions for the assignment. While her final reflection is primarily a summary of her previous material rather than a picture of her thought at the end of the semester, this reflection included several statements that demonstrated the type of thoughtful reactions I hoped students would include in their reflections, suggesting that the heuristic I was using was not effective in helping students engage in reflective thought or design thinking. For example, she says, "I used description to make the story come to life and intrigue the audience to want to continue reading this narrative." Many of her statements refer to 
meeting the needs of the audience, but she also shows a sense of design when she discusses her deliberate choice of "paper and pen over digital media."

One of the most revealing words from student reflections may be "capture," as in their desire to capture the attention of the audience. Only three students among all 21 participants used the word "capture" in discussing audiences; however, the combination of "capture" with the references to ease, quickness, and interest suggest that students tend to construct audiences that are a reflection of themselves. It seemed that students were actually expressing their own reading preferences combined with a desire for either being held captive by their reading or being so interested in what they read that they can't help but be engaged. However, this captive engagement is contrary to the engagement that I hope they will choose to bring to their work. At one point, I started to write that students seem to demonstrate a surface engagement, but I immediately realized that the terms "surface" and "engagement" are contradictory. The irony seems to be that students seem to be seeking engagement of audiences while not being fully engaged themselves. An alternative interpretation, the one that arose most loudly in my mind as I was coding, is that students are only writing about audience because I expected them to. I did not ask about audience for the final reflection, but it may have been because I asked about audience in the units 1 and 3 reflections that several students continued to discuss audience in their final reflections, perhaps in an effort to please the instructor.

\section{The Hero's Journey as Commonplace}

As I argued earlier, students made use of various commonplaces in their reflections, including an emphasis on "time and effort" and on the importance of a supportive community for writers. The students in my classes also seem to reproduce the work Clark (2019) observed, "creating compelling narratives about their past, present, and future selves" (p. 153). The most common narratives woven into the student reflections I studied were hero narratives. The idea of the hero's journey as described by Joseph Campbell emerged as a way of describing the statements students made about the difficulties they encountered in starting and completing 
their projects. Frequently these claims were a significant part of a narrative in which students depict themselves as heroic figures who have overcome the challenges presented to them in the form of the major class project. Consistent with the concept of the hero's journey, the students employing this conceit often seem to see themselves as a solitary figure acting against the backdrop of the course, not unlike the triumphant figure at the end of Micky's reflection.

Even the arc of the semester resembles the hero's journey, with the most difficult challenges near the end of the semester and which may contribute to students' depictions of themselves as heroes. Out of the 22 participants, I found that 17 of them made use of the hero's journey to some degree, and the hero narrative was often recognizable through the presence of codes associated with difficulty, challenge, and ease. While students still suggested uncertainty in these hero narratives (in part through the "I" claims mentioned earlier), they often demonstrated greater confidence in their claims when framing their experiences as a heroic journey.

The concept of the hero's journey originated with Joseph Campbell's (2008) work on mythology and archetypes, and he describes this journey in three basic stages of separation, initiation, and return, each of these broken down further into a set of challenges unique for that portion of the journey (p. 28-39). Christopher Vogler (1985) has adapted Campbell's stages of the hero's journey into a series of 12 steps for screenwriters, and this model can also be found in both secondary and college pedagogy (Hamby and Hamby, 2021; Arenas, 2018, p. 18). These twelve stages consist of the following:

1. The ordinary world

2. The call to adventure

3. Refusal of the call

4. Meeting the mentor

5. Crossing the threshold

6. Tests, allies, enemies 


\section{Approach}

8. Ordeal, death, and rebirth

9. Reward, seizing the sword

10. The road back

11. Resurrection

12. Return with elixir

Each group of four experiences above (1-4, 5-8, and 9-12) correspond with Campbell's three main stages of the journey. The journeys students describe in their reflections do not represent each one of the steps above but do incorporate some of the steps in the first two main groups, and to some extent, the last step of "bringing of the elixir." The length of the reflections may have limited the ability of students to develop versions of the hero's journey that were more complete, but they bring in enough elements to make this journey recognizable.

One of the common sequences presented by students, usually in a unit reflection instead of their end of semester reflection, includes a challenge, often confusion, sometimes followed by resistance but almost always a mentor of some sort, whether a fellow student, a parent, or the instructor (myself). Quinn, for example, consulted his roommate, classmates, and a parent when he needed help with the third unit. While some of the narratives conclude at this point, several go on to describe how much easier it was to complete the project after receiving help.

Heather's reflection on the first project contains a line that resonated with the idea of a hero's journey in that she worked to "make sure that I was staying on the right path," this path suggesting the start of a journey. Her narrative begins with a challenge in the form of the assignment and then continues with her uncertainty on how to format the essay and then to transform it into a multimodal project. Her reflection does not present the stages of the hero's journey in linear fashion, but she touches on some of the first few elements of the journey, such as the resistance to the call. She does not outright resist, but she says, "I did put effort into them and took time to complete the essay and the media portion but I feel as if I did not manage my 
time properly," suggesting that she could have taken a more active role. Although she admits she did not use the resources available to her, she reports that she utilizes her classmates in the same way a hero might make use of the mentor: "During this project I used my classmates as a resource a lot. We all had different topics and medias that we chose to do but we all still had the same guidelines and questions throughout, so we asked each other questions quite frequently." For Heather, though, the journey has not ended since she looks ahead to the next project: "I think that I will continue to use both of these resources next unit but I will also ask more questions to my professor to make sure I am getting correct information and to help so I am not as confused." She anticipates that more trials await her, just as they await the hero depicted in many forms of media in popular culture.

Although consulting help seems like a straightforward step to take when students are confused or frustrated with a project, it also fits into the pattern of the hero's journey, and students almost always report that their problems were resolved after they sought help. Matthew reported that after asking a friend for help, he had a better understanding of the third project. At least 10 students specifically discussed consulting with classmates, friends, and even parents when they were struggling with a project. Although Quinn consulted with his roommate, the instructor, and his mother, he stated that

The most helpful resources for my game description were my classmates who peer reviewed my game description and gave me some advice on how to improve the design and the content in the description. Had I not received any constructive criticism from my classmates, my projects would not have been as well done as they were.

Matthew's help from classmates came in two ways as he first asked friends from the class to help him understand the project better, and then "after seeing the final product of other classmate's descriptions, I realized I did the project completely wrong." Thus, the hero's journey is not just a social construct, but the path along this journey also includes social engagement, from the 
encounter with the mentor to the end of the journey when the hero returns with the elixir and must re-enter society.

Resistance is more apparent in the work of a few students, such as Helen, who initially thought of the third project as "dumb," and Quinn, who reported that he "struggled to accept the changes that [the instructor] recommended for my game description.” Stacey also resisted the norm when she says, "So I knew I had to change" - her goal was to create something out of the ordinary, through which she found enjoyment and motivation. Likewise, Devon was concerned that her project in Unit 3 was not like those of other students in the class, but she said she wanted "to come up with something different." The decision not to seek help from the instructor, as Heather did, might also represent an instance of resistance.

When students found solutions to their problems or gave up their resistance, they often reported approaching the rest of the project with a new ease, which perhaps represents the elixir the hero discovers and brings back from his or her journey, even though this journey is a truncated version of Campbell's model. Tracey, Pat, and Maria all observed that their writing or the work on their multimodal project came easier when they had found solutions to their difficulties. Tony says that when he solved his challenges, the rest of the project was marked by a “nonstop process of writing." Other students spoke of confidence, which may suggest that their work came easier for them. Most of the students appeared to realize that this course did not represent the end of their writing or learning about writing, and although this ease may represent or be the result of an "elixir," the journeys described in these reflections do not compete the cycle of the hero's journey. This is not unlike the way movies that make use of the hero's journey often continue the story of the hero in sequels.

It is perhaps not surprising that many students make use of such structure since it appears so often in popular movies and books such as Star Wars, Tolkien's novels about Middle Earth, The Wizard of $\mathrm{Oz}$, and even the Coen Brother's film O Brother, Where Art Thou? (loosely based on The Odyssey). Even if students have not been exposed to this narrative through 
Campbell's work or other direct instruction on the concept, they have been exposed to it through popular culture, including video games. For example, Tristan Ettleman (2015), in a contribution to the website US Gamer, lists 17 popular video games that each exemplify one of the stages of the hero's journey. Thus, while the use of this heroic narrative structure may be creative in the context of these reflections, it is drawn from socio-cultural resources that students use to process their experiences in composition, perhaps in place of the details they seem to have trouble accessing to support their claims.

The hero's journey is not unlike the other tactics students use to distance themselves from their work since it seems to smooth over the experiences of the students who use this commonplace. They write about generalities, such as in many of their statements about audience, fitting them into a familiar narrative. On the other hand, when students frame their experiences through this narrative, they may be designing an identity of themselves as writers. Therefore, the hero's journey may represent a movement toward greater agency, whether in the planning and writing of papers or in reflection.

\section{In Which Students Begin to Reflect in More Recognizable Ways}

The difference between the texts in the previous section and those that I will discuss in this section tends to be subtle, and some students are represented in both sections. While the emphasis of this chapter has so far been on distancing strategies, such as the use of "I" claims, passive voice, and heroic narratives, my analysis in this section turns to the ways students appear to engage with their reflections, particularly through the use of design thinking. One of the common themes that emerge here is a focus on the concept of creativity, using it to refer to work that is unique and wholly their own. This movement seems to require students to not only be more aware of the distinctions between their work and that of their classmates but also to discuss those differences and their own motivations. Their reflections become a means of representing themselves as writers, testing out their writerly identities. Therefore, in this section, I focus on creativity, agency, and satisfaction in conversation with other themes that 
emerged during my analysis of these reflections. These themes may be broadly represented as engagement but can also be examples of design thinking.

\section{Agency and Creativity}

The number of students who discussed creativity in their reflections was higher than I would have expected in a first-year writing class, and as I noted in my previous chapter, I was curious about why this seemed to be such an important aspect in a composition class. Students varied in the extent to which they considered themselves creative but tended to fall into two groups: they would refer to the ways they were able to express their creativity, or they would emphasize that they were not creative. Interestingly, only the students who described themselves as non-creative thought that the course had developed or improved their creativity. The assessment of creativity by Pat, a member of the second group, was also revealing in that she cites a common misunderstanding that creativity is not compatible with the STEM fields: "I would not consider myself a creative person, I was always good at subjects such as math or science in school.”

In some cases, the significance of creativity seemed related to a student's career goals and even current activities in other areas of their lives. Margie, a theatre design major, for example, explained in her interview that "I like how creative you could be in the class too. Um, and with my major, again, that's a very important part of what I do, um, is being creative. So I think having that both...because I have to be creative" (the ellipse here indicates a pause and not an edit of her original comment). Other students referred to their "creative side" without referencing a major or career goal. Michael said he was able to "tap into [his] creative side," and Ben referred to "[his] imagination and creativity.” Although these students do not always explain how creativity helped them in the course, the number of times it was referenced indicates the relevance and significance of creativity in their visions of themselves as writers.

As I discussed in Chapter Three, I included the codes "unique," “different," and "originality" under the general concept of creativity due to a tendency of students to perceive 
creative projects as those that are different from work that has come before. Several students hoped to present work that was different from that of their classmates, and the word "different" was the seventh most used word (not counting articles - a, an, and the) across all of the reflections and interviews with students, appearing 287 times. In comparison, "writing” appears 521 times, "games" (the course theme) 402 times, and "audience" 180 times. Although difference suggests an attempt to stand apart from others, it also relies on a social context by which to judge a work as different. In order for a project to be judged as unique, it must be compared either to a set of works that contain similar features or must be among projects which are all distinct from every other project in the set.

In addition, the students who indicated their desire to make their work distinct from that of other students also tended to consider themselves to be creative. Seven of the eight students who had described themselves as creative or using creativity also claimed or hoped that their projects were unique. In contrast, only one of the students who did not describe themselves as creative spoke of her projects being unique, which suggests a connection between creativity and the perception of projects as unique. Although some of the projects that students claimed were different were actually not unique, their claims indicate the value students placed on difference when writing their reflections.

Interestingly, two students set out to create unique projects but used themes that they acknowledged were more common. Margie chose the option of creating an original game description of an existing traditional game, and she chose to write a fictional origin of chess. This option, I realized later, was itself perhaps a contradiction but one that Margie works within effectively. She explains that "Once I committed to this topic the idea of aliens crossed my mind. I chose the alien theme because most people have read or seen an alien story before in their lives.” Likewise, Stacey's use of “different” or “creativity” in discussing her work echoes this paradox in her use of the popular theme of zombies. She admits that she has had significant "experience with horror games" and that they are "so amazing I wanted to take their ideas, but I 
knew I had to come up with my own." In this way, she shares Margie's dilemma of creating something that allows the audience to explore a familiar topic - whether through a traditional or a novel game - in a new way.

Other students focused more on the creativity of a project than on the reception by an audience. Ben, for example, demonstrates a strong connection between creativity and creating a unique project: "It required me to use my imagination and creativity to construct a unique piece of work." He also wrote that he "did not want to do a game that everyone already knows about." Likewise, Quinn says “I enjoy being unique and creative with my work." Helen uses the idea of a unique game in a different way when she describes the way the blind character in her game would navigate the world:

It's like a gray matter and you could see vague outlines, like when you squint your eyes and you can kind of see only a little bit; that's kind of what it looks like you're doing. And like I said, he uses echolocation where you if you kick something, you'll see the sound waves go down the wall or whatever. So I think that was also an interesting element because it's really...this isn't something that I've seen in a game before. (Noncomparative "likes" removed; emphasis added).

Ironically, Helen based her game on one with a similar theme that she had played on her phone. However, difference was not always synonymous with creativity or a unique project. One of the students I interviewed, Lindsey, used the word "different" 14 times in her final reflection, and during her interview, I asked her to account for this use. I pointed out this comparison you made between writing and a piano, and when you begin talking about that, you use the word different a lot. So different genres of writing, different types of music, different reaction, different feeling. And I noticed in this paragraph...you said, "That's why I want to make a difference by using what I learned in teaching others who need that may or may not have the resources to... Different ways to help people... different projects.” 
Lindsey responded by focusing on multimodality as the means of presenting information in different modes and the different ways people might receive this information. When I asked her to explain this further, she said

I feel like the information is definitely affected because, uh, we perceive things differently in the context that they're in. So, if I see a video, like my reaction to that video will be different. What if I read a tweet or if I read, um, like a four-page paper versus me reading or watching a movie like that, it's definitely going to be a different, like, um, you're just going to have a different attitude and perception of those for sure. But I feel like the message is, as long as it's done in the similar ways, it's the message should be the same. In her commentary, then, Lyndsey sets up a paradox in which she perceives of the mode of communication as affecting a message while expecting the mode to be a neutral container delivering the same messages to different audiences.

Devon used the word "difference" more so to refer to her development as a more versatile writer, but she also valued unique projects. She wrote, "Through the semester we learned about different ways to write and specific details to incorporate like...multimodal, and different forms of media to use. Overall, we discussed and wrote in different ways" (emphasis added). Although Devon could simply be using "different" as a general term to fill in the space before the words they modify, in the next paragraph she discusses originality as well: "At the beginning of the semester I struggled in being original when I wrote." She goes on to say "I was a very repetitive writer and needed some change. [The style of writing we did in this course] helped me develop different points to hit when I write, instead of repeating myself constantly." Difference in this case refers both to creating something unique as well as on her own development.

It is possible that other students who valued unique or original projects also judged that difference as contrasting their previous work rather than against the work of others, whether in 
their class or in the wider world. However, Lindsey alludes to a wider context in her interview when we were discussing the idea of "difference":

what I was getting at was kind of like a bigger than just United States. Like out of the country. Like a lot of people, um, they don't, you know, like not everyone like reads, you know, articles that are online because not everyone has access to that.

Consequently, the drive to be unique or original is not only rooted in one's own desire to be different but also in social contexts, including an understanding of texts and genres as well as an understanding of audiences.

\section{Satisfaction and Creativity}

As I discussed in Chapter Three, for each of the reflections, I asked students how satisfied they were with their work in that unit. In many cases, it seemed that students did not respond to the "how" part of this question but merely indicated whether or not they were satisfied with their work. However, I noticed during my coding process that students seemed to demonstrate different levels of enthusiasm about their satisfaction. Although 21 of 22 participants indicated in at least one of their reflections that they were satisfied with the work they completed, the language they employed demonstrated varying levels of enthusiasm. For example, a caption to an image that Helen included in her final reflection seemed to show high satisfaction: "The final product of the box of the game I created. ${ }^{9}$ I was so proud of this and how it turned out and I loved the whole project itself. I loved coming up with my own original game idea, and I also loved hearing the ideas of my fellow student.” Another student whose statement about satisfaction also seemed enthusiastic says, "I am proud of the work I put into...this assignment as a whole" while another discusses how "pleased" she was with a project that turned out "exactly what I pictured it."

\footnotetext{
${ }^{9}$ Due to Helen's use of copyrighted images, I am not able to include her project. However, she created a box cover for a video game with an image of a male and female to represent the siblings in her game, and the cover included features such as the video game rating and the name of a video game studio.
} 
In contrast, one of the references from the group with low enthusiasm says, "After going through the process of creating a game description, I would say that I'm pretty satisfied with it and think it was both creative and interesting." The length of the introductory clause seems to promise greater insight into the project, but the main clause is simply "I would," placing the statement of satisfaction in the following subordinate clause and qualifying it with "pretty." Another student writes "I feel as though I sound fairly passionate about my topic," with the word "fairly" essentially contradicting the possibility of a "passionate" approach to a topic.

Although I include most of my tables associated with coding in the previous chapter, Table 6 seemed more appropriate to include in this chapter since it represents a more involved analysis of codes. In analyzing the level of satisfaction each student expressed, I determined that the more accurate term for this level seemed to be "enthusiasm." I transferred all of the quotations that addresses satisfaction into a spreadsheet, to which I added a column for High, Medium, or Low enthusiasm. I then identified the other codes associated with each reference in order to determine a broader context for each reference. The results of this analysis are shown in Table 6 below, and I have only included the 42 references that clearly fell into one of these three levels. I was uncertain about 18 additional references and have not included those in this table.

The references I identified as demonstrating a higher level of enthusiasm were those that used alternative ways to describe their satisfaction, such as "I loved the story I was able to tell." I labeled references in which students used "fairly," "pretty," or "kind of" as showing a low level of enthusiasm, and I labeled references in which students used no modifiers for "satisfied" as demonstrating a medium level of enthusiasm. In the high category, I included two references that used modifiers, but this was based on other language used in the reference that suggested a higher level of enthusiasm. References in the low and medium categories were also more likely to use "I think" or "I feel" in their statements than in the high category, which included none of these statements. Also, since I labeled references rather than files, one student had statements 
in both the high and low category, but the reference I labeled as low described a paragraph rather than her entire project.

\section{Table 6}

Level of Enthusiasm about Satisfaction Correlated with Associated Codes

\begin{tabular}{|c|c|c|c|}
\hline \multirow[b]{2}{*}{ Associated Codes } & \multicolumn{3}{|c|}{ Number of references } \\
\hline & $\begin{array}{c}\text { High } \\
n=7\end{array}$ & $\begin{array}{c}\text { Medium } \\
\mathrm{n}=24\end{array}$ & $\begin{array}{l}\text { Low } \\
n=11\end{array}$ \\
\hline Creativity & 5 & 11 & 5 \\
\hline Audience & O & 9 & 5 \\
\hline Help from others & 2 & 3 & 2 \\
\hline Interest in topic & 1 & 1 & 1 \\
\hline Effort & O & O & 3 \\
\hline $\begin{array}{l}\text { Personal } \\
\text { experiences }\end{array}$ & 1 & 3 & $\mathrm{O}$ \\
\hline Processes $^{1}$ & 1 & O & 1 \\
\hline Fun & 1 & 1 & \\
\hline Expanded thinking & & 1 & \\
\hline New project & & 1 & \\
\hline Interesting idea & & 1 & \\
\hline
\end{tabular}

One of the striking things about this table is that within each of the three levels of satisfaction were one or two codes that were not used in that level. The students who seemed the most satisfied with their work (high enthusiasm group) valued creativity much higher than any of the other groups of students; however, none of these students seemed concerned about their audiences. Only references with low enthusiasm associated satisfaction with effort. References that fell into the medium category also avoided connections between satisfaction and effort as well as between satisfaction and references to composing processes. Finally, in the references that showed low enthusiasm, there were no connections to personal experiences. While codes for "creativity" and "help from others" appeared in all levels of enthusiasm, a higher percentage of the references in the category of high enthusiasm than in the other categories were associated with an interest in receiving help from others with their work. Ultimately, the students who expressed the highest level of satisfaction seem to value connection with others as they work on 
projects while students with lower levels of satisfaction seem to value approval (from audiences).

\section{Creativity, Enjoyment, and Engagement}

In a further comparison of the codes associated with engagement and creativity, I also discovered a correlation between a sense of creativity and of enjoyment or fun, students often reporting such enjoyment when they develop something new and original. Ben exemplifies the connection between enjoyment and creativity: "I enjoyed this project the most because it was not simply a paper to write, and it required creativity." Pat also suggests a connection between enjoyment and creativity: "This was by far one of the more fun projects to complete. It involved using creativity to initially create the game description, then revising it by using pictures or videos...." Tracey develops the ideas of fun and creativity further, linking them with motivation to do her best work: "The fact that I found the game description to be fun to create, provided me with a lot of motive to put a lot of time and effort into my assignments and to make sure that I was completing them to the best of my ability." Like Tracey, Pat also adds to an understanding of why students reported enjoying projects when she says that she developed "skills on add[ing] important details, and describ[ing] people and settings better."

Even students who did not think of themselves as creative offered a variety of reasons for finding the multimodal projects interesting. While Pat attributes her enjoyment to creativity and developing skills, Maria points to her interest in her topic and the potential for others to enjoy the game she created:

I believe that because I was really passionate about the topic and I was able to add my own ideas it really helped my game. I was able to showcase things I was interested in which in the end made me enjoy finishing the projects for this Unit. I think that the audience would enjoy to play a game like this.

Although Maria uses "I" claims (I believe, I think) in this quotation, she avoids the incoherence that often occurred with these statements, perhaps because of her interest in the project she was 
writing about. Michelle remarked that she "also really enjoyed hearing other peoples' ideas." Michelle also reported enjoying the first project because she was able to bring her interest in crafting to her poster.

Tony presents an interesting contrast when he says, "Making the poster was very fun and forced me to be creative." He does not seem to make a choice to be creative as much as he is subjected to it, and he seems to have been surprised to find the process of the last unit to be enjoyable. In his interview, he seemed to struggle a little to explain his enjoyment of projects he completed in English 101 even though he had appreciated the theme for the course. However, his discussions about his classes at the time of his interview suggested he was not particularly interested in the work he was doing currently. He said one of the things he had liked about English 101 was doing multimodal projects more frequently. When I asked about how these impacted his writing, he replied, "it made it...made me more interested and actually wanted to do it. Besides just the boring essay it was more fun.... I don't know. I thought I thought it was more enjoyable" (non-comparative "likes" removed).

Stacey did not refer to herself as either creative or not creative but did use the word as a verb to describe her processes of completing the projects for English 101. She also reported experiencing fun or enjoyment during the semester, and her experience seems similar to that of Tony in that she says she did not "[expect]...to really immerse myself into this [the game description] but I ended up enjoying this project more than expected. I was able to get creative and make a game with whatever I wanted which made me really want to keep working on it harder and harder."

Overall, eleven of the participants in this study reported enjoying their work in the course, and a greater number of students who considered themselves as creative (six out of eight) reported enjoying the projects. Of the thirteen students who did not describe themselves as creative, only five of them spoke of enjoyment in completing work during the semester. This experience of enjoyment may be the most significant in determining the level of engagement of 
students in writing courses; however, enjoyment often seems at odds with previous experiences of students who enter a composition class already disliking the process of writing.

As I discussed in Chapter Three, in addition to the codes for "enjoyment" and "fun," I also included the codes of "interest" and "motivation" in the category of engagement. Just as students made connections between their topics and enjoyment, the subject matter they write about also appears to be a significant factor in fostering student engagement. The students who made connections between their creativity and their interest in a project were more likely to have also discussed the way their topic motivated them and kept their interest. Lindsey also discussed the importance of "pre-existing knowledge" and experiences, which would impact her choice of a topic, as helping her to compose better projects. Some students also focused on the meaning of a topic or assignment. In her reflection for the first unit, Lindsey wrote about how drawing on her experiences made her paper more "meaningful," and she also emphasized the importance of her topics in her interview. At one point I said it seemed like she was referring to having more depth to a paper, to which she agreed and then went on to explain how personal experience with a topic "gives you more options, like on what specifically you want to write about with that topic. Like, if you know, like there was something else you can do with this topic, then that would be like, um, make like it makes you stand out." Margie, the theatre major, emphasized that being able to choose a topic to write about makes her "writing meaningful and passionate." However, while Lindsey saw in the course theme a way to bring in her own experiences, Margie felt that the theme of games limited her options, with "no room to expand my thoughts."

\section{Student Interest in Topics}

The students discussed above were not alone in expressing their interest in the topics they chose - several other students had also discussed their interest in the topics they wrote about. In my previous pilot study, the students I interviewed had told me that their interest in a topic was a major factor in their success in working on a project, so I was not surprised to find 
the same pattern in this project. However, this larger selection of student reflections and interviews revealed more insight and nuance about their interests. First of all, few of the students actually identified specific topics that they preferred to write about, which suggests that the freedom to choose a topic may be more important than the topic itself. In fact, only three students discussed developing a specific topic based on their interests. Lindsey connected her experiences working at a retirement home with Alzheimer's and dementia patients with the game creation project, and Joyce said she focused on children in her research project "because I love seeing how their minds work." Tony's interest was in board games, so he was enthusiastic about the entire course.

Other students had more general responses about topics to write about, such as Felecia, who said she tries to find connections to her own life, and Pat, who tries to incorporate her life experiences into her writing. Lindsey and Pat both stated that the topics had to be meaningful in order for them to do their best work. Lindsey preferred to write about "things that hold meaning or are relevant, and Pat said she has to "be passionate about what I'm talking about.” Joyce pointed out that she was also concerned about "how others could relate to the topic I chose."

In other cases, though, students seemed to take a more passive approach rather than to seek out subjects, which made me wonder if they had a sense of what interested them before such a topic presented itself. Helen stated that she needs to care about an assignment to put forth her best efforts, but it seemed to be only by chance that she was able to incorporate her psychology major into a project. Likewise, Margie says that she needs to write about "something that interests me" to produce her best work. Margie also expressed her frustration that the entire course had been centered around games but did not indicate what she might have preferred to write about. Nevertheless, she exercised agency in not only her choice of topics but also in the format of her reflections, drawing on her theatre design experiences to complete these assignments. 
I suspect that students are conditioned to accept assignments passively instead of actively seeking more meaningful connections, which may be more difficult to coordinate with the expectations of writing in genres that may be new to them. They may also believe that writing about a common topic, such as gun control, capital punishment, or abortion, will be less difficult and easier to research since they know they will be able to find sources for research projects. Too often, students appear to simply want to meet the expectations of the instructor so that they can earn a "good grade" on a project even when I try to assure them that I value creativity as much as they say they do. Students may also be uncertain about what actually interests them, and they report choosing to work on topics based on how easy it is to research them rather than topics that really appeal to them. Students seem to expect an instructor to provide interesting topics for students to write about, but in my experience, it is difficult, if not impossible, to select a topic that is universally interesting without also being too broad or vacuous for students to really engage with.

\section{In Which Students Engage and Take Ownership through Design Thinking}

The ways in which students understood the importance of audiences aligns to some degree with the process of design thinking, perhaps the most widely referenced model of creativity at the moment. I think it is significant to note that this type of thinking is a social process that includes both the designer and stakeholders ultimately working together to create solutions to problems. As shown in Table 7 below, the model developed at Stanford University's d.school (design school), each step of the design process is related in some way to the needs of an audience (referred to as "client" or "user" in the chart below) for the proposed designs. 


\section{Table 7}

Relationship between Design Concepts and Audience

\begin{tabular}{ll}
\hline Design concept & Relationship to audience \\
\hline Empathize & Understanding the needs of the client or user \\
Define & Defining the problem from the perspective of the \\
& client: "[Name of user] needs a way to [user's need]. \\
& Unexpectedly, in his/her world, [fill in with insight]." \\
Ideate & Generating solutions to the client's problem and \\
& receiving feedback
\end{tabular}

Prototype Creation of the product for the use of a client

Test Observing how the client uses the product

Note: The steps in the design process and their description are taken from "An Introduction to Design Thinking: Facilitator's Guide" from the Institute of Design at Stanford.

However, while students frequently spoke of creativity and of audiences, I found limited examples of design thinking in their reflections even though I had constructed questions I had hoped would spark this type of thinking as students wrote about their projects. However, while I tried to model my questions, as described in the previous chapter, after the characteristics of design thinking, I did not actually instruct students in the concept of design thinking outside of demonstrating how to complete their projects. Students may have been better equipped to employ design thinking if they had used it more throughout each unit. The multimodal projects I assigned throughout the semester did not necessarily fully engage students in design thinking. Students thought about audiences and sometimes tailored their projects to audiences, but since 
I did not use all of the steps of the Stanford model in my classes, I did not expose students to the full range of design thinking.

However, when students did demonstrate design thinking, their reflections also stood out in their degree of engagement. Although I came to recognize that all of the students in this student were engaged at some level with the content of the class and their process of creating their projects, the reflections written by a few students stood out in their degree of engagement. Since an early question I had asked was about the genre characteristics of reflections, particularly those that made them engaging, I noted four students who made rhetorical moves in their reflections that resulted in particularly interesting submissions. Two of these students also participated in interviews with me the following semester, and both of them - Helen and Margie - referenced characteristics of design thinking in their responses to my questions. These conversations also provided me with insights into their writing processes that built on their reflective assignments from the previous semester.

Margie brought a broader perception and practice of writing to class because her major in theatre also required her to write in a variety of genres and settings. She was also actively involved in a play ${ }^{10}$ during the semester of her interview, and this involvement led her to do a significant amount of writing at that time. One of the topics that made her interview particularly interesting for this project was her use of reflection in combination with her design projects in costumes and staging for other courses. These reflections included her thoughts on the designs of scenes in plays performed on campus, on her own visions for plays, and on her own costume designs. We spent a considerable amount of time discussing her design process, which she said primarily consists of collecting images and then later writing about the design. Within her major, the design of both material and digital examples seems to be privileged over the writing that eventually accompanies the designs. Rather than using writing to support her points, she

${ }^{10}$ I am intentionally omitting the details of her specific involvement to maintain confidentiality. 
said "you always have to have your text supported by a piece of, um, like a rendering or a scale model." However, the three-dimensional models created by designers for theatre remain with those designers, and directors only take the reflections - the actual text - with them while considering their choices. Surprisingly, she overlooked the questions I had providing for the first unit's reflection, which I originally interpreted as carelessness. Instead, she had written her reflection in the same format she would use for a costume or scene design. During my analysis, I came to realize that in drawing on her extensive background in reflecting on designs, she had exercised a considerable degree of agency in constructing her reflection.

In Helen's interview, we focused more on her game creation project, but she also discussed her major and ways she used her interests to develop projects in both English 101 and her other classes. I also appreciated her recognition of the importance of revision balanced with a discussion of how she gets started on projects. She indicated that revision was one of the most important skills she took away from English 101:

So I would always just kind of rush through it and be like, okay, that's good enough. I wouldn't go back and look over it and make sure that I had everything that I needed. I would just kind of rush through it and turn it in as is, and then it wouldn't turn out so well. So I think this class definitely showed me that, um, like revising multiple times is good because I would usually only revise it once or I look at the revisions my teacher would give me and be like, "Eh, I don't need to do that.” So this class definitely showed me that revision, revision, revision is very important.

This passage also demonstrates Helen's tendency to be self-deprecating, which appears more strongly in her final reflection for the course. She also demonstrated self-criticism in her interview when she brought up procrastination and described turning in a project that was due at 5:00 p.m. (the start of class) at 5:02 p.m. She said this was a problem she was working on but did not indicate how she was doing so. It was this honesty in both her interview and final reflection, though, that interested me because instead of making the more common claim about 
improvement throughout the semester, she presented her faults, which made her participation in the class seem to go deeper than fulfilling a requirement. She seemed to use the reflections as not only assignments to complete but also opportunities to recognize the areas in which she hoped to improve. In a sense, she was designing her own persona of herself as a writer.

Helen also spoke about the trouble she had committing to a topic for a project and provided an example from the communications class in which she was currently enrolled. She talked about giving a speech about the FBI earlier in the semester but later in the interview revealed the number of topics she had considered before developing her speech:

I think I changed my mind on the topic of my speech like six times. Like because she said you could write about whatever you want and like, Oh God. So I think like my first topic was like, I'm like, I'm going to write about the Avengers, and then like it just switched over and over and over. Like it was like Avenger's, Harry Potter, and then something else, and I don't know what the other one...then I finally decided to like, okay, the FBI I can write about. So I went with that.

What is particularly striking about this observation is that she never identifies the audience as playing any role in choosing her topic for the presentation. Her vacillation, however, was relevant to the discussion of her game creation project, which we were discussing at the time, because she said that this project was the first she had ever completed without changing her topic: "that was the first project that I was like, 'All right, I'm going to stick with this idea and we're going to go with it.' So I think that was the first project that really stuck and like I think was like the most important project that I've done and probably the most fun I've had making a project." Her responses to my queries about the project showed how design thinking - with the exception of the audience involvement - appeared to help her to use multiple influences from two other games, a television show, and memories of playing a video game with her father to develop her game description. The most salient point in her interview, however, may be her agency in deliberately choosing to commit to her topic, echoing the responses of students in my 
pilot study, that being able to write about a topic they cared about was important to their success.

Two other participants in this study wrote reflections that resonated with me, not only while I was grading assignments but also in re-reading reflections during my analysis for this project. Together with the work by and interviews with Margie and Helen, the reflections by Micky and Miguel stood out as ideal examples for the type of reflection I hoped students would produce. While Micky was more introverted and Miguel more extroverted, both in class and in their reflections, each of them explored and revealed their "inner" thought processes in a way that I would expect in a reflection. I also observed several similarities between Micky's background and my own, which made her reflections resemble the type of thinking I hoped students would use. Both Micky and I had kept journals when we were growing up, we both wanted to be a writer, and we were both somewhat introverted. She begins with her personal history of writing:

Writing may be a burden or a chore for some, but to me? Writing is a way that lets me express myself like no other. I have days where I have so much on my mind but no one that I want to tell it all to. That's when I can turn to my laptop and let the thoughts spill from my head out onto the screen in front of me. Writing has been a stress relieving outlet for me for as long as I can remember... I had friends that turned to sports or [musical] instruments ${ }^{11}$ as their escape, and although I also tried these things... nothing ever put me at ease the way writing does.

Unlike many students who said they thought of themselves as good writers before enrolling in English 101, Micky writes about how the class "expanded my writing skills" and how "they will help me years down the road." In this way, her reflection differs from other students who

\footnotetext{
${ }^{11}$ A key difference between us is that I was (and am still) involved in music and learned to play several instruments, but this has also meant another dimension for writing as I also compose music.
} 
already saw themselves as good writers since they revealed resistance to the types of the assignments and to suggested revisions. In contrast, Micky indicates that the class gave her more ways to start the process of writing a paper and to research the topic.

In addition, she chose to write and record a poem for her remediation in Unit 1, a project unlike any of the others that students attempted. Micky admitted that if she had been required to share it with the rest of the class, she wasn't sure she would have done it, but this is itself an example of her weighing the risks against her preferred mode for the project. Another item of interest in her final reflection was her inclusion of a second image to represent what writing meant to her. In a previous homework assignment, I had asked students to submit an image that represented writing for them and to explain what it means. When students worked on the final reflection, I encouraged them to include this assignment as the introduction to their reflection. As I explain in my previous chapter, the rest of the images they would include in this project would be selected from their projects, homework, screenshots of doing research with the library databases, and perhaps photos of their workplaces. The images Micky uses to represent writing at both the beginning and end of her final reflection are of solitary figures. The first of these images depict a girl sitting outside and writing in a notebook, while the second is a silhouetted figure standing on top of a peak and raising one hand, perhaps in triumph or pointing higher, with gold-tinged clouds in the background. In Micky's final paragraph, which frames this image, she emphasizes her "drive to succeed": "I know what I am capable of and turning in work that doesn't live up to those capabilities makes me incredibly disappointed in myself....All I have to do is put the time and effort in and I can achieve anything I put my mind to.” Although she includes the phrase "time and effort," her determination seems to overshadow this commonplace, that determination seeming to also suggest her use of agency in developing projects.

While Micky's final reflection indicated more self-reliance, Miguel balances his own selfreliance with an awareness of the support he has received with his writing. In his first unit, he 
refers to his creativity in Unit 1 as a "long but thoughtful process" as he struggled with his "internal conflict about games to writing about." He makes a conscious decision to set himself apart from his classmates by creating a video, a decision he says he made after hearing many students refer to making a poster. Like Micky, Miguel chose to make a video for the remediation of project one, but his final project seemed to be intended more so for a public audience, with a friend asking him questions. He says he was most influenced by the interviews by Trevor Noah, a popular interviewer, as well as his own strength in speaking. He edited his video to account for camera changes between his friend and himself, and he seems to look through the camera at his audience, speaking animatedly about the game he chose to write about. He reports in his reflection that he originally considered writing about ping pong or soccer but ultimately chose a game called Mau (also known as Mau-Mau and Mao), which he played repeatedly with friends and which he says helped him become a bolder person. He explains that this game begins with only two basic rules with a new rule added with each round. The catch is that the rules can never be explained or discussed - only discovered during play. Consequently, the game relies on social interaction through trial and error and through approval and disapproval of actions taken during the game.

Miguel also makes multiple references to working with classmates, whether during class or out of class. He writes in his Unit 1 reflection that one of his sources of help came from class discussions. In his final reflection, he reports that he was "in constant communication [with] my fellow peers and classmates" and knew he "could rely on them." In his final reflection he also uses plural first-person pronouns frequently, switching to singular pronouns only when talking specifically about his own work. He is clearly concerned with improving as a writer, but he is also concerned with influencing his audience, which is an important aspect of design thinking given its attention to stakeholders. He argues in his first reflection that his three points of "creativity, awareness, and the ability to be bold could apply to all if not most of the people who decide to read this." Although I am sure he meant "most if not all people," I wonder if switching 
this order is a function of an emphasis on social connections, wanting to reach all of one's audience rather than just a part of that audience. His commitment to these connections with other people is likely rooted in his philosophy that people should want to improve and to be "the best versions of themselves."

The emphasis both Micky and Miguel place on individual development suggests the importance of agency in writing their reflections. While Micky depicts success as an individual achievement, Miguel emphasizes the importance for his peers as well as himself to be successful both now and in the future. He goes on to make his argument primarily with plural first-person pronouns: “...regardless of how well [off] we think we are, for most college students, these are the times we are most experimental so it seems appropriate to push important ideas [about] being yourself...." Miguel's image representing writing - an abstract depiction of the ocean with blocks of similar color across the center of the image - contrasts that of Micky's realistic girl writing in a notebook. Miguel explains that he chose his image to "resemble the way a good paper should be written" with the waves representing paragraphs, purposes, and depth.

Although he uses passive voice in this last quotation, his reflective writing overall demonstrates his sense of agency.

\section{Conclusion}

Throughout this chapter I have attempted to balance my analysis of student reflections with their own words, allowing them to reveal the ideas that they deemed important to include in their own narratives about their composing processes. My own struggle throughout this process was to avoid critiquing the work of these students rather than interpreting what they seemed to be saying to me or to another reader they may have imagined. Indeed, sometimes they referred to me in third person rather than speaking to me directly. The ambiguity in their reflections, though, made me start to question the value of reflection if it is intended to help them to become aware of and to reinforce their writing processes. As I read and re-read these reflections, these students seemed to display more anxiety and confusion than confidence and 
self-awareness. Even the process of making an assignment out of reflection seems to reinforce their student roles, and they acted out these roles in voices that report instead of analyze and in language that distances themselves from their processes and projects. They hover at the edge of agency, but instead seek out approval for their work.

Even as they express doubt in their writing (whether or not they are conscious of their own doubt), though, they demonstrate how they value connections with their classmates and with audiences, whether real or imagined. In these connections, they also seem to seek approval for their writing, and they use this social context as a means of comparing their work to that of others for the purposes of both confirming that they are doing a project "right" and that their project is unique. While they use strategies that seem to distance themselves from their work, suggesting a lack of agency, as Grossman points out, students must be able to "stand apart" in order to reflect on their experiences. While they also use commonplaces such as hero narratives that leave out details of their writing processes, they appear to use these to construct their identity as writers.

In previous chapters I have explored the scholarship on reflection within composition, paying close attention to the substantial work of Yancey in this area as well as to the influence of Schön's work on reflection. I have also identified models of design thinking as well as the parallels that have been drawn between design thinking and writing processes. As I pointed out, I drew from scholarship connecting education in design thinking and reflection in order to propose the use of design thinking for reflection within composition. Admittedly, this has created a complex network of links between the concepts I have attempted to draw together in this project. In the chapter that follows, therefore, I will do the work of accounting for the themes in this chapter while overlaying this analysis on this network of concepts in reflection and design thinking. 


\section{CHAPTER V: DESIGN THINKING AND CULTURAL NARRATIVES:}

\section{FOCUSING ON THE SOCIAL}

In the previous chapter I examined several themes that emerged in my reading and coding of more than 60 texts by 22 students. The responses to reflective assignments ranged from mechanical and distant from the experiences of students to greater engagement and a strong sense of agency. Throughout this project, my goal has been to examine these reflections directly rather than looking past them at the primary assignments or focusing on the outcome of those assignments, and I believe the reflections revealed more collectively than when studied individually. I wanted to know how the reflection questions I developed from design thinking would affect the reflective writing of students. To this end, I examined the texts from my study's participants to see what they could reveal to me about their processes of reflection. In this chapter I will further examine the narratives students tell in these reflections as well as the way these texts draw not only from personal experiences but also from ideas circulating throughout the cultures in which these students are immersed.

As I discussed in my introduction to this project, I first noticed a difference in the reflections of students in a multimodal composition course as compared to students in more "traditional" composition courses focused on producing alphabetic texts. In the classes in which I conducted this study, I not only assigned multimodal work, but I also required students to complete the final reflection assignments as a multimodal text. This chapter constructs a theory that accounts for the place of design thinking specifically in the reflective writing students completed during this study. In addition to presenting further details about my findings, I will also propose further research on the pedagogy of reflection and design thinking. Finally, I will discuss the value of reflection and offer reasons for teaching and assignment reflective writing.

In my review of literature, I surveyed writing studies scholarship on reflection and explored the connections between design and reflection. I also offered different perspectives on the characteristics of design thinking that are pertinent to multimodal composition. Part of my 
interest in multimodal composition lies in the way it embodies material processes in writing and composing. My methodology, as I describe in my third chapter, required a significant degree of reflection on my part as I struggled to leave behind assessment of the reflective texts and to concentrate on coding them as objectively as I could. I then moved into the fourth chapter to center my analysis of these reflections on the intersections between codes and the themes that emerged from this process. The key terms in my project have remained relatively consistent: reflection, multimodality, design thinking, and engagement.

I began the analysis in the last chapter with discussions of ways students distanced themselves from their work, whether the projects they completed during the semester or their reflections. Examples of the ways students used language to create this distance were "I" claims, passive voice, and the overuse of the concept of audience. Students would also cast themselves in heroic tales of their struggles in English 101. Together, these distancing strategies reinforced their roles as students, and in doing so, they seemed, whether consciously or unconsciously, to limit their own agency and sense of responsibility for the outcome of the course. However, as I observed in the previous chapter, distance is also a possible requirement for reflection. With this in mind, I also analyzed the relationship between agency and creativity as it points to greater engagement by some of the participants. Finally, I described the reflections of four students whose reflections more strongly demonstrate design thinking, engagement, and agency.

\section{Reflection as a Social Process}

Reflection has been recognized as a social process since early in the adoption of reflection in composition instruction. In writing about a particular student, Yancey (1998) first observes that this student has come to understand writing as "a social and negotiated act" (p. 63). Further, Yancey points out that this student also realizes that "Constructive reflection...is both individual and social. To be meaningful, reflection must be situated: the writing creates meaning in context, in community" (p. 63). My understanding of these statements is that the production of reflection is rhetorically situated to the same extent of any other form of writing, 
the audience, or the students' understanding of audiences, shaping the reflections of students. It seems that in the model of reflection Yancey employs, the social aspect of reflective writing is still directed inwardly - toward the writings - as they account for the social forces acting on themselves and their writing.

Of course, writing instruction has long been influenced by the concept of writing as a social process, not the least of which is the attention to audience in Aristotle's work and his discussions of the ways to influence various types of listeners. Likewise, textbooks typically instruct student writers to tailor their texts to an audience, and recent scholarship rooted in activity theories has further defined the interaction between writers and audiences. McComisky (2000) identifies the focus on production, distribution, and consumption of texts as "crucial moments in the process of developing social relations in lived cultures” (p. 25). Similarly, Prior, et al (2007), include the social explicitly in the redefinition of the canons of rhetoric in order to more fully account for literate activities. However, while composition courses emphasize writing directly for an audience and using the audience as constraints, I have questioned whether such thinking discourages agency to some degree. However, this agency is arguably required in order to engage design thinking.

Reflection is frequently presented as a process of accounting for the production of a text or texts by students. Although genre theory advocates for the use of texts as models in composition, McComisky refers to these as "cultural texts" that are used as "objects of critique, as representations of social values that institutions would impose on their readers" (p. 54). The use of model texts, whether for reflection or for the many other genres students might produce in writing classes, are not static examples but do more than exemplify an assignment. In spite of this emphasis on the social in current composition classes, tension between the social and the personal persists in Yancey's 2016 collection on reflection. Inoue and Richmond (2016), for example, describe the difficulty a female Hmong student experiences in distinguishing between her "stance as a segregated racial and social reflective self" - a self formed in the context of 
social interactions - from an "individual self learning in the classroom" (p. 139). Writing in the same volume, Clark (2016) focuses on the self-representation of students through ePortfolios but also presents the importance of balance between the individual and the social - through academic reflection "students are able to mesh their understanding of self-presentation and audience with writing” (p. 153). Finally, Yancey devotes a section of her conclusion to this book to the idea of community and reflection, sharing examples of locations in which some of the book's contributors "are reimagining how we learn, construction classrooms as semipublic spaces where learning is a communal process" (p. 310).

Indeed, during my coding and my analysis of the codes, I became aware of a sense of community in these reflections, suggesting a social rather than individual process of not only writing but also of reflection. While many composition theorists have dismissed the Romantic idea of a coherent self at the core of each writing, theories of reflection have continued to focus on the transfer of writing skills of individual students, often using a case studies approach which highlights the work of individual students. The results of my study, however, suggests a model of reflection that relies heavily on the context in which students find themselves. My findings also show how reflection was as much a social as a personal phenomenon with this group of students. Research on reflection has often focused on metacognition of individual students, but my readings of this set of reflections suggests that studies in reflection and transfer may need to also examine the context of writing in communities. The section that follows will parallel the first part of the previous chapter as I revisit themes from the perspective of the social element in these reflections.

\section{Audience and Social Connections}

Although several students seemed to substitute surface language about audience for a deeper concern for their potential readers, their narratives seemed to express a desire for connections and for approval. In her reflection for unit 1, Devon writes "I think my class will really appreciate my project because it's a good visual aid for those who are more visual learners, 
color and actual pictures connecting you to your project also draws attention to an audience." She supports her claim by providing specific details that would appeal to her audience. In the next sentence, though, she demonstrates the connections she hopes to establish with her audience and with her classmates: "I also think others will have similarities in their projects and I also like to compare [them] to help me in the future with other projects that are similar to this." With her last sentence in this paragraph, she then sums up her prediction of an audience's response in a way that reinforces approval for her work: "So overall I was pleased with the outcome and I think my audience will like my project and think it describes my narrative well." Two students who wrote about using the genre of a blog post for the remediation of their narrative in Unit 1 emphasized the potential for a blog to help people communicate with each other. Jamie writes that

with a blog there is more of a way to interact with my audience and have them interact with each other since they can comment on them.... There can be a discussion on the topics and many could share their experiences rather than just read mine. So through this type of media it allowed for socialization, since many could be engaged....

Stacey also reports that due to her previous experience using a blog in her sociology class, she also chose this genre for her Unit 1 remediation:

I think this is an easy interactive way to engage your readers. There are links that readers are able to click on and learn more about what I am talking about. Also, I share personal experiences on the blog that I'm sure some people can relate to. This allows for readers to want to read more and...connect themselves to my story.

Both the word choice and the content in these quotations reflect the desire of these students to form connections with their audiences.

The "I" claims about meeting audience expectations ultimately contrasted with the confidence students displayed as they described their connections with audiences. Felecia, for example, starts with a general statement about audience, saying that "I think my narrative made 
its point and still went into enough detail to make it interesting." In her next two sentences, though, she goes on to reveal her value of connections: "This unit pushed me out of my comfort zone and made me look at writing in different ways. I think by experiencing new writing it helped make my writing more relatable and understandable to the audience.” Although she uses an "I" claim in the second sentence, it is not used to make a claim about her writing but to explain an outcome. In contrast, Heather uses this theme of connection indirectly by pointing out how she "included games that everyone for the most part either knows of or has played before." In this statement is a sense of making sure everyone is included while also drawing on the social nature of playing games with others. In her reflection for Unit 3, Michelle demonstrates the use of "I" claims in saying

I think my video-game description can be appealing to almost anyone. It is friendly for all ages and it can show different people different spots around the world that they didn't even know existed. You can also play with up to four other people online or with four people in the same room as you and it can bring people together.

The first sentence of this selection is very general, as is the use of "different people" and "different spots," but with the end of this quotation, she emphasizes the value of games as not simply providing knowledge but to make connections with other people.

While Lindsey uses "I" claims to discuss the value of her work for audiences, her discussion about Unit 1 provided more nuance about audience than many other reflections for that unit. She makes a strong point about the popularity of "family and board games" and says she hopes her description of playing games with her sisters with give "the audience something to think about with their own siblings." Although she uses "I" claims as she goes on to explain the importance of writing for an audience, in this case, it may be appropriate since she does not know exactly how an audience would receive her work: "Overall, I feel as though my audience gains something from my paper, whether it be memory that is turned on, a connection, or something to think about.” 
Discussions of improvement also often included references to hard work, and the frequency at which these themes appeared in different students' reflections suggests that these claims are influenced by expectations rather than of specific improvements that students are able to articulate clearly. While answering questions at the 1995 WPA conferences, Yancey (1996) addresses the use of hard work when she advises instructors to "rule out effort and time as evidence" (p. 67) of student learning. While I would agree with encouraging students to avoid focusing on their time and effort but instead to discuss specific examples from their process of composing projects, this and similar phrases are used frequently enough by students that they warrant further examination. Indeed, as I demonstrated in Chapter Three, students used a variety of phrases to emphasize their "time and effort," suggesting the value that they place on their work. In addition, this phrase ("time and effort") emphasizes the subordinate status of students both to their instructors and to their audiences. Students rely on the instructor, who is arguably standing in for an audience, to approve their work instead of taking responsibility for both failures and successes.

Although I was concerned, from a pedagogical standpoint, that students had missed opportunities to speak to their own experiences, I also saw that all but one of the students used plural pronouns when discussing class activities. By placing themselves in a group and narrating broader events in which all students participated, they highlighted the social nature they experienced in their composing processes: "Throughout the semester, we were given assignment sheets every time we started up a new unit” (Helen). While narrating the actions of the entire class may be an indication of a lack of engagement and less recognition of the actions taken by the individual student, it may also demonstrate a sense of community and perhaps a collective agency. It was rare and even unexpected when a student used "I" to describe an assignment everyone was assigned, as in this example, since all students were assigned the same project: “At the beginning of this semester, I was assigned a narrative to write in english (sic) class" (Helen). Even more interesting is that Helen uses passive tense when she uses "I" but tends to use active 
constructions when using plural pronouns, such as at the beginning of this sentence: "We decided as a class exactly what was expected in the assignment so there was no confusion." Although she does use passive voice in the middle of this sentence instead of identifying who would have these expectations, since the development of the rubric for the assignment was a joint class effort, the expectations do not come from an individual, whether from students, from myself, or from another sources. She also words the beginning of the sentence strongly, with the active verb "decided" and the word "exactly" to describe the process of determining the expectations for the assignment.

Several students also made links between interest and audience, and I began to see that when students were excited about their projects, they wanted audiences to share in this excitement. Although several students seemed ambiguous about their concern for audiences, Adam wrote about audience in interesting ways at two different places in his final reflection. He first highlighted the importance of maintaining the audience's interest: "The first thing I normally did was to think of a topic I could write passionately about and more importantly that would please the audience." Later in his final reflection, Adam again claimed that his first consideration for his readers "is to make sure the audience is entertained by making the content interesting." Students seemed motivated to create these social connections and perhaps validate their own experiences.

Likewise, students sought to balance their own values and experiences with the expectations of an audience. Jamie explains that "My narrative was a story about my own personal experience with games in my life which brings an audience of other who are interested in the same topic including our class and beyond that." Matthew seems to imply a similar connection when he describes "trying to think of the perfect game description I could write about that will keep the audience interested." Presumably, a "perfect” project would satisfy both his own interest and that of an audience. Margie seems to make the strongest connection in her reflection on the first unit: “To convey my passion for this game I wanted my audience to be able 
to feel the emotions I felt whenever I played this game. make the story come to life and intrigue the audience to want to continue reading this narrative." The beginning of her narrative for the first unit is particularly effective through the use of a frantic repetition that reflects the game of Spoons and certainly also captured my own attention:

My clammy hands try to grab and grab and grab until I find a matching card. I grab and grab and grab. Cards are being thrown at me nonstop; my hands try to keep up with the fast pace of the game. My eyes try to comprehend each color, suit, and number as the cards fly from my right hand to my left. I grab and grab and finally end up with a matching number card.

While Margie was unenthusiastic about not only the third unit of the course but of the overall course, she nevertheless created interesting projects. For her third project, the game scenario, she created a brochure by hand instead of on the computer, her rationale being that she wanted to create a more "personal experience." She goes on to explain:

I believe there is a different connection between media and reader when something is physical rather than digital. To be able to touch something and read words that are handwritten makes for an overall better experience for me personally, so that is the work I want to produce for my audience. Something that can create an enjoyable experience while they read my work.

Here again, she demonstrates the link students seem to perceive between their own experiences and those that they design for an audience.

Finally, three students tell stories in their projects or their reflections that represent heroism in an action not associated directly with writing. Two students tell stories of becoming more outgoing due to playing board/card games, and a third student writes about a gamewinning play in a sport. Tony employs the hero narrative in his reflection for the first unit, describing at least three different times the difficulty he had in starting the project but then finding it easier to write the narrative once he decided on a topic. At the end of his reflection, he 
describes his passion for games and how he started to play card games with a group of friends at school. He goes on to reveal that this ritual actually began with just one friend, and the group gradually grew, eventually leading him to "[break] out of my shell."

Another student, Maria, also uses the first unit to show how she found a way to become more outgoing. In her reflection, she describes some of the topics she considered and includes descriptive sentences that could have been part of her actual narrative: "I thought about when I was in elementary school and used to play Super Mario Tennis with my younger cousins as we drank banana smoothies. How our family would gather on hot summer days in July to barbeque and play a board game." In her narrative, she describes herself as a shy person who had to adjust from being an only child to having two roommates and sharing a bathroom with 20 other women when she arrived at college at the beginning of the semester. As in Campbell's hero narrative, she faces a challenge and crosses a threshold between her comfortable home to the new environment of the dormitory. Eventually, at the urging of a roommate, she overcomes her shyness and joins a group playing a board game, perhaps representing the hero re-entering society.

The third student writes about his experience at an important baseball game in his narrative and revisits his play in his reflection. Ben says early in his reflection that playing baseball "helped me build character, and taught me how to work through difficult situations on my own." He further describes the significance of baseball and the opportunity he had to play in the state championship game with his high school team two years in a row. The most important play he describes, however, was at a sectional game leading up to the state championship.

Perhaps because his team lost both of the championship games, he focuses his attention instead on "the biggest play I made in my entire career" in a winning game to represent his success in baseball. He explains how “If I had not done this, we wouldn't have won the game, my career would have been over, and I [would] forever remember that I had an opportunity to succeed but I didn't.” Although these narratives of Ben, Tony, and Maria do not relate directly to writing, 
they seem to demonstrate the social influence of hero narratives, whether in film, books, or video games, and a desire to recognize heroism in their own lives. In addition, each of these three instances depict the student being involved with a group of people rather than as an individual: Tony and Marie with groups of friends, old and new, and Ben with his teammates.

Ultimately, one of my discoveries in this project was that while students may not have fully understood how to craft a paper for an audience, they demonstrated engagement in their reflections through a greater number of ways than I had realized, whether in simply attempting to meet the expectations for a particular grade or in exploring their topics in greater depth, but most importantly, they sought social engagement with their peers and their audiences. While the intention of reflection is often to reinforce the metacognition of individual students, these reflections seemed to reveal a great deal about the community of writers that developed over the course of the semester. Students tapped into a cultural consciousness that they mapped out in the reflections they wrote in composition and most likely in other types of writing courses.

The question of engagement has been important for me in personal as well as academic ways. As I read scholarship on reflection, I find myself anxious about my own teaching since I seem unable to motivate students to produce the same types of reflection that I read about. I have also realized that I value engagement as highly as the development of writing skills, perhaps under the premise that if students are engaged, then they will also develop as writers. Therefore, I wanted to identify types of engagement that may not have been discussed in other studies of student reflective writing and to think about what these types of engagement might mean for not only my own pedagogy but for the practice of reflection in general. The ways I identified engagement in the writing of these student reflections are the following:

- Emotional responses of enjoyment, interest, and satisfaction

- Concern for grades, supported with a claim of putting "time and effort" into their projects 
- Emphasis on the self - through interest, "I" statements, and casting themselves in improvement or heroic narratives.

Although I sometimes questioned the claims student made in their reflections, their discussions of enjoyment were rooted in their interests and sometimes contrasted with other projects in the class that were less enjoyable to them. These details were more effective than claims about the "time and effort" they put into their projects. Their claims of enjoyment seemed to be made without conditions, focusing on their own emotion - looking inward - rather than seeking approval or suggesting a reward in the form of a good grade. Discussions of interest also tended to be personal.

Based on these analyses, I concluded that reflection may have a social aspect that counters the inward focus that is commonly associated with reflection. The term social may suggest something similar to that of rhetoric and the significance of communicating with an audience. Social is also an indispensable component of language in that word meanings and sentence construction, for example, are socially determined and necessary for human beings to understand one another. What I mean by "social" in the context of this project, however, is the sense and desire for connectedness with those around us. Reflection has been taught in composition as a self-directed activity focused on recognizing and revealing one's own processes of thinking about and producing texts. The texts I analyze in this project, however, demonstrated some of the ways culture has influenced the perceptions students had of their work and how students sought out connections in their reflections.

Because many reflection assignments ask students to account for their process or to demonstrate their learning, the texts students produce are rhetorical, which may be one of the reasons the process of reflection has been considered social. For example, Jung points out the view of several scholars "that when written and read within contexts of high-stakes assessment, all reflective writing is, in fact, rhetorical argument-discursive appeals targeted to external audiences for specific purposes” (p. 629). This results in an apparent contradiction in which 
students are expected to look inward to discover and to describe their processes while also writing for an "external" audience. What I have argued is that the movements the students in this study made in their reflections are the opposite: they looked outward for connections and then sought to draw those connections into their reflections.

\section{Engagement and Embodiment}

While I have argued that these narratives are socially constructed, it is also relevant that these narratives were a means of depicting or defining the self, representing engagement as a form of embodiment. Bolter (2001) has argued that writing has always depended on physical tools, regardless of the level of technology, and multimodal composition seems to underscore composition as an embodied process - working with different media makes the process of composition more tangible, more visible. Whether through the use of images or graphics in an electronic document or in the composition of physical objects, multimodal composition makes the process of composing visible in a way that alphabetic composing alone is unable to provide. Both handwritten and word-processed alphabetic text has been naturalized to an extent that students often seem unable to access their processes of writing a more traditional assignment. Many students speak of "flow," of starting at the beginning of their paper and achieving a state of writing that allows the words to "flow out of him," as a student in my pilot study observed. Depending on the technology students use, multimodal composition may still disrupt this type of unreflective process, allowing students to better visualize their work, which is what led me to assign the multimodal reflections I analyzed in this project.

One of the earliest studies of reflection in composition focused on actions of the body when Pianko (1979) observed students stop writing and look about the room, and in interviewing them about their writing later, found that they were engaged in thought about their writing. As it is used today, reflection is arguably still a moment of pause, whether between projects or at the close of a period of time, such as at the end of a semester. In the multimodal reflections composed by students at the end of the semester, the images they included in their 
documents might be viewed (literally and figuratively) as pauses between writing. As I was considering embodiment in these reflections, I paused to view all of the multimodal reflections again to see which of them seemed engaging to me at this point. In my notes, I even wrote the question, "Which ones made me pause?" before I remembered Pianko's research. In many cases, it was the images in these reflections, particularly their placement, that made me take a few more moments to view the reflection and to read some of the passages.

In Helen's reflection, I noted the way she discussed the images in detail in her captions. Devon's reflection contained only two slides, but the number and variety of images on the slides would have made me want to start making sense of the collage these images created. Mandie's first slide contained images from the first unit with a bold arrow pointing from her alphabetic version to her remediated version in the form of a visual essay. The placement of Miguel's images seemed carefully planned, which made me pause to read some of his text, which was as thoughtful as the image placement. Tracey's first three slides showed the evolution of her project for Unit 3 - the game description - from an alphabetic text with just a few images to a fully formatted brochure.

What struck me the most, however, might have been the text I had highlighted earlier at the end of Maria's reflection: "One problem that I did have with this was trying to describe the descriptions of the memory because they did not always come out in the way that I was trying to describe them and this at times was very frustrating." In my annotation to this text, I observed that the student had, until this point in her reflection, summarized the class and explained her methodical approach. At this point, she seemed to have discovered the way writing sometimes presents us with difficulties that appear to be roadblocks (that may later become opportunities). When I viewed it this time, however, it was the word "frustrating" that stood out, and I reached for the stack of papers on which I had organized codes to find the codes on emotion. I initially looked for a single Post-It note but instead found an entire page filled with multiple Post-It notes with additional lists below them. While it may be beyond the scope of this project to fully 
consider the relationship between emotion and embodiment, it seems that this relationship may offer a gauge of engagement within student reflection, if not all student writing.

Arola's (2012) analysis of the embodiment of mixedblood American Indians on MySpace likewise comes from a place of emotion - doubt, confusion, outrage. The space in which mixedbloods occupy between the stereotypical images of the full-blooded Native American and the other race(s) that make up their biological identity is probably more complex than the space most of my students occupied, but both spaces are characterized by uncertainty and emotion. While Arola's study focuses on the "embodied nature of the online self" (p. 217), students embody their experiences and their identities in their reflections, both alphabetic and multimodal, not only through images but through the emotions they express in their texts. Like the subjects of Arola's study, my students used the affordances available to them as they constructed reflections, and while I asked them to account for their composing processes, they drew on a variety of resources in constructing their identities as students and writers.

Although I incorporated elements of design thinking into the questions for reflection that I provided for students, I wanted to know if they would adopt this type of thinking, whether through the influence of the questions or through other means. The model of design thinking I applied to my assignments was a product of researchers describing abductive thinking, a type of thinking that brings abstract thought together with concrete models (Shearer, 2015; Orthel, 2015). This model is different from the more common representation of design thinking developed at Stanford University, a model that would be better described a process since it represents a series of steps to a design project. What both models of thinking have in common, however, is a focus on the stakeholders of a project and attention to tangible results. Since the design process, like the composing process, goes through multiple stages, one aspect of design thinking is shepherding the project from the beginning to the end states, taking responsibility for the various iterations the project goes through. This also means taking an active role in determining the argument a project will advance and the media that will best make this 
argument. Design thinking also relies on recognizing the problem a design is intended to solve and asking the questions that will help to frame the problem as well as contribute to the design. Finally, one must recognize when a design satisfies stakeholders — or audience - as well as solving the problem that led to this process originally. As I discussed in Chapter Three, I used these precepts to develop the questions for students to use in writing their reflections at the end of units 1 and 3 as well as at the end of the semester.

From these concepts, the idea of the audience occurred most frequently and with the most variety in the wording of students and in my interpretation of their texts. In Chapter Four, I identified multiple relationships students appeared to form with their audiences. Many students discussed the ways they appealed to audiences with several more references to audience interest. However, throughout my analysis of these reflections, these references were unconvincing. Students knew that they were supposed to appeal to an audience, or they at least acknowledged the importance of addressing their work to an audience. The various codes I discovered ranged from an "in vivo" code for "audience" as well as audience appeal, audience interest, audience benefit, and audience expectations.

The attention students paid to audiences, though, seems to contradict the emphasis they placed on their own identities, but it is unclear whether audience was a genuine concern or something they believed they should value in a composition course. The argument could be made, however, that when students learn a concept, it may not be integrated fully within their process. Students made many references to audience and the importance of an audience, which we expect them to learn in a composition course after all. This may also represent a step toward the use of design thinking as students write their reflections.

Their emphasis on creativity — or in developing unique projects — seems to be linked much more to their own values and aesthetics, perhaps not unlike designers whose own preferences show up in their creations for the stakeholders who will ultimately use the products as their own. Ultimately, the two aspects of design thinking that showed up most strongly in 
student reflections - an emphasis on audience and the motivation to design something original (creativity) - were potentially in conflict with each other. Students demonstrated that they know their writing should be for audiences, but they wanted to put their own stamp on their work, to claim it for themselves and their own fulfillment. Their reflections suggest an ambivalence about the fate of their work and about their control over it.

Therefore, design thinking and engagement exist in a tension with each other in the context of these reflections. Design thinking emphasizes the role of stakeholders, or in the case of writing, the audience. Engagement, however, is a phenomenon or experience in which students embody their personal emotions in their work. Instead of reinforcing their experiences in composing their work, reflection may act as a means of separating students from their work, making it a subject to be dissected and analyzed instead of a way to express themselves.

Reflection may also introduce ideas that lead to ineffective strategies for writing when students focus more on the emotions that accompany their writing process. The students whose work I studied for this project often pointed to personal interest in a topic and to their own satisfaction in their work, which seem to counter a concern for communicating with an audience.

\section{Challenges in Redesigning Reflective Assignments}

The impulse to teach reflection more effectively is not new as Yancey first introduced difficulties in designing reflective prompts in her 1998 volume. She also says that it is difficult to even define what a good reflection looks like though she provides some examples of reflections that she believes do not work well. She cites several prompts in succession, suggesting that each is closer to prompting students to write "good" reflections. In her 1996 talk at the WPA conference, she also analyzes a document written by a professional who laments a job loss and his diminishing prospects throughout his search for a new position. Yancey observes that he fails to consider other possibilities for continuing his career, whether through a career change or a less drastic change to follow a different path within the same field. She equates this lack of 
choices as a lack of different voices in his reflection. Throughout her work in reflection, she has emphasized reflection as a multi-voiced process, but if we consider these voices the possibilities in a discussion of choices, this model approximates design thinking with its consideration of different design choices in order to meet the needs of stakeholders.

The decision to redesign assignments is a common response when reflection in a writing classroom fails to produce the results expected by the instructor. Like Yancey's progression of prompts in her 1998 volume, Jeff Sommers (2011) describes an evolution of his own earlier writer's memos by incorporating reflection throughout the semester, starting with asking students at the beginning of the semester to anonymously identify their beliefs about writing, revising, and writing courses. In addition to various forms of reflection throughout the semester, he creates "a class collage by publishing all of the credo statements the students wrote at the beginning of the semester in a single document” (p. 105). After further discussions about these statements near the end of the semester, the process culminates in each student writing a "Class Collage" essay with the goal of "[prompting] students to think about their beliefs in the context of a full semester's work, comparing what they now believe to what they may have believed at the start of the term" (p. 106).

Although not a composition instructor, Grossman (2008) also uses the term design to describe his process of revising his reflective assignments for service-learning experiences: "this article introduces research and theoretical frameworks that have helped me design assignments that have led to more productive, reflective papers" (p. 15). Grossman's approach to helping students learn to write reflections about their service learning also includes extensive scaffolding in order to help students use the concepts from his class in their reflections. After recognizing that students do not possess inherent knowledge on how to use reflection in writing, he developed an extensive scaffolding focused on encouraging students to use the concepts introduced in his psychology courses. 
Although Ryan (2010) does not specifically use the term "design" in describing her methods of improving her students' reflective assignments in teacher education, her practice is arguably an example of linguistic design. While she draws on social understandings of genre that resonate with the scholarship of genre in writing studies, she advocates for an approach that emphasizes linguistic structures such as nominalization and groupings of adjectives and adverbs. Although her focus seems to be primarily on the surface of reflection, the text that students produce rather than the thinking that occurs in the production of the text, she acknowledges the importance of "a transformative approach to learning" (p. 101). She argues that "if students are explicitly taught key structural elements and linguistic realisations of an academic reflection using a social semiotic approach, they will be more likely to be able to reflect critically on the professional or learning context” (p. 101).

Rather than redesign an assignment, Harding (2014) anticipates the difficulty students may have with reflection by developing a multimodal approach to her end of semester reflection - she reasons that the use of visual media would provide an "accessible entry point" for students to engage with reflection in more critical and academic ways. In addition, she provides scaffolding in the form of a self-survey to help students develop a theme for their portfolio and to connect that theme with each of the elements they will need to include in the portfolio.

While both Harding and Sommers present evidence that their assignments were effective, Sommers points out that he has "selected outstanding [examples] in an effort to illustrate how this approach can work" (p. 124), also noting that the responses to almost any writing assignment will vary in quality. Where Harding and Sommers seem to disagree is in the ability of students to achieve reflective writing that meets the critical and academic expectations of the instructor. Harding argues that even with "enough preparation and scaffolding leading up to a more tradition, text-based essay assignment," students would still struggle to complete an adequate reflection in alphabetic text. Sommers, however, lays out scaffolding that he argues does lead to satisfactory and even exemplary results. 
The contradictions between these claims and the varied approaches outlined in these articles suggest that the design or redesign of a reflective assignment is not a solution for improving student reflection and that my efforts in this direction were unlikely to be successful. Indeed, for several years, I refined my reflective writing assignments by rewriting the list of questions I provided and varying the length of the student writing. During one semester, I also had students keep a sort of journal. I assigned short reflections to write during class throughout a unit, but too often their answer to the question or prompt for a particular day was only one sentence. After noticing how often scholars in design made connections between reflection and design, I endeavored to use questions associated with design thinking to encourage more effective reflection. This took place in a program that asked students to document their learning, but these documents were intended to present students' understanding of the concepts and processes from the course rather than to document their own processes. It could be argued that since the program asked instructors to focus on writing as both a practice and a subject, the papers that they produced would include insights about their own writing, but papers produced in the course could very easily focus on the processes of writing practiced by other students or professions who use writing in their workplaces. To some extent, I thought of the "uptake genres" and reflections as terms for processes that were essentially the same thing, but the reflections I received and studied for this project often did not represent learning. Instead, they documented the values of students and their longings and desires.

In some of the classes I have taught since I began this study, I took a step in the opposite direction and eliminated all questions from my reflective assignments. Instead, I asked students to imagine the questions another person might ask about their writing. I also assigned readings on reflection, and I conducted discussions in which I asked students to identify what the concept of reflection meant to them. Although these discussions have usually been limited to a single class session, the results have been encouraging, at least in that students submitted reflections that were more focused on their own experiences with their projects and seemed to make fewer 
arguments about improvement or heroic efforts. In an upper-level writing class, I did provide questions for an end-of-semester reflective assignments, but I required students to record their answers through video, imagining that they were being interviewed about their writing. In this embodied process, I also provided detailed requirements for business casual attire. This focus on the appearance may be similar to Ryan's (2011) argument that improvement in the linguistic, or surface, features of a reflective text can lead to transformation at the cognitive level.

Ultimately, the outcome of these assignments requires further research in order to determine their value for continued or modified use.

A problem with relying on design may be related to the exigence for Schön's work on reflection in the first place. In The Reflective Practitioner, Schön frames the purpose of his book as a means of confronting a "failure to solve social problems" (p. 12) with the reflection of professionals necessary to "surface and criticize the tacit understandings that have grown up around the repetitive experiences of a specialized practice, and can make new sense of the situations of uncertainty or uniqueness when he (sic) may allow himself to experience” (p. 61). Schön extends the definition of design to include many professions that we might not typically associate with design, such as psychotherapy and music. He acknowledges that multiple researchers "have suggested that all occupations engaged in converting actual to preferred situations are concerned with design. Increasingly, there has been a tendency to think of policies, institutions, and behavior itself, as objects of design” (p. 77). However, Schön shows that the attempts to solve problems through design often "created problems as bad as or worse than those they had been designed to solve" (p. 10). He cites the process of urban renewal, which resulted in large-scale of destruction in cities without fulfilling its promise of ending poverty.

Following this logic, it would seem that the answer to helping students to produce better reflective writing, however "better" is defined, cannot be found in the design and redesign of reflective prompts. Again in Schön's work, reflection-in-action is a process of reframing a problem when one is immersed in the situation rather than looking back at past actions: "The 
situations of practice are not problems to be solved but problematic situations characterized by uncertainty, disorder, and indeterminacy" (p 15-16). Perhaps nothing describes writing better than these characteristics - uncertainty, disorder, and indeterminacy - with writing instruction targeted at students who conversely seem to crave certainty, order, and clearly defined practices.

Writing, and by extension, writing instruction, is arguably less a process of teaching students the skills for producing content as it is a process of helping them to manage "wicked problems." Instead of providing solutions to specific problems, instruction ideally provides the means of managing the complexity that characterizes writing situations in both college and professional writing. The same could be argued about reflection - that it is not defined by specific skills or genre characteristics but by the management of the processes that allow a writer to produce a text. In this way, it is perhaps not unlike the cognitive models of composition developed by scholars such as Flower and Hayes (1980, 1981). A key component of the model Flower and Hayes describe is a monitor that "functions as a writing strategist," visually represented as underlying the writing processes of planning, translating, and reviewing (p. 370, 374).

\section{Should We Teach Reflection?}

Given the complexity associated with reflective assignment, a logical question to ask might be whether we should continue to assign reflective writing in first year writing classes; however, I believe reflection has value for students when they understand the ways reflective practice is able to benefit them as students, and later, as professionals. In spite of Ryan's (2011) assertions about academic reflections, it may not be possible to teach reflection in the same way we teach genre since reflection is not limited to a single genre. As previous scholars have argued, reflective writing may take the shape of memos and letters, for example. In fact, the prompts for reflective assignments suggest the type of thinking that emerges in the process of writing an essay, even a research essay, as discussed by Davis and Shadle (2000). In their cataloguing of different methods of presenting research, Davis and Shadle include the research essay, a form in 
which the author may explain the idea of "truth and reality as multiple, provisional, dialogic. The essay...allows for multiple viewpoints, puts these viewpoints in dialogue with one another, and arrives...at a provisional conclusion to be questioned in the dialectic's next round, or a recasting of the question" (P. 430). Paul Heilker (1996), cited by Davis and Shadle, presents the essay as an alternate to "thesis-support" driven writing, arguing that "this form limits students' development: by closing rather than opening their minds" (p. 3).

What I find striking in these texts is the similarity to the type of writing Yancey and others identify as reflective in nature even when they are not identified as "reflection." Yancey's call for multiple voices, for example, resonates with Heilker's pedagogy of teaching the genre of the essay as a means of asking questions and proposing different possibilities in a space that allows writers to "reinvent" themselves. Teaching students to write reflectively, therefore, should not be limited to reflection for the purposes of instruction, whether in the form of portfolio cover letters or closing projects (end of a unit or end of a semester).

Emphasizing reflective writing for pedagogical purposes, even for the admittedly important goal of facilitating transfer, seems to reduce its value, which may lead to the reflective assignments that leave instructors - and perhaps the students - unsatisfied, even hollow.

Perhaps it was a sense of isolation that led students to weave a desire for social connections into their reflections.

In his pedagogy of the essay, Heilker compares the essay to a journey, particularly one that wanders, but my students described journeys that were incomplete, perhaps even cut off before they could proceed further. Instead of being bounded by the pedagogical purpose it has been assigned, reflection may need freedom to roam more widely. Providing opportunities for students to work in various modes creates the space for students to wander figuratively, even when assignments are not specifically labeled reflection. Students in this study demonstrated reflection when they paused to consider an alternate way to represent writing or when they had the opportunity to compose a project that was particularly meaningful. 
The first step of Grossman's (2009) scaffolding is particularly relevant to my conception of reflection as an embodied process in that he asks students to pay close attention to sensory input during their service-learning activities. When Grossman moves to the metacognitive functions of reflection, he describes an experience similar to the challenge I faced in asking my students to write about their writing processes:

Asking a student to report her or his thoughts or feelings while working to solve a Rubik's Cube, for example, is fruitless if she or he has not yet developed this mental place in which to stand apart and reflect. That student is so completely enmeshed in trying out different strategies...that she or he is unable to stand apart from what through her or his mind during the process." (p. 17).

My intuition that reflection is as much an embodied as a cognitive process appears to be confirmed by Grossman's scholarship. It is particularly significant that he uses this image of "standing apart" as a metaphor for the metacognition reflection requires, particularly in thinking about the distancing strategies I described in my previous chapter. On one hand, standing apart suggests a separation from others as well as from oneself, but the metaphor also underscores the role of embodiment in reflection. As he helps students to develop their metacognition, Grossman also asks them to recognize the "bodily sensations that usually accompany feelings" in order to discover the differences between these feelings and their thoughts (p. 18). In the next step of his process of developing metacognition, he brings social relationships into play as he asks students to observe the behavior of other people in order to apply the concepts from his psychology courses and adds that some of his students needed additional practice to reach the level of description that allowed them to take the next step of "identify[ing] perceptions, thoughts, feelings, and actions in themselves" (p. 19).

Scholarship on reflection indicates the importance of reflection not only in the learning of new material and processes but also for recognizing and articulating that learning. At the same time, this scholarship also underscores the difficulties faced in developing the ability both 
to teach and to practice reflection. Framing reflection in terms of design thinking does not alleviate but increases the complexity of developing one's awareness of problem solving regardless of the discipline. Therefore, recognition of the role of reflection must lead to asking not if reflection should be taught but when and where it should be taught. Because reflection is inherently part of at least some genres of writing, such as the essay, a writing classroom is certainly a natural site of teaching reflection. But I argue that reflection should not be limited to a means to an end, whether for assessment of a project or for the transfer of writing skills, but that it should also be the subject of direct instruction and informed by both emotion and embodied experiences. 


\section{REFERENCES}

Alexander, Kara Poe. (2007). More about reading, responding, and revising: The three Rs of peer review and revision. In Cynthia Selfe (Ed), Multimodal composition: Resources for teachers, pp. 113-131. Cresskill: Hampton Press.

Alvermann, Donna E., David G. O’Brien, and Deborah R. Dillon. (1996, January/February/March). On writing qualitative research. Reading Research Quarterly, 31(1), 114-120.

Anderson, Paul V. (1998, February). Simple gifts: Ethical issues in the conduct of person-based composition research. College Composition and Communication, 49(1), pp. 63-89.

Anson, Chris. (1989). Response styles and ways of knowing. In Chris Anson (Ed), Writing and response: Theory, practice, and research, p. 332-366. Urbana, IL: NCTE.

Arenas, Therese, et al. (2018). Composition Currents. $2^{\text {nd }}$ ed. Reno, NV: U of NV Core Writing Program - Fountainhead Press.

Arola, Kristin L., and Anne Frances Wysocki. (Eds.). (2012). composing(media) = composing(embodiment): bodies, technologies, writing, the teaching of writing. Logan: Utah State University Press.

Arola, Kristin L. (2012). It's my revolution: Learning to see the mixedblood. In Arola, Kristin L., and Anne Frances Wysocki (Eds.), composing(media) = composing(embodiment): bodies, technologies, writing, the teaching of writing, p. 213-226. Logan: Utah State University Press.

Bal, Mieke. (2002). Traveling concepts in the humanities: A rough guide. Toronto: University of Toronto Press.

Bawarshi, Anis S., and Mary Jo Reiff. (2010). Genre: An introduction to history, theory, research, and pedagogy. West Lafayette, IN: Parlor Press. 
Belanoff, Pat. (2001, Feb). Silence: Reflection, literacy, learning, and teaching. College Composition and Communication, 52(3), 399-428.

Berlin, James. (1987). Rhetoric and reality: writing instruction in American colleges, 19oo1985. Carbondale: Southern Illinois University Press.

Bolter, Jay David. (2001). Writing space: Computers, hypertext, and the remediation of print. Mahwah, NJ: Lawrence Erlbaum.

Broad, Bob. (2012). "Strategies and passions in empirical qualitative research.” In Gesa E. Kirsch (Ed.), Writing studies research in practice, pp. 197-209. Carbondale, IL: Southern Illinois University Press.

Buchanan, Richard. (1989). Declaration by design: Rhetoric, argument, and demonstration in design practice. In Margolin, Victor (Ed.), Design discourse: History, theory, criticism, p. 91-109. Chicago: University of Chicago Press.

Burt, Forrest D., and E. Cleve Want. (1978). Invention and design: A rhetorical reader. 2nd ed. New York: Random House.

Camp and Levine. (1991). Portfolios evolving: Background and variations in sixth- through twelfth-grade classrooms. In Belanoff, Pat, and Marcia Dickson (Eds), Portfolios: Process and Product, p. 194-205. Portsmouth, NH: Boynton/Cook.

Camp, Roberta. (1992). Portfolio reflections in middle and secondary school classrooms. In Kathleen Blake Yancey (Ed.), Portfolios in the writing classroom, p. 61-80. Urbana, Ill.: National Council of Teachers of English.

Campbell, Joseph. (2008). The hero with a thousand faces. $3^{\text {rd }}$ ed. Princeton: Princeton University Press.

Chamorro-Koc, Marianella, Andrew Scott, and Gretchen Coombs. (2015). Bombs away: Visual thinking and students' engagement in design studios contexts. Design and Technology Education: An International Journal, 2o(1) 18-28.

Chomsky, Noam. (1975). Reflections on language. New York: Random - Pantheon. 
Clark, J. Elizabeth. (2019). In Kathleen Blake Yancey (Ed.), A rhetoric of reflection, pp. 149-167. Logan, UT: Utah State University Press.

Cope, Bill, Mary Kalantzis, and the New London Group. (2000). Multiliteracies: Literacy learning and the design of social futures. New York: Routledge.

Corbin, Juliet, and Anselm Strauss. (2008). Basics of qualitative research: Techniques and procedures for developing grounded theory. ( ${ }^{\text {rd }}$ ed.). Los Angeles, CA: Sage Publications.

Cross, Nigel. (2006). Designerly ways of knowing. Board of International Research in Design (Bird). Basel: Birkhäuser.

Davis, Robert, and Mark Shadle. (2000, February). Building a mystery: Alternative research writing and the academic act of seeking. College Composition and Communication, 51(3), $417-446$.

Dewey, John. (1910). How We Think. Boston: D.C. Heath \& Co.

Doorley, Scott, Sarah Holcomb, Perry Klebahn, Kathryn Segovia, and Jeremy Utley. (2018). Design Thinking Bootleg. Retrieved from https://dschool.stanford.edu/resources/design-thinking-bootleg

Elbow, Peter. (1991). Foreword. In Belanoff, Pat, and Marcia Dickson (Eds), Portfolios: Process and Product, p. ix-xvi. Portsmouth, NH: Boynton/Cook.

Etkina, Eugenia, Anna Karelina, Maria Ruibal-Villasenor, David Rosengrant, Rebecca Jordan, and Cindy E. Hmelo-Silver. (2010). Design and reflection help students develop scientific abilities: Learning in introductory physics laboratories. Journal of the Learning Sciences, 19(1), 54-98. DOI: 10.1080/1050800903452876

Ettleman, Tristan. (2015, May 15). The hero's journey explained through video games. www.usgamer.net. (Accessed 22 Aug 2019). 
Faris, Michael J., Sarah E Austin, Erica Stone, and Joyce Carter. (2017). Remediating the CCCC Chair's Address for video. Kairos: A Journal of Rhetoric, Technology, and Pedagogy, 22(1). Retrieved from http://kairos.technorhetoric.net/22.1/inventio/faris-etal/index.html

Flower, Linda, and John R. Hayes. (1981, Dec.). A Cognitive Process Theory of Writing. College Composition and Communication, 32(4), 365-87.

Flower, Linda. (1989, October). Cognition, context, and theory building. College Composition and Communication, $40(3), 282-311$.

George, Diana. (2011). "From analysis to design: Visual communication in the teaching of writing." Cross-Talk in comp theory: A reader. Victor Villanueva and Kristin L. Arola (Eds.), Urbana: NCTE, 765- 790. (Reprinted from "From analysis to design: Visual communication in the teaching of writing," Sept. 2002, College Composition and Communication, 54[1], 11-39)

Goswani, Usha. (2011). Inductive and deductive reasoning. In Usha Goswani (Ed.), BlackwellWiley handbook of childhood cognitive development, pp. 399 - 419. London: Blackwell Publishing.

Grossman, Robert. (2009, Winter). Structures for facilitating student reflection. College Teaching, 57(1), 15-22. DOI: 10.3200/CTCH.57.1.15-22

Hamby, Zachary, and Rachel Hamby. (2021). The hero's journey. Creative English Teacher. Retrieved from http://creativeenglishteacher.com

Harding, Lindsey (2014, March). Writing beyond the page: Reflective essay as box composition. Teaching English at the Two-Year College, 41(3), 239-255.

Heilker, Paul. (1996). The essay: Theory and pedagogy of an active form. Urbana: NCTE. Hess, Mickey. (2007). Composing multimodal assignments. In Cynthia Selfe (Ed), Multimodal composition: Resources for teachers, pp. 29-37. Cresskill: Hampton Press. 
Horner, Bruce. (2016). Reflecting the translingual norm: Action-Reflection, ELF, translation, and transfer. In Kathleen Blake Yancey (Ed.), A rhetoric of reflection, pp. 105-124. Logan, UT: Utah State University Press.

Inoue, Asoa B, and Tyler Richmond. (2016). Theorizing the reflection practices of female Hmong college students. In Kathleen Blake Yancey (Ed.). A rhetoric of reflection, pp. 125-145. Logan, UT: Utah State University Press.

Jung, Julie. (2011, July). Reflective writing's synecdochic imperative: Process descriptions redescribed. College English, 73(6), 628-647.

Kisgen, Darren. (2016). Dragonwood: A Game of Dice and Daring. Newton, MA: Gamewright. Kornweibel, Theodore. (2010). Railroads in the African American experience: A photographic journey. Baltimore: The Johns Hopkins University Press.

Lauer, Janice M., and J. William Asher. (1988). Composition research: Empirical designs. New York: Oxford University Press.

Learning Outcomes for [English] 101. (2015, February 28). Grassroots Writing Research Illinois State University. Retrieved from http://isuwriting.com/learning-outcomes-101/

Lee, Chien-Sing and Kuok-Shoong Daniel Wong. (2015). Design thinking and metacognitive reflective scaffolds: A graphic design-industrial design transfer case study. 12th International Conference on Cognition and Exploratory Learning in Digital Age (CELDA 2015).

Leverenz, Carrie S. (2014). Design thinking and the wicked problem of teaching writing. Computers and Composition, 33, 1-12.

Marback, Richard. (2009). Embracing wicked problems: The turn to design in composition studies. College Composition and Communication, 61(2), W397-W419.

Margolin, Victor (Ed.). (1989). Design discourse: History, theory, criticism. Chicago: University of Chicago Press. 
McComiskey, Bruce. (2000). Teaching composition as a social process. Logan, UT: Utah State University Press.

Mezirow, Jack. (2011, June). Fostering critical reflection in adulthood. Proceedings of the 3rd Asia-Pacific Regional Conference, Lingan University.

Moon, Alan R. (2004). Ticket to Ride. Los Altos, CA: Days of Wonder.

Nes, Anders. (2016, February). Assertion, belief, and 'I believe' - guarded affirmation.

Linguistics and Philosophy, 39(1), 57-86. DOI: 10.1007/slo988-015-9181-o

Nevskiy, Oleksandr, and Oleg Sidorenko. (2015). Mysterium. Paris, France: Libellud.

Orthel, Bryan D. (2015, September). Implications of design thinking for teaching, learning, and inquiry. Journal of Interior Design, 4O(3), 1-20.

Palmeri, Jason. (2012). Remixing composition: A history of multimodal writing pedagogy. Carbondale: Southern Illinois University Press. CCCC Studies in Writing and Rhetoric.

Perl, Sondra. (1980, Dec). Understanding composing. College Composition and Communication, 31(4), 363-369.

Pianko, Sharon. (1979, Oct). Reflection: A critical component of the composing process. College Composition and Communication, 30(3), 275-278.

Prior, Paul, et al. (2007, Summer). Re-situating and re-mediating the canons: A Culturalhistorical remapping of rhetorical activity. Kairos, 11(3). Retrieved from kairos.technorhetoric.net

Purdy, James P. (2014, June). What can design thinking offer writing studies? College Composition and Communication, 65(4), 612-641.

Rittel, Hart, and Melvin Webber. (1973, June). Dilemmas in a general theory of planning. Policy Sciences, 4(2), 155-169.

Ryan, Mary. (2011, February). Improving reflective writing in higher education: a social semiotic perspective. Teaching in Higher Education, 16(1), 99-111. DOI: 10.1080/13562517.2010.507311 
Schell, Eileen E. (2010). Introduction: Research feminist rhetorical methods and methodologies. In Eileen E. Schell and K. J. Rawson (Eds.), Rhetorica in motion: Feminist rhetorical methods \& methodologies, pp. 1-20. Pittsburgh, PA: University of Pittsburgh Press.

Schön, Donald A. (1983). The reflective practitioner: How professionals think in action. New York: Basic Books.

Schön, Donald A. (1987). Educating the reflective practitioner: Toward a new design for teaching and learning in the professions. San Francisco, CA: Jossey-Bass.

Selfe, Cynthia. (Ed.). (2007). Multimodal composition: Resources for teachers. New dimensions in computers and composition. Cresskill: Hampton Press.

Shearer, Allan W. (2015). Abduction to argument: A framework of design thinking. Landscape Journal, 34(2), 127-138.

Shipka, Jody. (2011). Toward a composition made whole. Pittsburgh: University of Pittsburgh Press.

Shum, Simon J. Buckingham, Allan MacLean, Victoria M. E. Bellotti, Nick V. Hammond. (1997). Graphical argumentation and design cognition. Human-Computer Interaction, 12, 267300.

Sommers, Jeff. (1988). The writer's memo: Collaboration, response, and development. In Chris M. Anson (Ed.), Responding to student writing: Models, methods, and curricular change, pp. 174-86. Urbana, IL: NCTE.

Sommers, Jeff (2011). Reflection revisited: The class collage. Journal of Basic Writing, 3o(1), 99-129.

Sommers, Jeff. (2016). Problematizing reflection: Conflicted motives in the writer's memo. In Kathleen Blake Yancey (Ed.), A rhetoric of reflection, pp. 271-287. Logan, UT: Utah State University Press. 
Thelin, Bill. (1994). The connection between response styles and portfolio assessment: Three case studies of student revision. In Laurel Black, Donald Daiker, Jeffrey Sommers, and Gail Stygall (Eds.), New directions in portfolio assessment: Reflective practice, critical theory, and large-scale scoring, p. 113-25. Portsmouth, NH: Boynton/Cook Heinemann.

Teston, Christa, Brittan Previte, and Yanar Hashlamon. (2019). The grind of multimodal work in professional writing pedagogies. Computers and Composition, 52, 195-209. https://doi.org/10.1016/j.compcom.2019.01.007

Vogler, Christopher. (1985). A Practical Guide to Joseph Campbell's The Hero with a Thousand Faces. Retrieved from https://chrisjonesblog.com/2017/05/christopher-vogler-and-theheros-journey-the-outline-archetypes-and-mythical-memo.html

Walker, Paul. (2012). Pausing to reflect: Mass observation, blogs, and composing everyday life. In Kristin L. Arola and Anne Frances Wysocki (Eds.), composing(media) = composing(embodiment): bodies, technologies, writing, the teaching of writing, pp. 4259. Logan: Utah State University Press.

Watkins, Matthew. (2014). Towards an understanding of the social aspects of sustainability in product design: Teaching HE students in the UK and Ireland through reflection and peer learning. Design and Technology Education: An International Journal, 19(1), 40-47.

Wierszewski, Emily A. (2017). Research starts with a thesis statement. In Cheryl Ball and Drew M. Loewe (Eds), Bad ideas about writing, pp. 231-35. Morgantown, WV: West Virginia University Libraries - Digital Publishing Institute.

Wysocki, Frances Anne. (2012). Introduction: Into between - On composition in mediation. In Arola, Kristin L., and Anne Frances Wysocki (Eds), composing (media) $=$ composing(embodiment): bodies, technologies, writing, the teaching of writing, p. 1-22. Logan: Utah State University Press. 
Yancey, Kathleen Blake, Liane Robertson, and Kara Taczak. (2014). Writing across contexts: Transfer, composition, and sites of writing. Logan, UT: Utah State University Press. Yancey, Kathleen Blake. (1996, Spring). Portfolio as genre, rhetoric as reflection: Situating selves, literacies, and knowledge. Writing Program Administrator, 19(3), 55-69.

Yancey, Kathleen Blake. (1998). Reflection in the writing classroom. Logan, UT: Utah State University Press.

Yancey, Kathleen Blake. (2004, December). Made not only in words: Composition in a new key. College Composition and Communication, 56(2), 297-328.

Yancey, Kathleen Blake. (Ed.). (2016). A rhetoric of reflection. Logan: Utah State University Press. 


\section{APPENDIX A: COURSE SYLLABUS}

Appendix A begins on the next page in order to preserve the formatting of the original document. 


\section{English 101: Composition as Critical Inquiry}

The Game of ... Writing Research

Fall 2017

Time \& Location:
Monday/Wednesday
Sec. 51: 3:35 - 4:50
Stevenson Hall 250J
Sec. 59: 5:00 - 6:15
Stevenson Hall 250J

\section{Your Instructor:}

Elizabeth L. Jones

Office: Stevenson 201C

Office Hours:

1:30 to 2:30 on Monday, 6:15 to 7:15 p.m. on Wednesday, and by appointment

Email: eljone3@ilstu.edu

Phone: 309-438-4568

\section{COURSE INTRODUCTION}

\section{Description}

First year writing courses at Illinois State University take a unique approach to writing in asking you to not only produce texts but to learn through genre analysis how these texts are constructed, what they accomplish, and who they address. Not only is this approach rhetorical, but it is also designed to help you develop your own identity as both a writing and a writing researcher (a researcher focused on writing). To some extent, this course is about the subject of writing just as the subject of a history class is history. While my classes this semester will focus on games, a significant portion of your writing this semester will actually be about writing. You will produce some drafts that will go through a writing process of drafting and revising, but one of the most important goals for this class is for you to understand and articulate how you completed writing projects and to explain the choices you make.

Games have been used as metaphors for concepts as broad as life or more narrowly to specific professions or academic disciplines. Consider the book titles such as The Inner Game of Tennis and The Inner Game of Music, for example - the author of these books used the concept the actual game of tennis to formulate the metaphor of a mental game 
to become better at playing music. In many areas of life, the metaphor of the game is used not only to suggest the rules people follow in different areas of their life but also to push against the accepted rules. The same is true in writing - people have learned the so-called rules of writing but have also learned when to break them. The writing program at Illinois State University itself is a break from traditional writing instruction with its focus on the development of students as writing researchers.

On your journey to college, you encountered and adhered to many rules both at school and at home. Sometimes these rules must be followed strictly, and other times they may and should be challenged. What I invite you to do this semester is to think about the "rules" you may have learned for writing in the past and to put these into a social and historical context while exploring your identity as a writing researcher. In this class we will research the ways in which writing works (and sometimes doesn't work) in academic, professional, and social settings. Our approach to writing will be rhetorical, meaning that writing occurs in and responds to specific situations and audiences. In keeping with the subtopic of this course, "The Game of Writing Research," I will also invite you to explore genres through an investigation of table-top and social games and the forms of writing associated with them. Please be aware that the main topic of this course is always writing and writing research, but one of the lenses through which we study writing will be the game experience. Again, while some of the readings this semester will be about games, this is not a course in game theory. As you explore games - ranging from board/card games to perhaps the "game of life" - I want you to think of them as a metaphor for writing.

\begin{abstract}
About Me
I am a Ph.D. student in English Studies with interests in multimodal composition/new media, space/place, and composing across disciplines (including music). My MA is from George Mason University, where I studied the teaching of writing and literature. I am still trying to decide what to be when I grow up. I recently completed a certificate program in trimming horse hooves, and this winter, I am working as a snowboard instructor on weekends. I am also a semi-professional low brass instrumentalist with several central Illinois ensembles. Although I am not originally from Illinois, I am a second-generation student at ISU, my father having received his bachelor's degree in Music Education here. I spend too much time playing games on my phone and not enough time playing my favorite board games.
\end{abstract}

\title{
Important Notice
}

This syllabus is subject to change to best suit the needs of the class. Always check the course ReggieNet site for the latest version of this document.

\section{Required/Optional Materials}

- Grassroots Writing Research Journal 8.2

- Spiral notebook or composition notebook dedicated to THIS class. 
- Portable storage device or adequate cloud storage space.

- Optional: Steam account and access to board/card games

\section{Learning outcomes}

Upon successful completion of this course you will be able to employ the following concepts:

- Writing Research Identity

- Peer and Self-Assessment

- All About Genres

- Researching Your Content

- Cultural-Historical Activity Theory

- Uptake and Antecedent Knowledge

- (Multi)Media and (Multi)Modalities

- Cultural and Ethical Impacts

\section{Classroom Expectations}

Participants in this course are expected to attend class regularly, perform assigned tasks, and engage in classroom activities, all in a spirit of friendly but rigorous inquiry. Intolerance based upon race, gender, sexual orientation, disability, or religious affiliation has no place in a college classroom, but some of the topics that take place in class may tread on these issues. I ask that all students be respectful of their fellow classmates, participating in discussions with a spirit of open discourse and honest inquiry. Disruptive or disrespectful activity is unacceptable. For more on conduct in the classroom, please feel free to ask the instructor or consult the ISU Code of Student Conduct: http://deanofstudents.illinoisstate.edu/downloads/CodeOfStudentConductRevised5.12.pdf.

\section{ATTENDANCE}

You may miss two class periods without penalty. The third through seventh absences will each earn a penalty of one-half of one letter grade deducted from your final course grade. For example, a student who would otherwise end the course with an $85 \%$ but missed four class periods would receive a $\mathrm{C}$, not a $\mathrm{B}$, as their final grade. If you are absent eight (8) or more times, you will fail the course - this is a policy of the Writing Program at Illinois State and is not negotiable. 
Absences related to school-sponsored activities will be excused if you meet with me in advance to determine what work you will need to complete outside of class and submit this work by the start of the next class after your absence. You must notify and meet with me in person (not by e-mail) before the planned absence.

No other absences will be excused except in extreme circumstances such as a serious medical situation, a serious incident that may occur on your way to class, or for bereavement (see policy at end of syllabus). Absences due to more common illnesses and doctor's appointments are normally not considered excused absences, nor are meetings with lawyers, Greek life events, or job interviews.

Under only the most extreme circumstances will other absences be accommodated, and in general there will be no excused absences other than those for school-sponsored activities or to follow the university's bereavement policy, which is located here. The two excused absences built into the attendance policy should not be squandered; if you skip class early in the semester and then are sick later, it may have an impact on your final grade. Illness and doctor's appointments are normally not considered excused absences.

I also reserve the right to count excessive tardiness as an absence. For example, arriving thirty minutes after the beginning of the class or being a few minutes tardy for three or four consecutive classes may be counted as half an absence. If you are late for the start of class and attendance has already been recorded, it is your responsibility to check after class to make sure you are not marked absent for the day. Please be aware that students who are frequently tardy often struggle to complete the course with a passing grade.

If you miss class for any reason, it is your responsibility to contact a classmate to find out what you missed during class, even if you missed class due to a school-sponsored event. We are not robots, and so I may adjust class activities on occasion. Please do not contact me and ask if you missed anything important or if I can get you caught up. In college classes, almost every class meeting is important since we only meet two or three times a week. If you have questions about information from a classmate, you are certainly welcome to get clarification from the instructor, but you must have contacted a classmate first. If you do not have contact information for any classmates, you can send e-mails to them through ReggieNet.

\section{UNIT OVERVIEWS}

\section{Unit \# 1 - Games Narrative}

You will be using the genre of the narrative to write about your experiences with games of any type: board/card games (tabletop games), role-playing games (e.g. Dungeons and Dragons), video-games, and sports (focus on the aspect of the game). Your final alphabetic (written) draft should be at least 850 words, and you will also "remediate" this project, which means to convert it into a different form of media, such as a video, a presentation, a podcast, or an infographic. The final step for this unit will be to write a reflection in which you discuss your choices and what you learned. 


\section{Unit \# 2 - Researching Games and Gaming}

Although this unit will not require you to write a traditional research paper, you will use the library to conduct research on a topic associated with games, and you will also construct a survey with which to gather primary research data. You will create an annotated bibliography, which will be incorporated into a collaborative bibliography for the entire class. In addition to the bibliography and the survey, you will also submit reports on the results of each activity. Finally, you will complete a reflection about your learning in this unit - both about the process or research and about games.

\section{Unit \#3- Game Description and Letters}

For your final project, you will use what you have learned about games and about the genre of the game description to create your own. writing a scenario for a potential game uses the same skills of genre study and of writing that you will practice throughout the semester. You will have the opportunity to choose the mode for your scenario (alphabetic text, video, storyboard, etc.). After you have had a chance to read scenarios by your classmates, you will also write a letter of endorsement for one of them. Finally, you will write a reflection about your process and about your learning in this unit.

Summary of major assignments and reflections:

Major assignments

- Games Narrative - revised

- Multimodal version of above narrative

- Annotated bibliography

- Review of literature.

- Surveys

- Report of survey results

- Game scenario - revised

- Letter of endorsement (of a classmate's scenario)

(Drafts of projects will usually count as homework assignments.)

Three unit reflections

Final, multimodal reflection covering the entire semester.

\section{Unit \# 4 - Final Reflection}

Your final project will actually begin this week or next as you begin to collect evidence of your composing processes throughout the semester. Sometimes I will have you do this during class; other times it may be a homework assignment to ensure that at the end of the semester, you have enough documentation to compose a final reflection on your work and your learning this semester. Be sure to save all of this to a secure place - a backup drive or cloud storage. 


\section{GRADING}

A very important aspect you need to understand about this course is that your grade is based primarily on demonstrating what you have learned in each project and overall throughout the semester. Students who are already competent writers and are used to turning in papers that receive an A sometimes have the most difficulty with this focus. The goal of this class is not just to create an excellent final product or even a produce one that is just good enough - the goal is to participate in a process of research and writing, and your grade should reflect your activities and learning, which may be different from your final products. A student who might get B's and C's on papers might actually demonstrate more growth and learning than the A student, but that doesn't mean the grade results will be the opposite of what you are used to. What I am asking is for you to keep an open mind and fully engage in the processes of genre research, drafting and editing, peer and self-assessment, and reflection on your own work.

\section{Peer Grading}

During this course, you will be expected to participate in peer grading for some of the major assignments, and this process requires objectivity and respect for the work of your classmates. The instructor will always make the final determination on grades, but it will be informed by assessment by both yourself and your peers. For each unit, the class will develop a rubric that will be used by both their peers and myself, so the expectations for major assignments will develop after you receive the initial assignment. I believe that an important aspect of developing as a writer is being able to assess what you and others have composed. It is only through this ability to assess work that you can then go on to revise and edit your compositions to better meet the needs of an audience.

\section{Grade calculation}

\begin{tabular}{|c|c|}
\hline Final Grade Calculation & Unit Grading \\
\hline $\begin{array}{l}\text { 20\% Unit \#1 - Games Narrative } \\
\text { 25\% Unit \#2 - Researching Games and } \\
\text { Gaming } \\
\text { 30\% Unit \# } 3 \text { - Game Scenario } \\
\text { 10\% Unit \# } 4 \text { - Final Reflection } \\
\text { 15\% Assignments, quizzes, etc. }\end{array}$ & $\begin{array}{l}\text { Reflections will be worth } 100 \text { points, } \\
\text { and major assignments (revised } \\
\text { drafts) will be worth 5o points. The } \\
\text { grade for most of the major } \\
\text { assignments will be determined by } \\
\text { rubrics developed over the course of } \\
\text { the semester. }\end{array}$ \\
\hline
\end{tabular}

Please be aware that you will not be able to calculate your grade by taking a simple average of your total points. Every semester I get e-mails from students who attempt to do this and find the result does not agree with the grade indicated on ReggieNet. The more important things for you to check in the gradebook are that your points are entered correctly and that no assignments that you have turned in are missing. Occasionally, assignments will have similar names, but I will try to make them as distinct as possible within the limitations of the grade book. 


\section{Late Work}

Meeting deadlines for assignments is a major component of academic success. For each assignment, you will have a 24 hour grace period. Any major assignment submitted more than 24 hours after the deadline will be reduced in grade by one letter for each delay of up to 24 hours or fraction thereof. (Example: an otherwise 'A' assignment handed in 24 hours and 6 minutes after the deadline - the beginning of class - will earn you a 'B', 24 hours after that it's a 'C', etc.) The clock for assignments begins at the beginning of the class for which they are due, which means that an assignment that was due on Tuesday and is turned in ten minutes before class on Thursday will be reduced one letter grades. Therefore, you should not wait until the next class to turn in a late assignment but submit it as soon as possible. I will provide an assignment link on Reggienet for almost all major assignments. Exceptions to this policy for late work can be made for documented emergencies, at the sole discretion of the instructor.

Homework and in-class assignments may be submitted only if I have not graded the set for the rest of the class already. There is no set deadline for my grading. I may grade some of them right after class and others might take a couple of days for me to get to, so it is to your advantage to submit all work promptly. Sometimes I will put the assignments online, which means that if you miss a class but can complete the work before the day is over, you may receive at least partial credit for it. This does not make up for an absence, however. Often this homework will be important preparation for a major assignment, and so I will accept late work for $1 / 2$ credit up to one week late. No homework will be accepted more than a week late.

\section{Academic Integrity}

Academic dishonesty, academic misconduct or academic fraud is any type of cheating that occurs in relation to a formal academic exercise. It can include:

- Plagiarism: The adoption or reproduction of original creations of another author (person, collective, organization, community or other type of author, including anonymous authors) without due acknowledgment. The act of plagiarism, defined by ISU as "unacknowledged appropriation of another's work, words, or ideas in any themes, outlines, papers, reports, speeches, or other academic work."

- Fabrication: The falsification of data, information, or citations in any formal academic exercise.

- Deception: Providing false information to an instructor concerning a formal academic exercise-e.g., giving a false excuse for missing a deadline or falsely claiming to have submitted work.

- Cheating: Any attempt to obtain assistance in a formal academic exercise (like an examination) without due acknowledgment (including the use of cheat sheets). (Note that consulting a tutor would not be considered cheating for a unit assignment.) 
- Bribery or paid services: Giving assignment answers or test answers for money.

- Sabotage: Acting to prevent others from completing their work. This includes cutting pages out of library books or willfully disrupting the experiments of others.

- Impersonation: assuming a student's identity with intent to provide an advantage for the student.

Academic Dishonesty can result in serious penalties, including a failing grade for the assignment in question and further disciplinary action at the University level. For more information, contact your instructor and/or consult the ISU Code of Student Conduct: http://deanofstudents.illinoisstate.edu/downloads/CodeOfStudentConductRevised5.12.pdf.

\section{GENERAL EDUCATION PROGRAM AT ISU}

Composition as Critical Inquiry (ENG 101) challenges students to develop a range of rhetorical and intellectual abilities. Students learn how to analyze the multiple dimensions and meet the multiple demands of any written rhetorical situation. These dimensions and demands include: topic, audience, purpose, primary and secondary research, forum, genre, ethos, and kairos (timing). Students also develop an array of strategies to help them navigate any rhetorical terrain. These strategies include: reading, brainstorming, writing to learn and think, drafting, research, giving and receiving helpful responses, revision, editing and proofreading, publication, and critical reflection on one's own rhetorical processes.

\section{ENG 101 addresses the following General Education outcomes:}

\section{II. intellectual and practical skills, allowing students to}
a. make informed judgments
b. analyze data to examine research questions and test hypotheses
c. report information effectively and responsibly
d. write in a variety of genres, contexts, and disciplines

\section{III. personal and social responsibility, allowing students to}

c. demonstrate ethical decision making

d. demonstrate the ability to think reflectively

IV. integrative and applied learning, allowing students to

a. identify and solve problems 
c. work effectively in teams 


\section{ADDITIONAL OUTSIDE RESOURCES}

\section{Student Counseling}

Student Counseling Services at ISU provides students with a variety of support systems to manage everyday life issues. Students can receive help from trained professionals on topics such as individual and group counseling, self-help and assessment, career and life choices, sexual assault, outreach workshops, and help for friends and family. Emergency walk-in service is available at Student Services Building, room 320. They may also be contacted via phone 309-438-3655 or online via http://www.counseling.ilstu.edu.

\section{Student Access and Accommodation Services}

Any student needing to arrange a reasonable accommodation for a documented disability and/or medical/mental health condition should contact Student Access and Accommodation Services at 350 Fell Hall, (309) 438-5853, or visit the website at StudentAccess.IllinoisState.edu. Please be aware that such accommodations can take a few weeks to process, and they are not retroactive. If you are eligible for appropriate accommodations, you should contact this office as soon as possible to start the process.

\section{Academic Assistance}

The Julia N. Visor Academic Center is a division of University College that provides services and programs designed to assist students in their pursuit of academic excellence at Illinois State University. Services and programs include group tutoring in general education courses, one-on-one writing assistance, workshops designed to enhance student study techniques and academic skills, one-on-one academic coaching, a computer lab that provides a quiet and supportive environment for study and the Mary F. English Technology Award program, which provides a new laptop computer and professional development opportunities for selected teacher education majors. Located at 12 Vrooman Center (between Manchester and Hewett Halls). Phone (309) 438-7100, http://ucollege.illinoisstate.edu/about/visor

\section{Diversity Advocacy}

Diversity Advocacy helps multicultural and lesbian, gay, bisexual and transgender (LGBT) students find their way at Illinois State University through a variety of resources, programs, activities and advising. Diversity Advocacy also works to facilitate a supportive campus environment in which multicultural and LGBT students can flourish academically and socially.

To contact Diversity Advocacy visit 87 Student Services Building room 87, phone (309) 438-8968 or email Diversityadvocacy@ilstu.edu

\section{Extended Absence/Bereavement}

The Office of the Dean of Students can provide notification to instructors when students have been/will be absent from class(es) for three or more consecutive days or for absence in the event of a death of a spouse, domestic partner, parent, child, 
grandparents, grandchild or sibling, uncle, aunt, niece, nephew, first cousin, in-law, or step-relative. Call (309) 438-2008 if you would like to make use of either of these services. 


\section{APPENDIX B: UNIT 1 ASSIGNMENT SHEET}

Appendix B begins on the next page in order to preserve the formatting of the original document. 


\section{Unit \#1: Games Narrative \\ English 101, Sections 52 and 61 \\ Fall 2017}

Learning ourcomes aaaressea:

- All About Genres

- Peer and Self-Assessment

- (Multi)media and (Multi)Modalities

\section{Deliverables:}

- Rough draft of narrative for peer review (homework assignment -10 points)

- Revised narrative of at least 850 words (50 points)

- Remediation of narrative - choice of media (50 points)

- Reflection (100 points)

\section{Description}

There are probably very few people who have not played games of some sort, whether video games, table-top (board and card) games, playground games, or even sports. The term "game" is also a metaphor some of the interactions that occur in relationships as well as for career and life in general. For this narrative, however, I want you to focus on experiences with organized games you may have played as a child or as a teenager. When I think of games myself, I think of board games and card games, so I will expect you to at least touch on these in your narrative even if your focus ends up being on another type of competitive game. You are certainly welcome to write about video games as well. If you write about experiences with sports (playing or watching basketball, baseball, or volleyball, for example), please draw comparisons with or make connections to board/card/video games. Think about how sports games are both like and unlike these other types of games.

The genre I expect you to emulate in this project is that of the literacy narrative, and you will also participate in a genre analysis of literacy narratives. You will help to develop an understanding of literacy narratives and how a games/gaming narrative may diverge from a literacy narrative. This analysis will then be used to develop a rubric for your alphabetic text. Although we will use the literacy narrative as a model, you do not need to write about literacy specifically. If you do include literacy, it should be in the context of games, which should remain the central focus. You may not be the biggest fan of games, but to some extent, this project will help to set the trajectory for the rest of the semester. Ideally, you will also discover something about yourself or your experiences in the process of writing this narrative.

To get started, you should start by listing games you have played as well as the people you played them with. Think also about the locations and time periods. Write this down on paper or type it in a word processing file so that you have notes to refer back to as you write your initial draft. You do not necessarily need to make an outline, but based on your notes, you should have some ideas about what you will write about and in what potential order.

Your revised draft must be at least 850 words, and while your rough draft may be a little shorter than this, it should not be much under 650 or 700 words. Some people tend to shorten their original text as they revise, but more people probably add to their text in order to include more details. Remember to include visual and other sensory details in addition to telling about events.

After you complete a draft and revised draft of this project, you will also put it through a process of "remediation." To remediate your project means to recreate it using a different medium, and 
you may choose the form of media. For example, instead of using the medium of paper and ink (or rather its digital representation), you may create a video, a podcast, or a presentation like a Pecha Kucha (a collection of Power Point slides is not adequate for this project). Any means of expressing your ideas in another medium is fair game (a convenient pun), but I will ask you to explain the reasoning for your choice.

\section{Reflection}

The writing program at ISU typically uses the term "uptake genre" instead of reflection, but because my research is on reflection, I will use this term more frequently in my class. In the writing program, we use "uptake genre" to refer to a document that outlines your thinking and writing processes, and this document may be in the form of alphabetic text or it may use multimedia. At least three of the learning objectives for this course - Writing Research Identity, Peer and Self-Assessment, and Uptake and Antecedent Knowledge - are associated with the type of meta-cognition that encompasses the uptake genres/reflection. Reflection is inherently focused on your own knowledge and practices, and to write a reflection means that you will capture this metacognition in a medium to communicate it with me (your instructor). A good way to plan your reflection is to think about the answers to a series of questions about your process of thinking of writing, and I will expect you to address these as fully as possible in your document:

- What are the different approaches/topics you considered before writing your initial draft?

- What choices of media did you consider for the multimodal version of your narrative?

- What influenced your ultimate choice?

- What problems did you face throughout this unit?

- What resources did you use for answering your questions?

- How satisfied were you with your projects for this unit?

- How well do you think you met the needs of your audience?

You should respond to these questions in a way that your answers stand alone, meaning that someone reading your reflection should not have to know what these questions were or even that you were responding to a series of questions. It is also not necessary to answer these questions in order, and you can add more information that these questions do not address. The most important goal is that you show responsibility for your projects and explain your thinking.

The length of your document should be determined by complete and honest attempts at answering the questions listed above. Typically, your reflection should be no less than 800 to 1,000 words, and keep in mind that it is weighted the most heavily of any assignments this semester. This is because of the emphasis in this writing program on your self-awareness as a citizen writing researcher. While I do not schedule peer reviews for these reflections (except for Unit \#4), you should share your work with another student and spend time revising your reflection before you turn it in. I will also ask you to submit some of your notes for the reflection, an outline, or a previous draft when you turn in your reflection for a grade, so make sure you create an extra copy of your computer file before you work on revising and editing.

\section{Schedule for Unit 1}




\begin{tabular}{|c|c|}
\hline $\begin{array}{l}\text { August } 21 \\
\text { Introduction to class } \\
\text { Initial writing }\end{array}$ & $\begin{array}{c}\text { August } 23 \\
\text { Conclude ice breaker/genre activity } \\
\text { Introduce Unit } 1 \\
\text { Read literacy narratives linked to ReggieNet } \\
\text { site } \\
\text { Brainstorm ClassCraft rewards and } \\
\text { sentences. }\end{array}$ \\
\hline $\begin{array}{c}\text { August } 28 \\
\text { Exploring games }- \text { meet in writing program } \\
\text { offices. } \\
\text { Bring a notebook for writing. }\end{array}$ & $\begin{array}{c}\text { August } 30 \\
\text { Read "I would not like writing here or } \\
\text { there...,"Jenn Coletta, GWRJ 8.1 } \\
\text { Review assignment - continue to analyze } \\
\text { literacy narratives and develop a rubric for } \\
\text { assessment. }\end{array}$ \\
\hline $\begin{array}{c}\text { September } 4 \\
\text { No class - Labor Day }\end{array}$ & $\begin{array}{c}\text { September } 6 \\
\text { Draft of narrative due for peer } \\
\text { review/assessment }\end{array}$ \\
\hline $\begin{array}{c}\text { September } 11 \\
\text { Introduce concept of remediation } \\
\text { Brainstorm for projects } \\
\text { Read "Transmedia Storytelling...," } \\
\text { Sydney Ybarra, GWRJ 8.1 }\end{array}$ & $\begin{array}{c}\text { September } 13 \\
\text { Revised narrative due - peer grading } \\
\text { Introduce reflection - } \\
\text { read “Atychiphobia, Failure, Genre, and } \\
\text { Vulnerability...," Shane Wood, GWRJ } 8.1\end{array}$ \\
\hline $\begin{array}{c}\text { September } 18 \\
\text { Analyze language - sentence structures } \\
\text { Read "Let's Sit Down for a Talk," Becky } \\
\text { Holdsworth, GWRJ 8.1 }\end{array}$ & $\begin{array}{c}\text { September } 20 \\
\text { Assign Unit } 2 \text { - research and collaborative } \\
\text { process } \\
\text { Read “Clichés and Other Stressful } \\
\text { Components of Writing,” Katherine Peterson, } \\
\text { GWRJ 8.1 }\end{array}$ \\
\hline $\begin{array}{c}\text { September } 25 \\
\text { Remediation of games narrative due } \\
\text { with reflection } \\
\text { Brainstorming through research } \\
\text { Analyze bibliography entries } \\
\text { Read “Annotated Bibliographies for } \\
\text { Dummies," Angela Gentile, GWRJ } 2.2\end{array}$ & \\
\hline
\end{tabular}




\section{APPENDIX C: EXAMPLE NARRATIVE FOR UNIT 1}

\section{Memories of Games and Places}

As a child, going to my maternal grandparents' house meant playing games - card games like rummy with my grandmother, who also taught me solitaire, and checkers with my grandfather. I believe I always pestered at least one of them to play games with me while I was there, not for my own amusement since I was perfectly happy reading a book on my own, but because I enjoyed the time with them. My grandfather seemed to spend most of his time lounging in his chair by the front door watching the news on television or reading the newspaper. When the news turned to soap operas, though, the TV usually went off, and the checker board often came out. It seems that we played checkers during the day, the sun streaming in from the picture window in the living room, my grandfather sitting in his chair, me on a stool or kitchen chair, and the checker board on an ottoman or TV table between us. When my grandfather went to work outside or go to the store, I sometimes took his place and enlisted my younger brother to play checkers.

It was in the evenings that my grandmother and I played cards at the kitchen table. It seemed to be only then that I could capture my grandmother's attention. During the day, she would stay busy by going to the store, working on projects like knitting or needlepoint, watching television (often game shows), and cooking meals. By the time dinner had been prepared and the dishes washed and put away, my grandmother was ready to sit down with a deck of cards to play rummy with me. We never counted points, just played hand after hand, and it didn't really matter who won. My grandmother would pause to offer ice cream - always vanilla with chocolate syrup available, her special lemonade/orange juice mix, or chocolate milk made from Kwik chocolate milk mix, a chunky mix I liked to sneak tastes of without milk.

When I started to list the games I played at home, I thought at first my brother and I only played Monopoly - and we did so many times. I can remember clearing the opposite end of the dining room table to make room for epic Monopoly games that lasted for hours and that we had 
to come back to after feeding animals and helping in the kitchen. But my list of games grew to include Sorry, Battleship, chess, Clue, and Scrabble. My brother and I usually played Battleship at my grandparents, probably when neither of them were available for the other games. I also realized how much these games were associated with place. Battleship, rummy, and checkers at my grandparents. Monopoly and Clue usually at home, and Sorry and Life (which I never owned) at my cousin's house, where I spent many overnight visits since we were only six months apart in age and in the same grade.

After I graduated from high school, life became much more complicated with my parents' divorce, my mom's move to another state with her new boyfriend, and my uncertainty about life in general. I started and quit college. I moved to Colorado where my mom and brothers now lived. I worked, started college again, and then decided to join the Marine Corps. In the meantime, I acquired a game of Risk somehow and remember playing it with my brothers at the kitchen table in Colorado. I am always trying to find at least two other people to play Risk again, perhaps to recreate that experience, but as a lengthy game, I never seem to find the time, and so I always associate it with that table in Colorado, the sliding screen door behind me with the dogs begging to go out or to come in. I'm not sure I have played Risk since I left home for the Marine Corps, but I still have the same game even after numerous moves since then. It is an awkward length, making it a challenge to find a box for it to fit, but I've always managed.

After marrying and moving to San Diego, one of the things I always did when family came to visit was to travel down to Tijuana for shopping, and on my first visit, I bought a small wooden chess set. The box that held the pieces folded out to become the chess board, and I still have this chess set among my games. I don't think I've actually used the set often since chess has not been my favorite game, but my daughter later developed an interest in chess and joined her middle school chess team.

It was with my daughter that I developed a different history with games, our all-time favorite being Uno. Even when she was in college, I never went to visit her without taking a deck 
of Uno cards along. When I wasn't sure the deck was even complete anymore, and we knew the folded card was a red 7, I bought a new deck. The box for the previous deck had long since been lost, and I kept a rubber band around the deck, so it still feels strange to pull the newer deck out of the box. We still play occasionally, but since we have both collected so many other games, we don't play Uno as often, but it has been a mainstay. I also bought the card game Set when my daughter was in either middle school or high school, and it was such a favorite that my daughter claimed it for many years. I didn't get it back until last year, and only because I argued that I needed it for my classes to try out. Like Monopoly and Risk, I also associate it with a particular place: the floor of the living room in the apartment I moved into her during her junior year in high school. Her dad and I had separated, and I found an affordable apartment nearby, with her school about halfway between our places. On many of the evenings she came over, we sat on the floor and puzzled over the Set cards, trying to use up every single card. It didn't seem to matter which of us won as long as we made every possible combination given the order the cards were laid down.

So when I try to think about how I started to collect my newer games, I realize that I have had a lifelong interest in games, and I can't really point to a specific moment that this interest developed. As I sit here, I remember learning about another game, Blokus, when I was in Colorado for a few months in 2010. I have purchased three versions of the game since then, and it was another favorite of my daughter and I before we moved on to more complex, Euro-style games. After looking again at my game collection, I remember that I bought two copies of the game based on Dr. Suess's Oh, The Places You'll Go when I worked at an educational toy store, and I bought a Shakespeare game when I started to teach high school English.

I started a new teaching job in Springfield, IL, at about the same time several other people were hired in the English and History departments, which shared a hallway. We began to get together as a group, alternating homes - BBQ at my house, wine and cheese at the creative writing professor's house, roast beef at the World Literature instructor's house, and various 
snacks at the house of a couple who both taught English. The common theme at most of these gatherings were games - yes, we were geeks. I brought the Shakespeare game to one of these gatherings, and ironically, we all chose the easy questions even though most of us were familiar with Shakespeare. I've always thought it was to avoid embarrassing ourselves in front of colleagues. When I allowed my high school students to play it, they were more daring and tried for the medium and sometimes even hard questions. It was at the apartment of the World Lit instructor, Roger, that I finally learned Settlers of Catan, a game I had seen several times before and thought would be interesting. I learned later that it is a "gateway" game into an obsession with a world of games I didn’t know existed. Carcasonne came shortly after Catan, followed by Forbidden Island, Dixit, Bang, Galaxy Truckers, Flux, and Tsuro, in roughly that order.

When I visit my daughter, it's a toss-up whether we play one of her games or one of the three or four I bring with me. The question is usually not whether to play a game, but what game do we have the time and enough players for. And since I like to learn new games, we almost always play one of her games. It was at my daughter's apartment that I also began playing Journey, the only video game that has made me want to buy a game system of my own. I think she regretted introducing the game to me because I wanted to play it every time I visited with her. I tried Mass Effect, one of her other video games later, but it didn't have the same appeal. After recently discovering that the game is available for computers, though, I am thinking of secretly playing it to better understand her interest.

After three of my colleagues moved on to other schools, Roger to Texas, one to a Ph.D. program in Kansas, and the couple to Nebraska, game nights ended until I found other groups. I discovered that one of my neighbors is an avid board gamer, and we often end up at the same game nights. I have lost Scrabble badly to a retired English professor who perfected her strategy with her daughters. I won an annual Mexican Train tournament the same night I learned the game but lost badly the following year. After playing Settlers of Catan several times, I finally won a game, and I seem to win about once in every six tries. I played Ticket to Ride with a 
Meetup group at a pub and made a fatal mistake in keeping track of my routes. I expect to move from Springfield in the next one to three years, and many of my memories will be associated with games. Certainly not all of my memories will be of games since I have spent more time living in my current house than any other residence I have had as an adult. I have been here long enough that I have trouble remembering which year I had surgery on my foot, or which years I rode in the Capital City Century, or when I repainted the shutters. I hope I make as many pleasant memories of both games and of life in general in the next place I live. 


\section{APPENDIX D: UNIT 3 ASSIGNMENT SHEET}

Appendix D begins on the next page in order to preserve the formatting of the original document. 


\section{Unit \#3: Game Description/Premise \\ English 101, Sections 52 and 61 \\ Fall 2017}

\section{Learning Outcomes Addressed}

- Cultural and Ethical Impacts - Translingual and Cultural Studies Approaches to Thinking about Writing

- Uptake and Antecedent Knowledge - Documenting Knowing and Learning

\section{Deliverables}

- Rough draft of game description for peer review (homework assignment -10 points)

- Revised game description (50 points)

- Letter of endorsement, recommendation, or revision (50 points)

- Reflection on process and learning (100 points)

- Homework assignments (vary but usually 10 points each)

\section{Description}

New games of all types are constantly being developed and tested, and some eventually make it to the production stage and to your local store or to an online shop. You can find many such proposed games on Kickstarter, where you are given the opportunity to invest in a future game with promised rewards. Imagine that you are such a developer. You have explored your own experiences with games, and you have conducted some research about games. Now you have the opportunity to work on your own creation, beginning with a description of a potential game. Creating an entirely new game is beyond the scope of this class in terms of both time and skills, but a description of a game requires the same skills of genre study and of writing that you have been practicing since the beginning of the semester.

The description or premise of a game may be "inspired" by personal experiences, your interests, politics/history, literature, etc. You may also choose the media for your description, and it does not need to match the mode of the game you imagine. For example, you might develop a description for a video game but choose to use a Word document to present the game. No matter what medium you choose, it must include graphics or sound. You might create an audio description, for example, but then it should include some sound effects, the equivalent of graphics in a Word document.

\section{Letter of Endorsement, Introduction, or Revisions}

In addition to your game description, I will also ask you to choose a description written by a classmate and to write a letter of endorsement or suggested revisions. Or you may choose to write a letter introducing your own description as a potential game. If you choose the first option, you will need to think of how to present yourself as a 
knowledgeable third party - will you write as a fellow game developer, an educator, a retailer, or from some other perspective? The main goal for this part of the project is to practice your genre study skills on another genre and to try it out for yourself..

\section{Reflection}

As with previous projects, I am also providing several questions (below) for you to consider in a reflection on your experiences and on what you learned during this unit.

- What influenced you in developing your description?

- What are some of the different possibilities you considered in both the type of game (board, video, card, etc.) and the topic?

- How did your previous projects - your games narrative and your research project help you with this project?

- How does your game description relate to culture or to ethnicity? Does it appeal to a wide range of people or narrow? Who are those people? Neither option is preferred for this assignment - I just want you to be aware of the implications of your choices.

- What problems did you face in this unit?

- What additional resources did you use beyond your research sources and assigned readings?

- How satisfied were you with your projects for this unit?

- How well do you think you met the expectations of your audience?

This document should be formatted as an essay, with a header appropriate for an academic paper. Five points will be deducted from reflections that do not include such a header. It should also be at least 800-1,000 words. Please answer all of the questions above completely and thoughtfully - don't short-change the later questions once you reach 800 words. I recommend that you brainstorm for details to use for each question before you begin writing, and consider responding to the last questions first (it helps me if you keep the answers in order in your final draft, but you don't need to do this). 


\section{APPENDIX E: EXAMPLE OF UNIT 3}

Appendix E begins on the next page in order to preserve the formatting of the original document. 


\section{Rivers and Lakes:}

\section{A Road Trip Game}

Imagine an adventure crossing North America using as many lakes and rivers as possible. While you won't make it without crossing a substantial amount of dry land, especially across the Great Plains, what if you could take a route that would hit as many bodies of water as possible? You don't have to enjoy water sports to enjoy this game, of course, since you only have to imagine being on the water.

In this game, you will choose your boat, your vehicle, and one or more traveling companions.

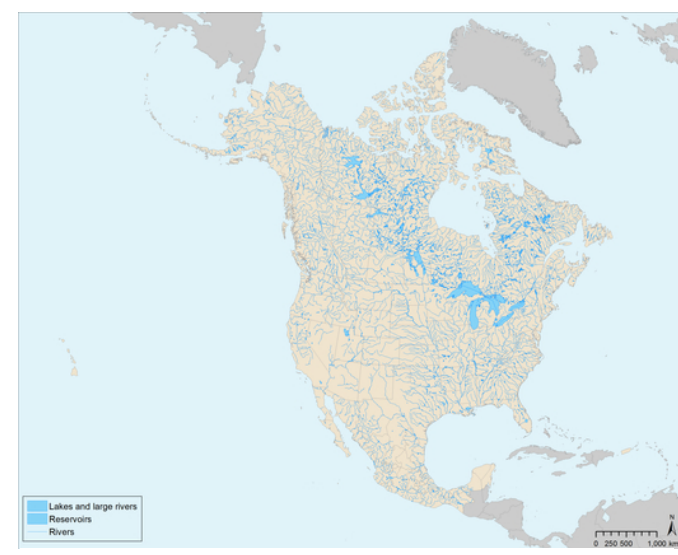

Image from the

Commission for Environmental

Cooperation Every choice you make, however, will determine the resources you need to complete your adventure. A large motorboat will require much more fuel to haul between lakes and rivers as well as fuel to run the boat, but you may finish faster than your competitors. A kayak will take far less of your resources but will be slower on the water. Your travel companions will also have an impact on your success. An adult companion will help with your travel and boating while a

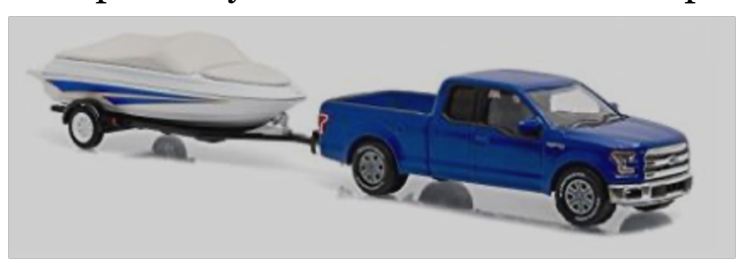

Ford Truck and Boat from Greenlight Toys child or a pet will take more resources and offer much less help, but you will gain in other ways if you choose to bring them along. Each player will also have an extra driver to meet them after they have navigated a waterway, but this will be a given - the driver will not affect your resources. It's just the game's way of accounting for your access to a vehicle when you need it.

Your route must take you from one coast to the other rather than from north to south, or vice versa. Sure, you could spend most of the time on the Mississippi, but where the challenge of getting from one body of water to another be? You can always go north or south on a body of water if it helps you in your journey, but it may take more time. The amount of time you take will be determined by both distance on the water and the number of longitude lines you cross. If you spend more than one turn without crossing one of the vertical lines indicated on the board, it will represent more time, but you can only move a certain distance per turn based on your resources. Sometimes you may even need to stop to work for awhile before you can move on.

Why take this odyssey? That would be like asking why take any epic trip. Think of this as the ultimate road trip. Perhaps you will become curious enough to visit some of the places from the game board/map in person. Maybe you will learn about a lake or river you didn't know about. For the game, the number of lakes and rivers is limited for ease of use and to include only navigable bodies of water. The direction of flow is not noted on the board, but you will find enough clues to decide which direction to go. Remember than tributaries, like the Missouri River, tend to form a V shape when they flow into larger rivers like the Mississippi. Lakes will be obvious from their shape, but you should pay attention to the rivers the flow into and out of them as well as the location of dams. You certainly don't want to make the mistake of getting too close to a dam in real life, but in this game, you don't have to worry about that - you'll just follow the designated boat ramp to exit the lake. 
On each turn, you will roll the dice to determine the number of cards you will select. The cards will then provide you with options for resources, challenges, and opportunities. The combination of your choice of boat and companions, calculated at the beginning of the game, will determine how you use these options. You can also change your boat and/or companions once during the game, but that will also come at a cost. Finally, you will use a chart on a corner of the board to determine the points you earn along the way. Keep in mind that the first person to reach the other side of the continent and launch their boat on the ocean will not necessarily be the winner.

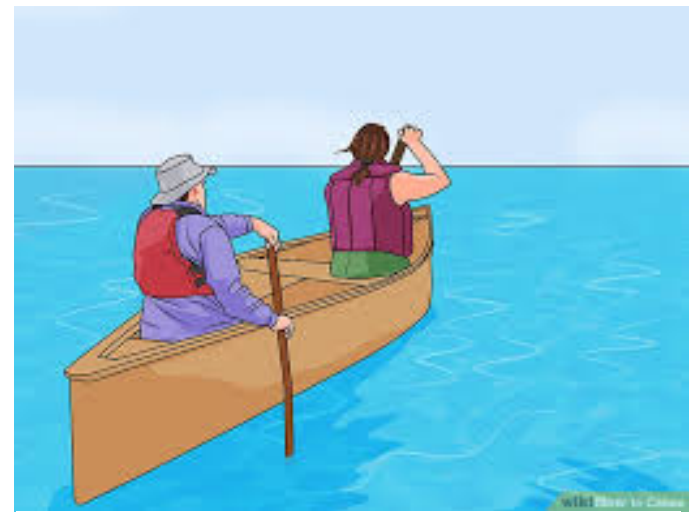

Image from WikiHow

Enjoy your boating adventure! 


\section{APPENDIX F: ASSIGNMENT SHEET FOR FINAL REFLECTION}

Appendix $\mathrm{F}$ begins on the next page in order to preserve the formatting of the original document. 


\author{
English 101, sections 52 and 61 \\ Fall 2017 \\ Unit \#4 Multimodal Reflection \\ Revised assignment sheet — 4 December 2017
}

\title{
Description and procedures
}

This unit encompassed the entire semester as you collected materials to present in a multimedia format with additional reflective text to be submitted during finals week. The purpose of this assignment is for you to develop self-awareness of your composing and revising practices, particularly those you thought were the most successful during this semester. The items you collected will have include screen captures, documents or fragments of files, images, homework assignments, reading responses, and possibly audio recordings. You should have saved these to a folder folder in Dropbox in Reggienet, but if you are missing items, you may use any of your work throughout the semester. You should also consider using notes that you took for class so that you can look back on what you were thinking as you worked on a particular project.

\section{All students need to answer the following questions:}

How has your writing process evolved during the semester? How do you envision your approach to writing projects in the future, whether for other classes or in your career? Don't assume you won't write - many nurses and engineers, for example, are surprised by the amount of writing they do in their careers.

How did you approach projects in which you had a choice of media or format? What media did you use when you had the opportunity to use someone other than paper and ink or its digital representation (word processing document)?

In addition to the above questions, also choose five of the following questions to answer:

- What resources did I use through the semester, and which ones were the most effective?

- How did I make sure I understood the expectations for each deliverable?

- What strategies and technologies allowed me to communicate my ideas most effectively?

- What procedures and processes (or steps) helped me to complete assignments successfully?

- How did I organize my ideas about both genre and topic as well as my time for each project?

- How did I make sure I could relate to the subject of the different projects? How did I keep myself engaged and motivated to do my best work? 
- What purposes did I have in mind when working on my projects?

- How did I use antecedent (prior) knowledge of both genres and my topics? How was this knowledge helpful, and how did it interfere?

\section{Format}

You will choose the items that best represent your process/progress throughout the semester and place them into a digital file best suited for their collection. PowerPoint or Google Slides are good options, but creating your reflection in a Word document and pasting in your images in the appropriate places is also a legitimate way to complete this project. I recommend that you create the text for your reflection in a Word file first anyway since the text in a PowerPoint or other presentation will not automatically flow from slide to slide.

Remember that your text should put your items into a context, not merely explain each one in turn. Think of your items as illustrating your text instead of your text describing the items. There are two basic approaches to this project. One way would be to work from the text first and then add the appropriate images. The other method would be to select images that relate to the questions you choose to write about and then add the text. In reality, your work process will probably fall someplace between these two possibilities.

If you choose to use presentation software, you do not need to put each item on a separate slide as long as all of the images clearly visible. Make sure all text and images can be viewed with the slide displayed full-size on a 13" to 15" screen. You can also use Prezi in order to create a document that is more like an infographic with a path that zooms into each section in turn. The word count does not change regardless of the medium. Another way to use presentation software is to create a screencast to include both verbal explanations and images - a presentation that can be viewed in your absence. Again, though, make sure your script contains the minimum number of words and submit this along with the screencast.

Please remember to illustrate your answers with examples from your work from throughout the semester. You should provide at least five visual examples but no more than twenty. You may use more than one per question.

Also, please include your response to the assignment to provide an image that represents what writing means for you, but do not include this in the 5-20 items above. Also include the text, which may make a good introduction or conclusion for this project.

Final due date and time: Monday, December 11 by noon 


\section{APPENDIX G: COMPREHENSIVE LIST OF CODES}

Academics and writing skills

Accessing information

accomplishment

actuality

Aesthetic

Agency

Agency - lack of

Ambiguous wording

antecedent knowledge

Anxiety

anxious

Appreciation for writing

Appreciation of class or activity

Aspiration

Assertion without support

assignment

Assignment sheet - graphic

assistance

Assistance

Assistance $\backslash$ From parent

attack

audience

audience - lack of concern

Audience appeal

Audience awareness

Audience benefit

Audience concern

audience expectations

Audience interest

Authenticity

Background for game

Background of poster

Became more outgoing

Beginnings - Focus on

beneficial

benefit

Benefit of English 101

Boredom

Brainstorming to revise

captured feelings

Career

Career $\backslash$ Career and writing skills

Carelessness

casual language

Casual language in research

Cause-Effect

Certainty

Changes in writing

CHAT
CHAT concepts

CHAT map

choice

Choice - passion

choice of media

Choices

Choices and reflection

Choices not made

claim

Class activity

Class assignment - little effort

Class notes - Graphic

Classmates

Color

combat

Communication

Communication $\backslash$ Through images

Compelled

computer screen

Conclusion

Confidence

confusing statement

Confusion

Connection to assignment

Contradiction

Contradictory wording

creativity

creativity $\backslash$ Creative

creativity $\backslash$ Creative style

creativity $\backslash$ originality

creativity $\backslash$ unique

credibility

Culture

curiosity

Definition

Description

Design

Design and choice

Detail

Details

Development

Difference - explanation

different

different angles

Difficulty

Difficulty $\backslash$ Challenge

Difficulty $\backslash$ Difficulty starting

Digital

Discouragement 


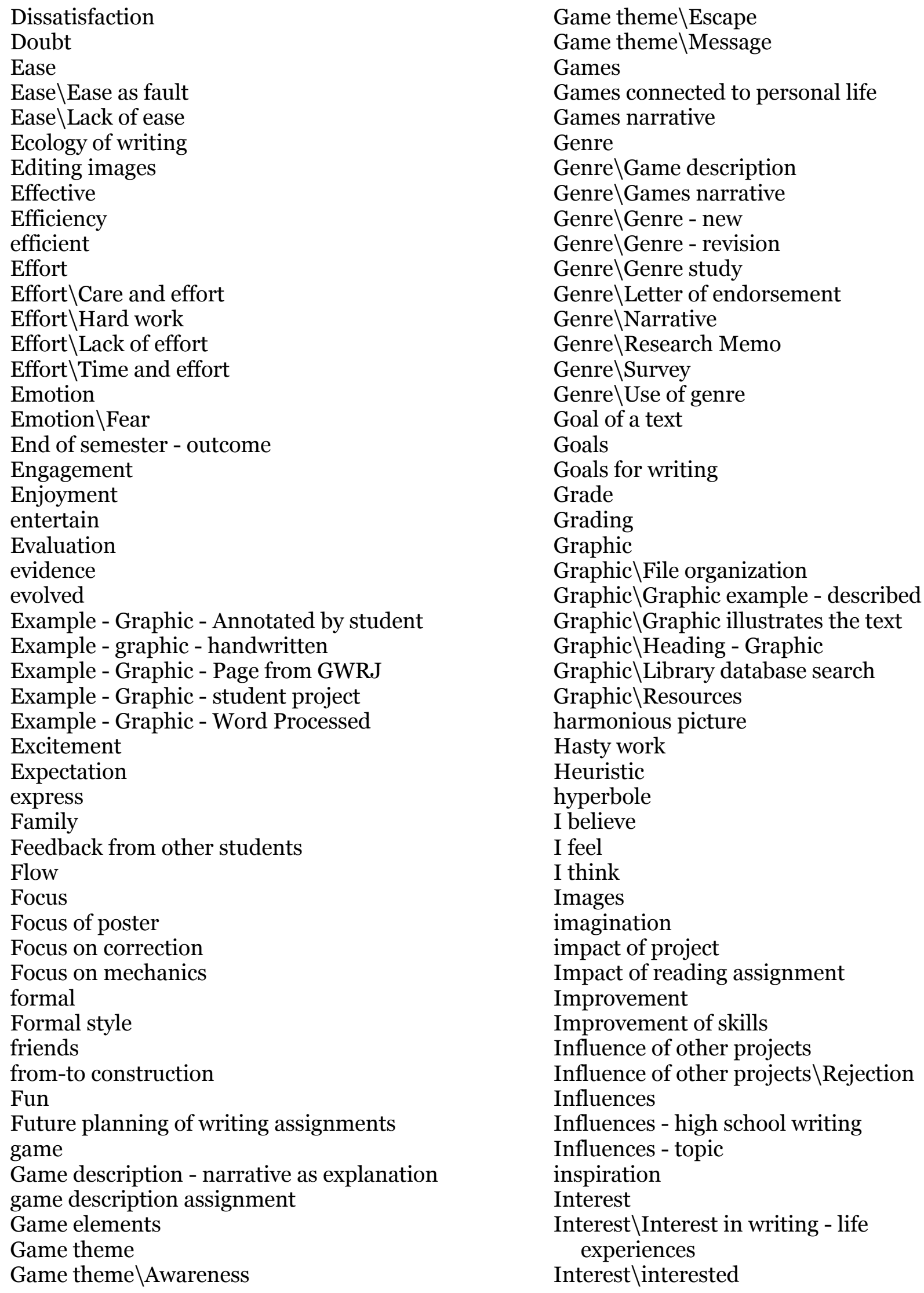


Interest $\backslash$ interesting

Interest $\backslash$ Lack of interest

Introduction

Introvert

Investment

Inviting

justification

Kinesthetic experience

Language - qualifiers

Language in the world

Layout

Learning

Learning games

length

Library home page - graphic

Living space

Love of writing

Making connections

meaningful

media

Memory

mind maps

misunderstanding

Misunderstanding of course content

motivation

motivation $\backslash$ Lack of

Multimodal

Multimodal $\backslash$ Textual

Multimodal $\backslash$ Visual

Multimodal project

Multimodal project $\backslash$ Computer Game Cover

Multimodal project $\backslash$ Multimodal project explanation

Multimodal project $\backslash$ Multimodal project graphic

Multimodal project $\backslash$ Poster

Multimodal project - process

Multimodal projects - information

Multimodal projects - other classes

Multimodal projects - previous experience

Multimodal projects - resistance

Music and writing compared

Mystery

Narrative

navigation

Nervous

new appreciation for games

New work

objective

open mind

Opportunity options

Organization

Outline

Overcoming

Overcoming procrastination

Overview

passion

Passive voice

Peer review

perfect

personal experiences

Personal experiences - lack

Personal Interest

Perspective

Persuasion - requirements

physicality

Place

poetry

Practice

Previous assignments

Previous experiences

Pride

Primary research

Prior experience

Prior knowledge

Problem as idea

problems

Problems - personal life

Problems with writing

Problems with writing $\backslash$ Choosing topic

Problems with writing $\backslash$ Construction (game creation)

Problems with writing $\backslash$ Word choice

Process

Process $\backslash$ Brainstorming

Process $\backslash$ Completion

Process $\backslash$ Drafts

Process $\backslash$ Improvement of process

Process $\backslash$ Lack of development

Process $\backslash$ Materials

Process $\backslash$ Outline

Process $\backslash$ Planning

Process $\backslash$ Resources

Process $\backslash$ Resources $\backslash$ Examples

Process $\backslash$ Resources $\backslash$ Grassroots Writing Research Journal

Process $\backslash$ Resources $\backslash$ Library

Process $\backslash$ Resources $\backslash$ Software

Process $\backslash$ Revision for visual appeal

Process $\backslash$ Time

Process $\backslash$ Work process 


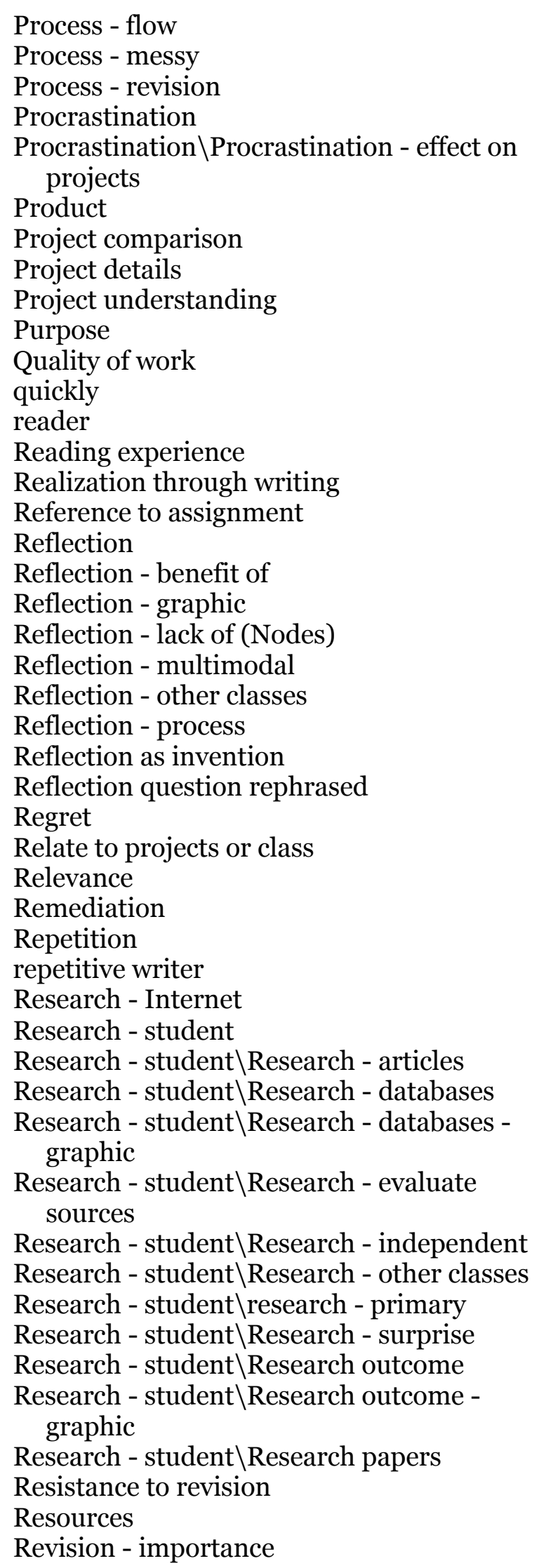

Revision as grammar correction rhetorical choices

Rough drafts

Rubric

rubrics

Satisfaction

Seeking help

Self help

Self-deprecating

Self-development

Self-doubt

Self-evaluation

Self-knowledge

Sentence breaks off

Shift - subjunctive to past tense

significance of experiences

Simplicity

sincere

Solution

Starting multimodal project

starting to think

Starting to write

state of mind

story

strategy

Strategy

Structure to writing

Struggle

Student explanation voice

Student reporting voice

Subjunctive mood

Subj-Verb Agr. Error

Success

Success - personal life

Success - progress to

Suggests writing from template

thinking

Thinking and writing

Thinking and writing $\backslash$ Thoughts IN writing

thinking process

Time

Time management - improvement

Time management - poor

Title page - graphic

Title same as the assignment

Topic

Topic $\backslash$ Commitment

Topic - importance of prior knowledge

Topic - influence of career

Topic - interest

Topic - many choices 
Transfer

Transformation

Transition

Transmedia

treasured

Uncertainty

Unclear text

Use of genres - future

Use of graphics - reasons

Use of prompt

Use of technology

vague

Value

Vintage game

Visualize

Voice

Works of others

write

writing

writing $\backslash$ Business

writing \Difficulty

writing \Everyday

writing $\backslash$ Exciting

writing $\backslash$ Importance of writing

writing $\backslash$ Improvement

writing $\backslash$ Purpose

writing $\backslash$ Study of writing

writing $\backslash$ Terrifying

Writing - non-academic

Writing - other classes

Writing about game as if it was developed

Writing and authenticity

Writing and frustration

Writing and life

Writing and place

Writing as an art

Writing as communication

Writing as unpredictable - Graphic and caption

Writing compared to music

Writing compared to object

Writing Image

Writing Image $\backslash$ Burning Office

Writing Image $\backslash$ Dog Eyeing Treat

Writing Image $\backslash$ Dog Tearing Up Box

Writing Image $\backslash$ Girl Outside Writing

Writing Image $\backslash$ Girl Wailing

Writing Image $\backslash$ Girl Writing

Writing Image $\backslash$ Light Bulbs

Writing Image $\backslash$ No Image
Writing Image $\backslash$ Person on Mountaintop

Writing Image $\backslash$ Piano

Writing Image $\backslash$ Roller Coaster

Writing Image $\backslash$ Sponge Bob

Writing Image $\backslash$ Text - Express Yourself

Writing Image $\backslash$ Thought Bubble

Writing Image - Description

Writing Image -

Description $\backslash$ Communication

Writing Image - Description $\backslash$ Creativity

Writing Image - Description $\backslash$ Difficult

Writing Image - Description $\backslash$ Difficulty Getting Started

Writing Image - Description $\backslash$ Escape

Writing Image - Description $\backslash$ Exciting

Writing Image - Description $\backslash$ Frustration

Writing Image - Description \Imagination

Writing Image - Description \Light Bulb Moments

Writing Image - Description $\backslash$ Love of Writing

Writing Image - Description $\backslash$ Messy Process

Writing Image - Description $\backslash$ SelfConfidence

Writing Image - Description $\backslash$ SelfExpression

Writing Image - Description $\backslash$ Stress Relief

Writing Image - Description $\backslash$ Success

Writing Image - Description $\backslash$ Terrifying

Writing Image - Description $\backslash$ Thoughts and Emotion

Writing Image - Description $\backslash$ Thril

Writing Image - Description $\backslash$ True Self

Writing Image - Description $\backslash$ Willingness

Writing Image - Description $\backslash$ Words

Compared to Musical Notes

Writing Image - Description $\backslash$ Writing as

Interesting

writing process

Writing prompts

Writing skills

Writing skills for future

Writing strength

Writing style

Writing style $\backslash$ Change of writing style

Writing style $\backslash$ Choice of writing style

Writing style $\backslash$ Development of Writing Style

Writing style - improvement

Writing to benefit people

Writing weaknes 


\section{APPENDIX H: IMAGES FROM ORGANIZING THE CODES}

In this appendix, I include images that represent the connections I made between codes as I began my analysis. These connections then drove that analysis as I examined these connections through the texts at which these codes were tagged. Although I often gathered several codes under a broader category, the scope of this project did not allow me to account for all of the codes I developed while tagging the reflective texts in NVivo. As I formatted this appendix, I attempted to display the codes I analyzed in the most depth on the earlier pages. Near the end of this appendix, I also list all of the images students included in their multimodal reflections since my coding of these images was not as descriptive as I hoped. Although the images did not seem to contribute as much as I hoped to the reflections, this does not invalidate the use of design when students added these images to their texts. 


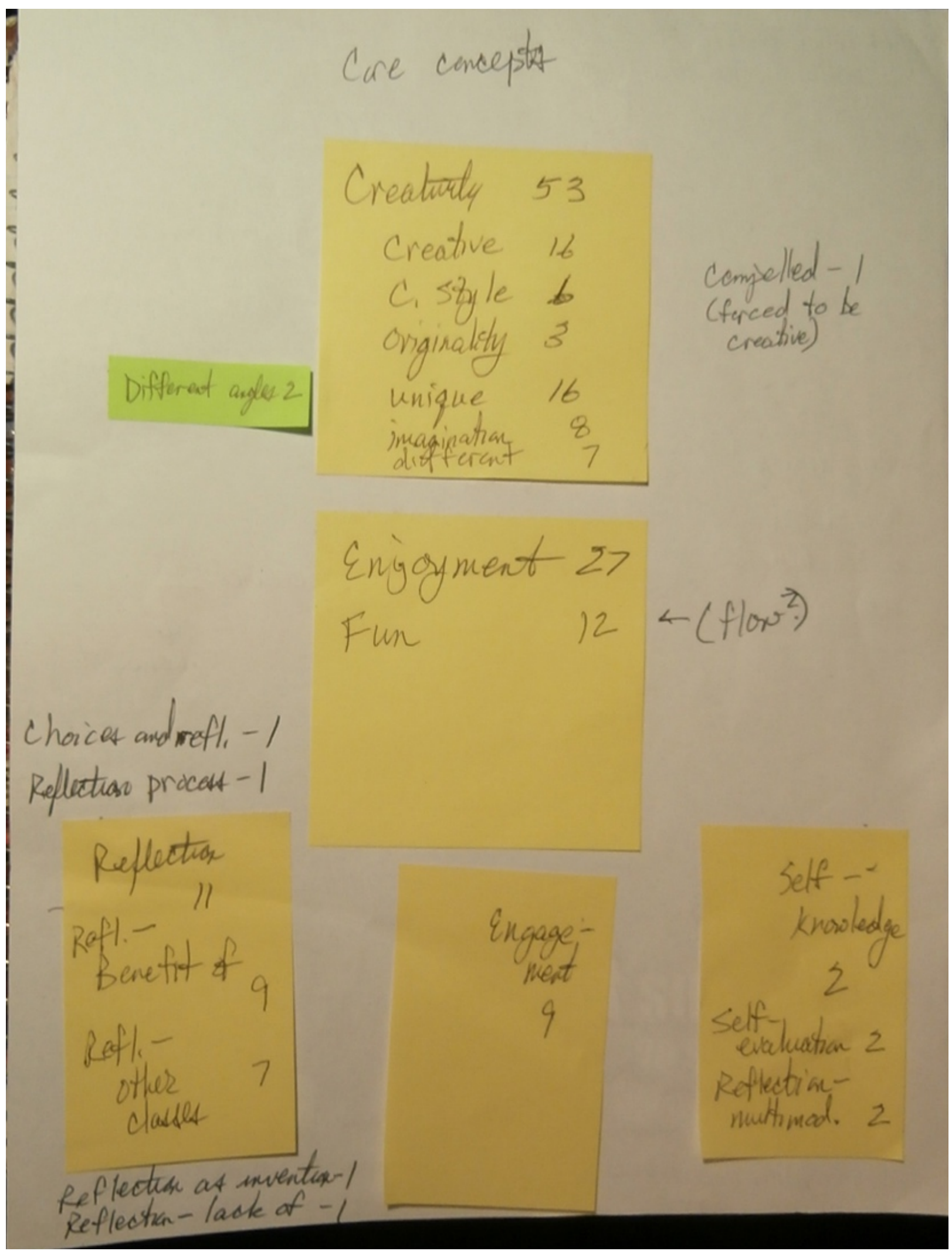




\section{Andience}

$$
\begin{aligned}
& \text { Andunce } 34 \text { wewe } \\
& \text { (ofter slemt usincere) } \\
& \text { Audience appeal } 61 \\
& \text { interest } 20 \\
& \text { Entertain berefet } 8 \\
& 934 \text { lack of corcer }
\end{aligned}
$$

Inviting

5

(Andiencer)

Reader - I

writing to benestit people - 1

efficient - I
Andience expectations

5

Entertain

9

culcosty - 1
(of viewer) credibility 4

friends - ! visnalize - I

(audiacecan) 


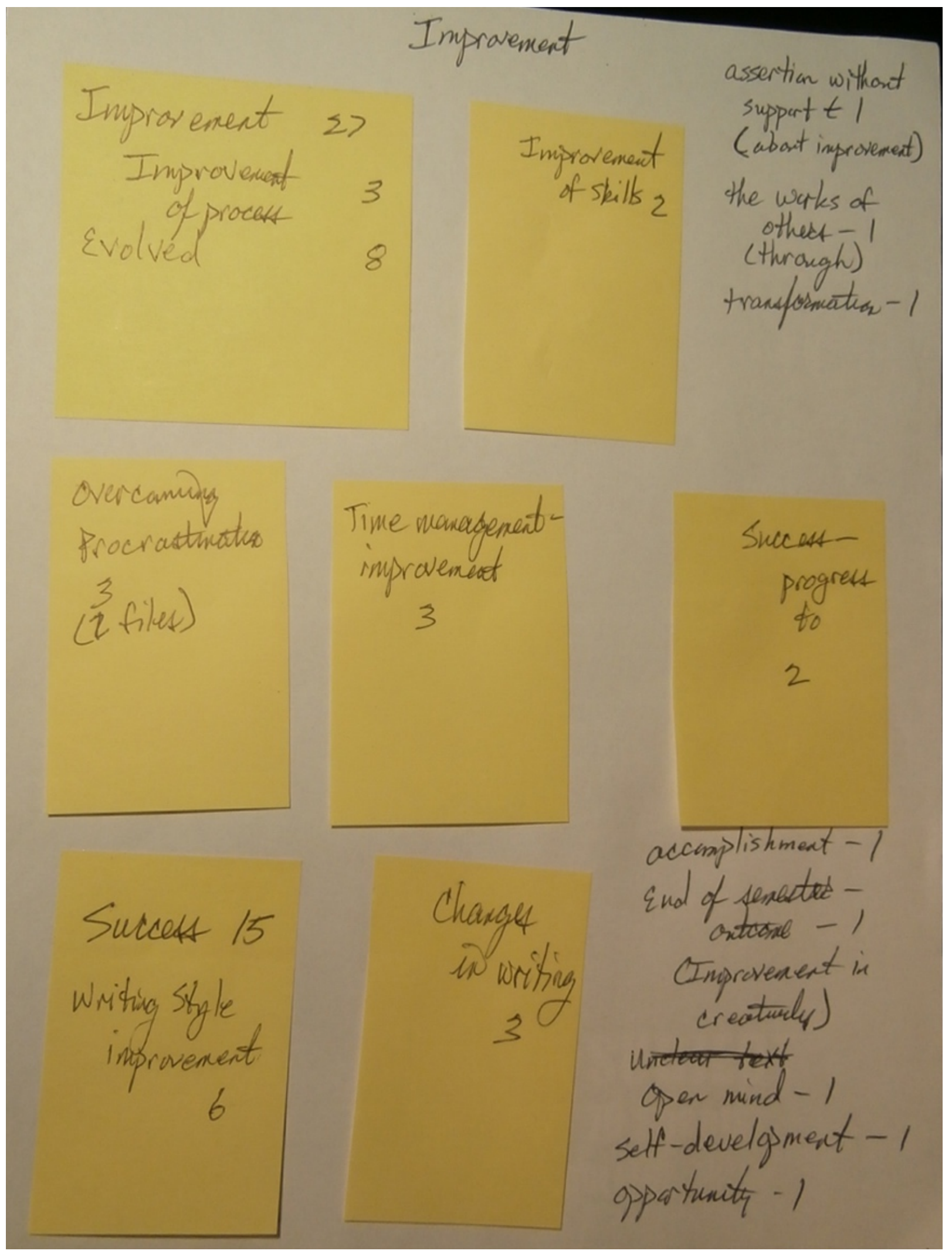


Codes associated w/ difficulty, challenges

Challenge 48

Difficulty 13

Difficulty

starting

confusion

3
8
8
Problems with

Writing 12

choosing topic 21

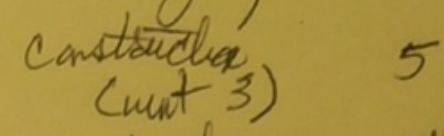

ward choice 4

writing -

difficulty

Uncertainty

Lack of

14

11

persona experience

2

Project $T^{\text {? }}$

understands

12

problems !

writing weakness -1

189 


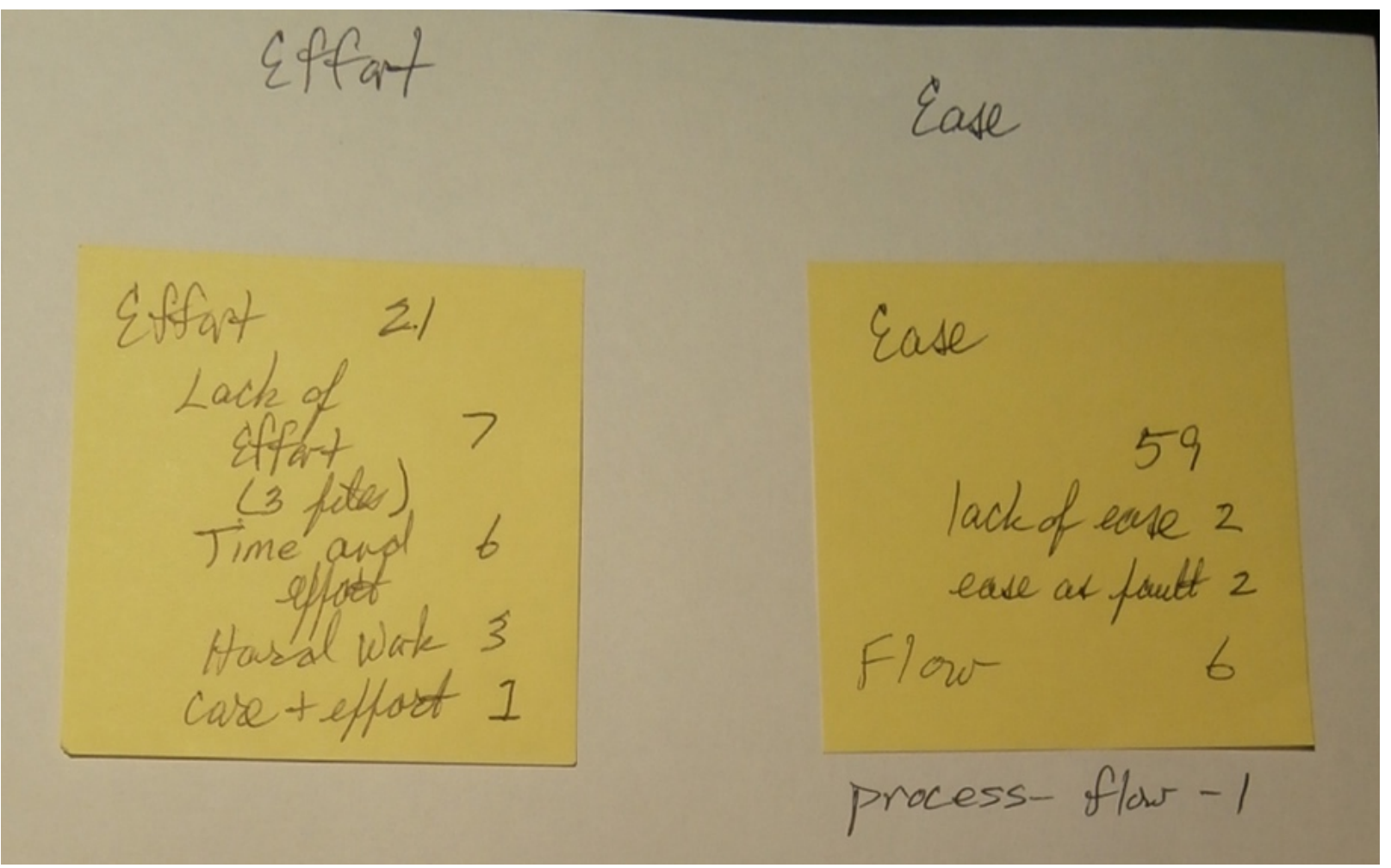


Procests of

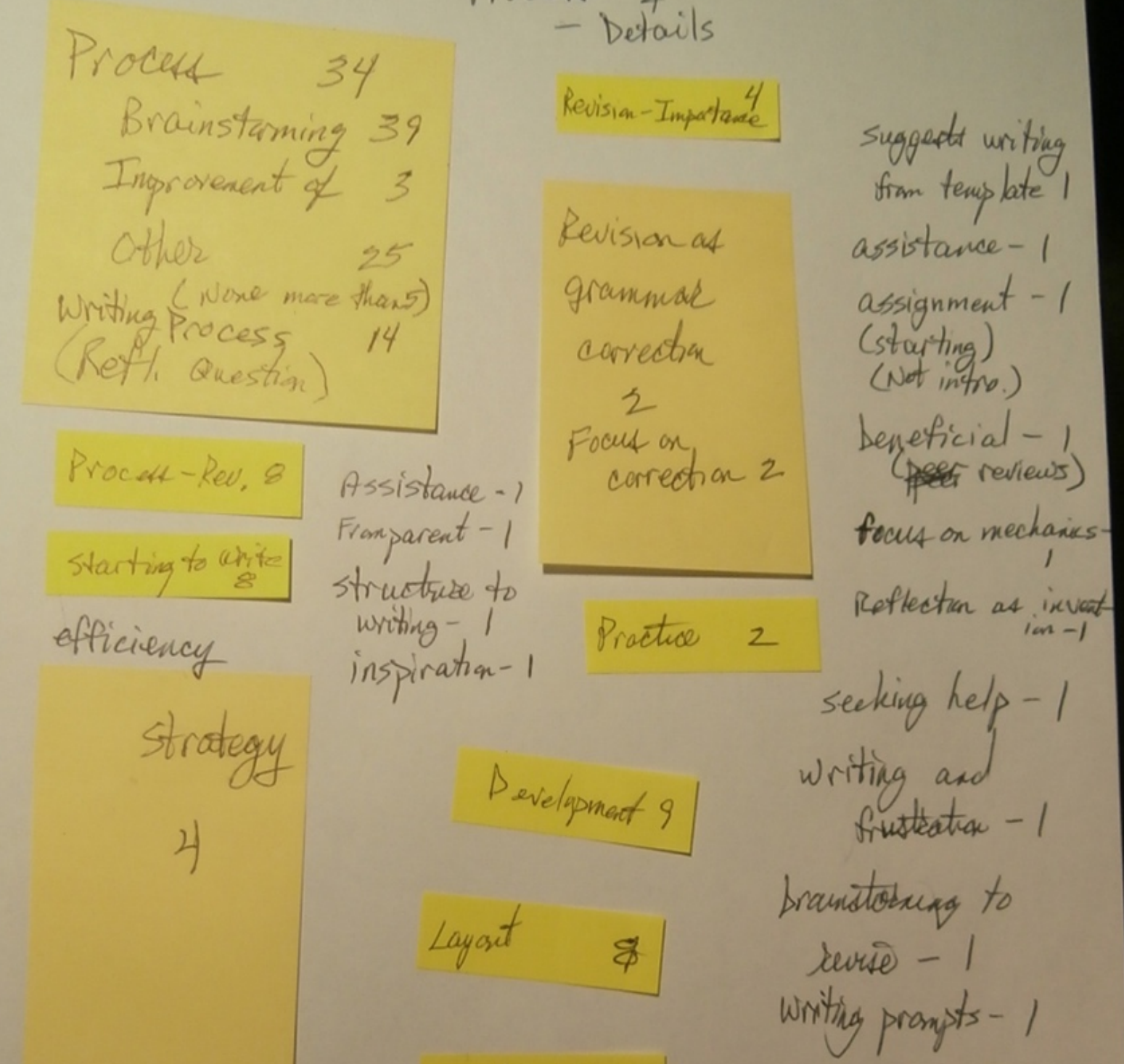

autline 2

beginniags-forus on 1

Living space - 1 same

strategy -1 cause-effect-1 Meuristic-1

pletarical chaices-1 attack-1

Rhetarical choices-1 (the proect)

191 
Topic

Topic 43

Influencet 23

Interest 29

Influenet 13

Topic-Impartance of aradedge

Relate to prijects or clast - 1

Relevance -

problem as idea - 1

treasued - 1

(choosing favaite gane)

certainty - I

Reflection as invention-1

problent - 1

topic- influence of career - 1
Gane thene (unit 3)

awaderess - 5 (1 fik)

message -1

(same fite as abarice)

Escape - 1

192 


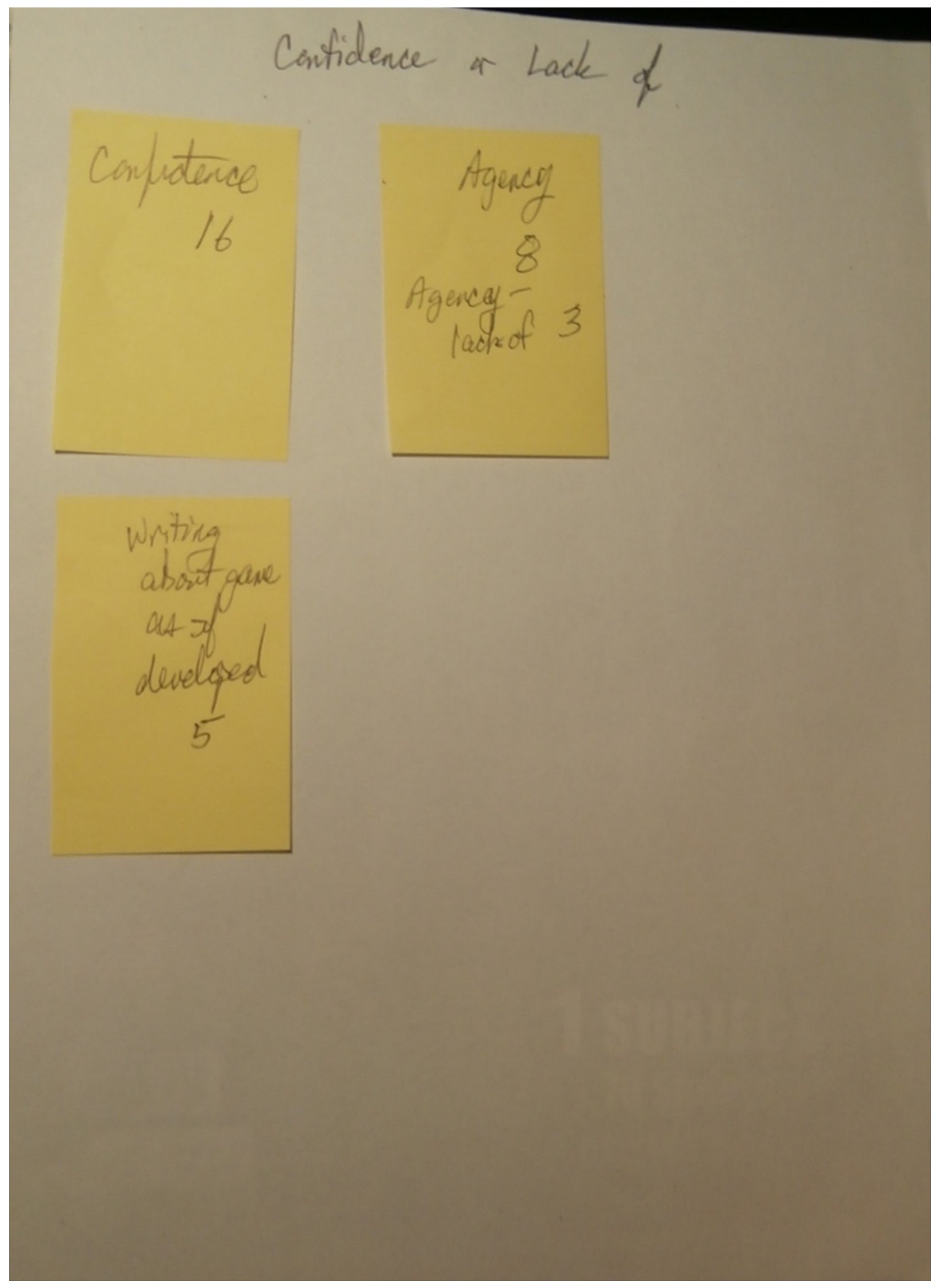




$$
\begin{aligned}
& \text { casual languge - I References to muttenodal projects } \\
& \text { muttimudal proj-info- poedy-1 attack - } 1 \\
& \text { Muttinodal Projed } \\
& 28
\end{aligned}
$$

Explanatian 22

Graphic

Poster

6

22

* Comp. Gane

caver I

Backegrasusl of m.m.prgi-resistance-1

poster Multimodal 2
4 (1 file $)$ Visual

Background far Textial I

gane 4

$$
\text { (ifile) }
$$

Inspiration - 1

option I

stacteng

multimodal project

3

P

Editingimaget 1

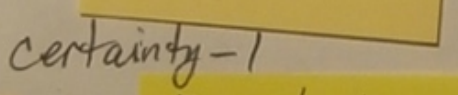

Remediation II

M.M. Proj. - Frocess

Transmedia 5

Digital 4

use

project adetails-1 (frax co-warkers)
Focus of poster 2 colar 2 Inages 
Misteps

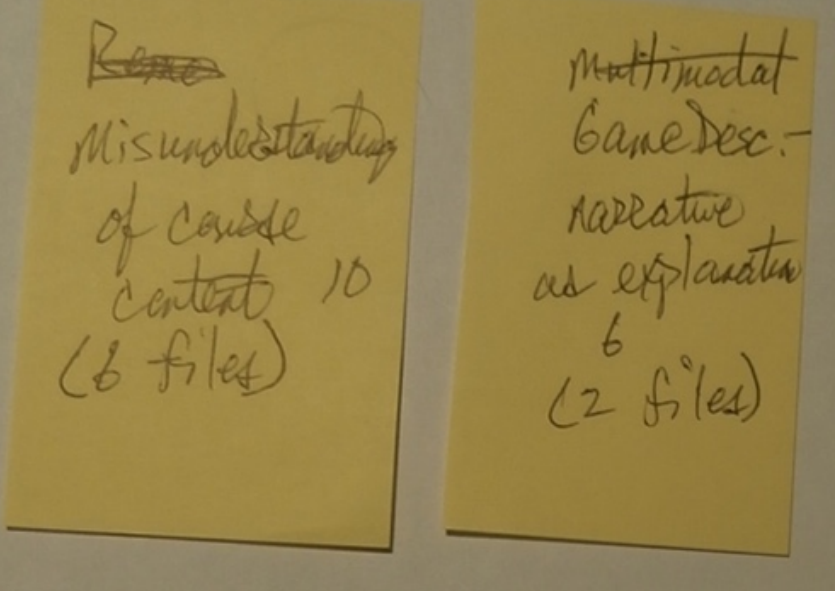

misunderstanding I

References to Research

Srimary Redeareh to Research-Studleat 3 Articte 13

- Datatana 12

- arteone 4 - evajers 3 - scride 2 Sounclaty 2
- Prinaly.
Casual language in reseorch I accessing informatios - 1

inspiration - 1

(frax searching axline) research-internet - 1

195 
Personal experiences and interest

Personal lack 2

experiences 37

Family

experiences

Prior knowledge

Porqueseriense 6 kinesthetic New appreciation

for games -1 Person Interest 14

13

3 topic-inthene Interest

Int in W. -Life experiences 9

Interesting 3

Design - 1

Lack of inter 1

Games 27

Problems -

"Connected to

personal

choice -

personal left personal

16 pasties

3

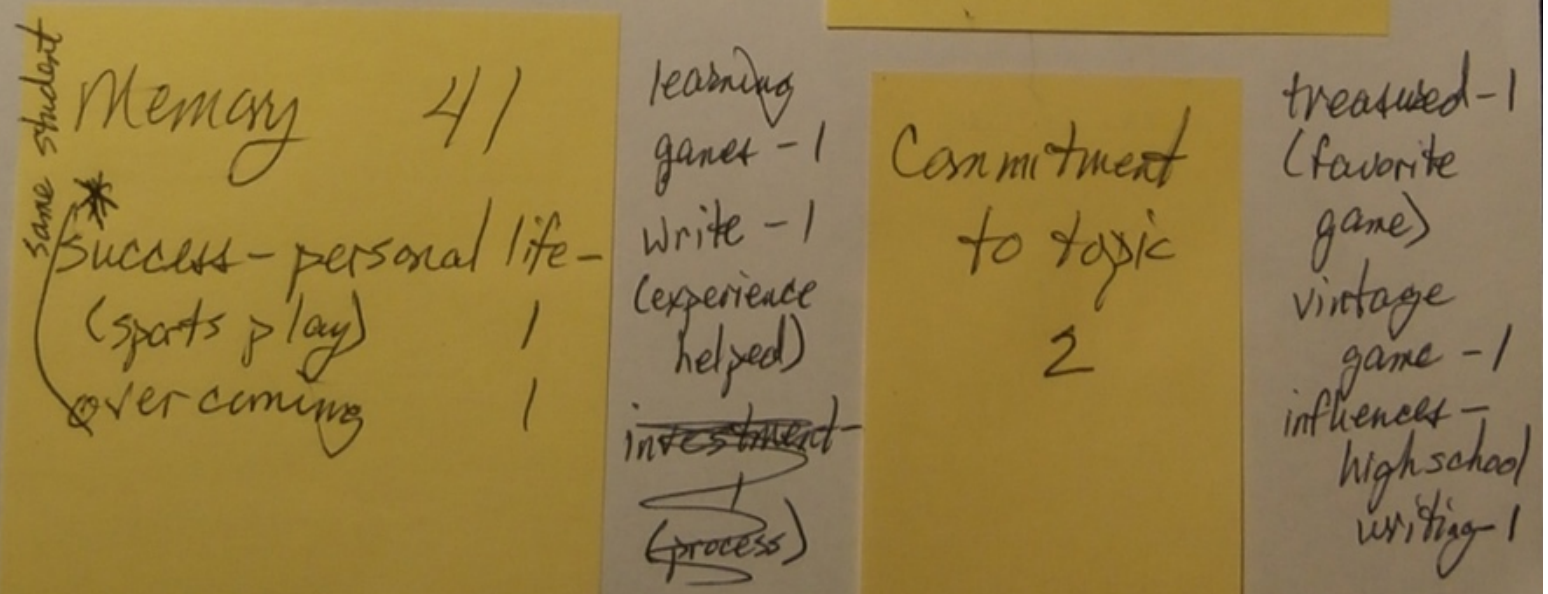

196 
Graphid is Reflectios (sequesed)

Graplic

$$
2
$$

Graphic illustrates text 1/5 Graphic example described 12 Heading-graphic

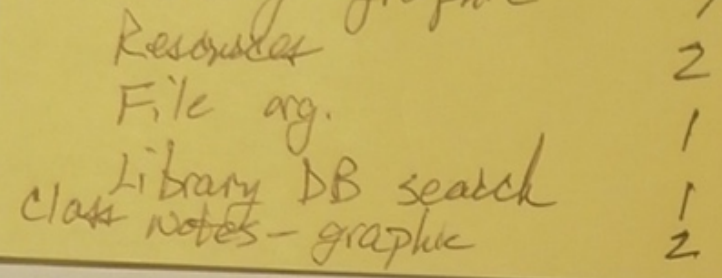

$\begin{array}{cl}\text { Resorsed } & 2 \\ \text { File arg. } & 1 \\ \text { clast Library DB search - graphe } & 1 \\ 2\end{array}$

Title Pg-gr. 2

Research-datatuares graphic 3

Research-artcare 3 graphic

Assignenet

sheet-

Use of

troft

graphic graphics-

Example - Graftic -

Reasont

student Prgeot

19

Exanule-Graphic-
Handuratlax

Wrod-procased

Example-Graphic-

anototed by

student -

cresearch assignneed
Library ttane Page - 1

seraphic

Writing as unpredictable-

graphic + caption - I

Exangle - graphic - page from GWKJ-1

197 
Reledencas to Wrativa (vers)

Writhing 21 + communucation

Difficuth 14

Purpose 5

Insruement 4

Evergady 2 strudy

Impatace I

Buscived I

Froture

Planning

of witing

ansigntaros.

4

Appreciatia

for

witing

Acaderuids

and unting
skills

7

Writing

Naxcead. 2
Writica

stulls

for

future?

Whitiog and autertedy-

Writing strengtt-1

witing weakness-
Reseadch-

other

clavef 4

whiting

other

classet 3 cares 3

Caroer
and
withing
slills

20

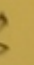

Writing Commumation Writing stells 3

Misio and

6

Effective 2

witing

writing + life 2

compared

images

Writing at ax

Lore of

3

usiting - 1

ant-1

(compared to

efficient-1

love of deg)

writing conpadel to

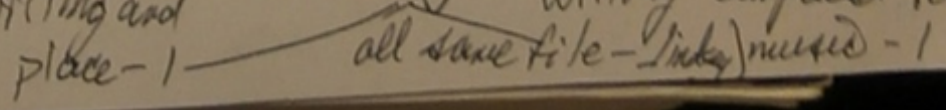

198 
Reflectar Question reiponser

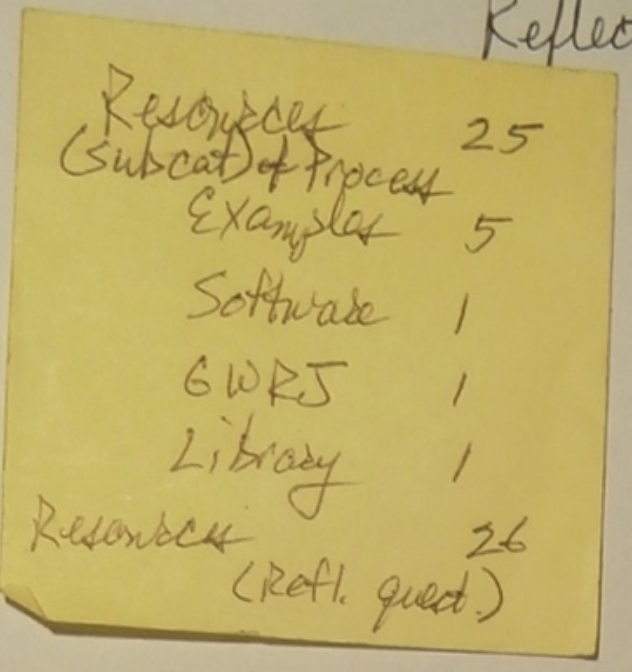

Sotusfactor 62

(commax)
(Refi Questuax) 8
Pride
Culture ${ }_{(\mathrm{CRA} T)^{8}}^{8}$

Influence of other prgects

35

(Reft. questiox) Rejectox ,

Prev. cossigss. 2
Purpose 16

(Refil quest.)

objective-1
Choices - vesice

caming (question ashed)

wp wet chose 85 treasured chices 85 optanchoice of Not made 32 gare) Choice ofinedia 25

Reflectian questian rephraned - 1 e chocerand soflestian

199 


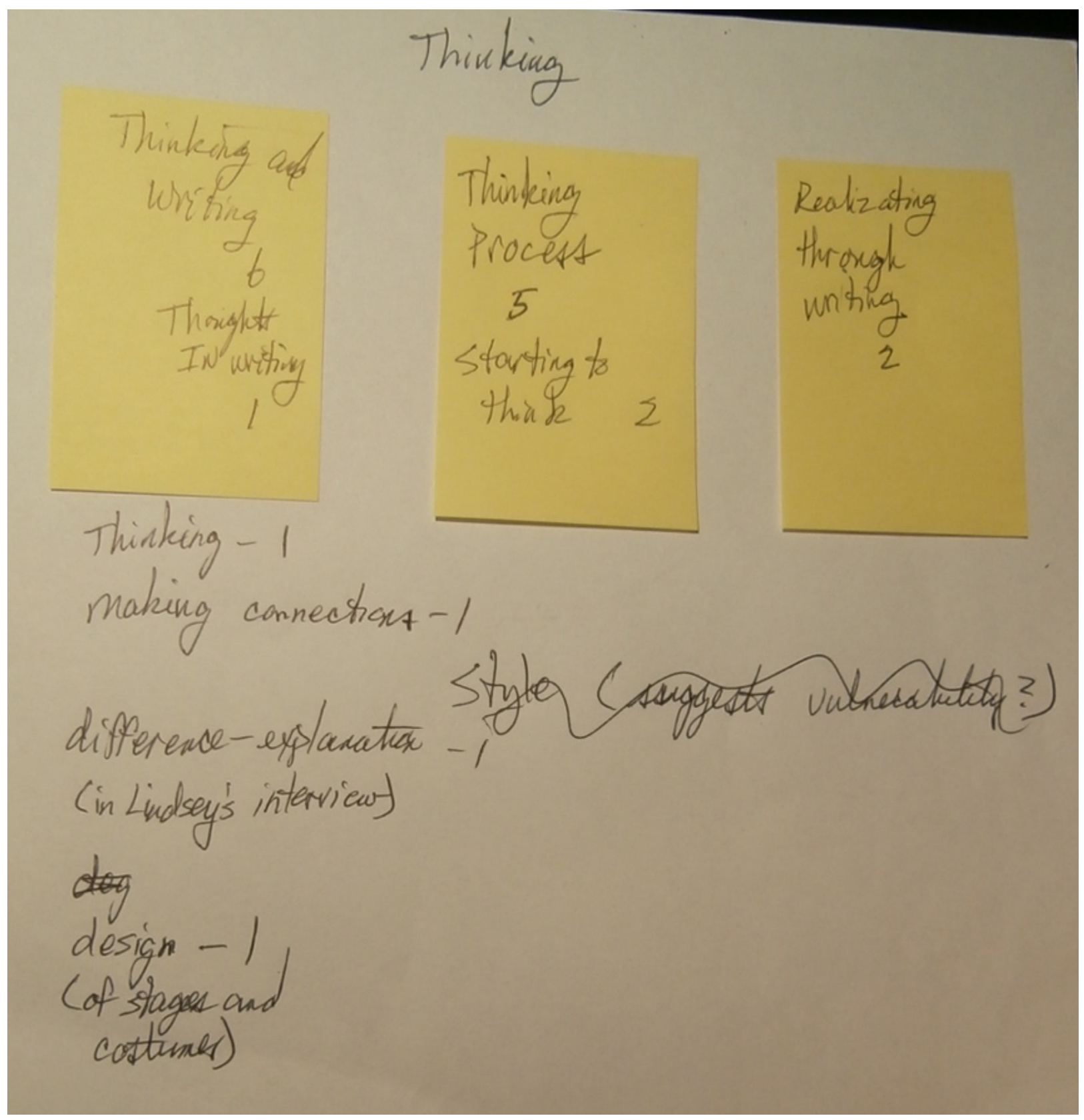




\section{Emotians}

Emotion Anvions

18 Fear 1

\section{.}

Meaningfyl

Boredon

Anviedy.

Assiration
Exitement

Avethentects

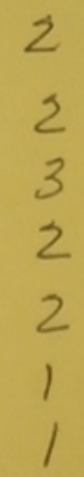

Regred

$$
\begin{aligned}
& \text { becane } \\
& \text { mure } \\
& \text { aitgoing } \\
& 3 \\
& \text { (i file) }
\end{aligned}
$$

\section{Faction \\ Discatis-}

9

\section{self-}

writing and frustrota - 1 deprecating cacolestrest -1
Selfdosst \&

donbt - 1

nervous - 1

sincere - I (unit 1) 
Codes associated w/ carrse content

CHAT

Tranded

Antecedent

Mrtecedent 6
Knowledge 3
Chat Mas
cHAt cancests 3

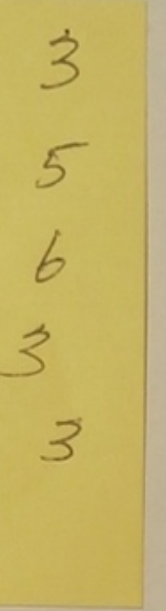

$\begin{array}{ll}\text { Gense } & 54 \\ -6 . \text { Etudy } & 18\end{array}$

mindmaps - 1

Individual genses 24 keft

usc of gerres-foture 2

Games 27

gane

Gane elements 3

(consele tgic)

202 
Embodiment Aspects of process and of products

quality of work

Petal $6 \mid$ IntroductionProduct $t$

Details 5

Transits 5

Length 2

conchusar - 1

Focus
9

organization

Evidence 3

12

Writing style

Der. of

change

Choice

Formal style 4

Description 4

Rough drafts 4

Time management- poor - 1

claim - 1

use of proust - 1

casual language - 1

(blog)

$2 \mathrm{U}_{3}$ 
Codes associated w/ writing style in reflector attack (ward use) - I

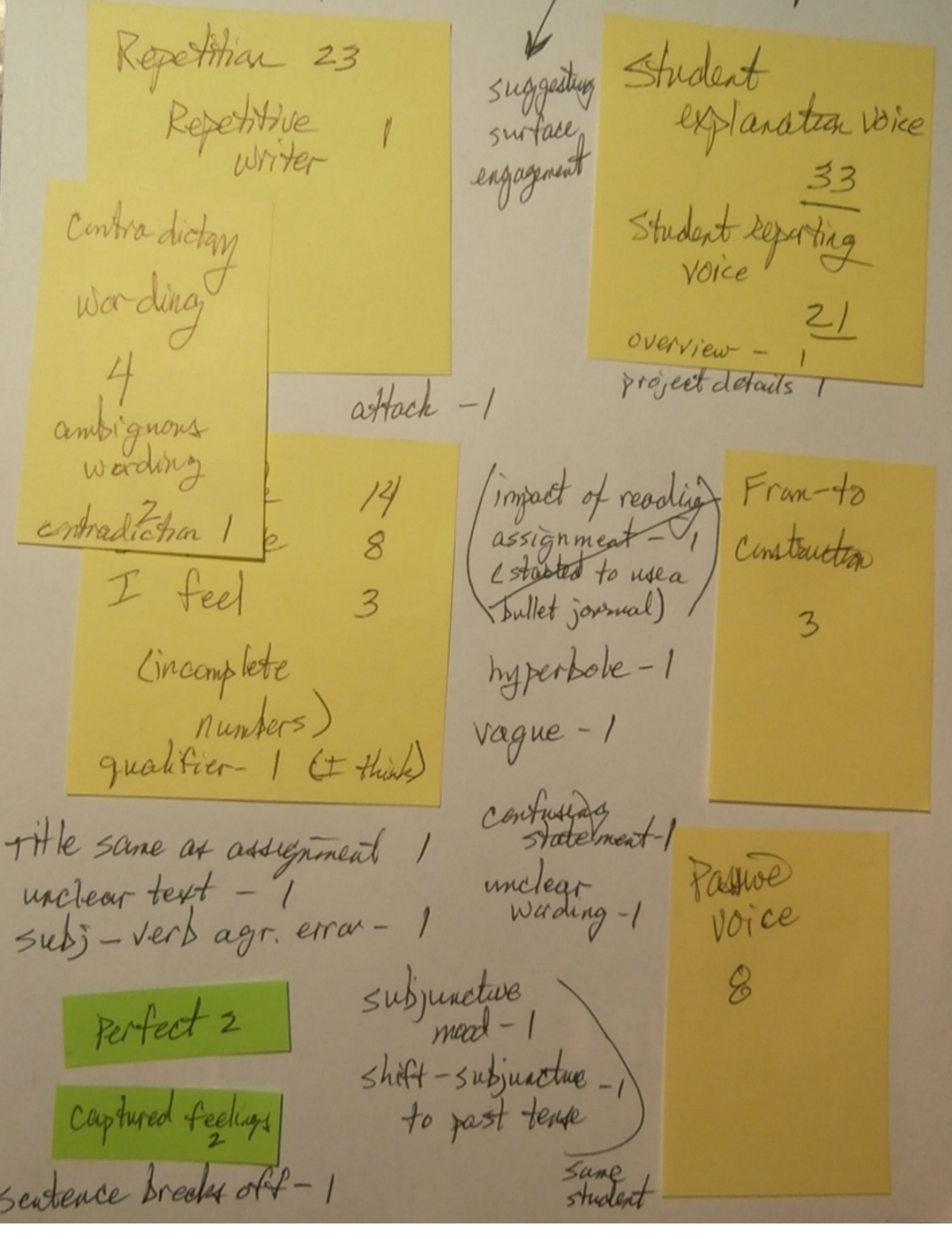


Writing Procest - descriptive of medal
state

Procrastixation

oxprogleot

$z$ (ifile) 9 ( 5 files)

Proc. - effect

writing

2

* $\begin{aligned} & \text { Exciting } 2 \\ & \text { Terrifing } 2\end{aligned}$

Research - Independent

Research-Surprise

Procest mesty 2

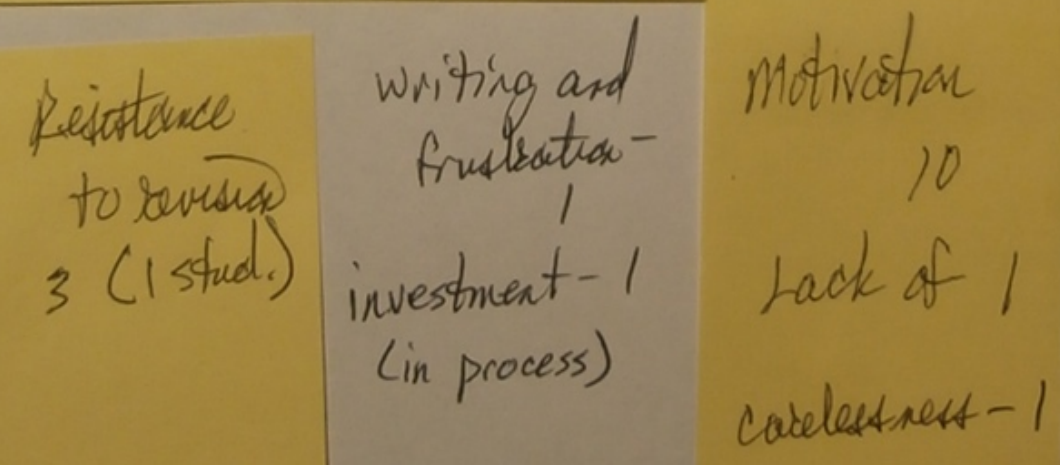

hasty wark I reflection-lock of -1
Gende- I

Gende Revision

Clast

assugnneent-

little effat

4
Hnesty (mostly Helen)
cobvious)
cexamiles - spelled ont examples - spelled 


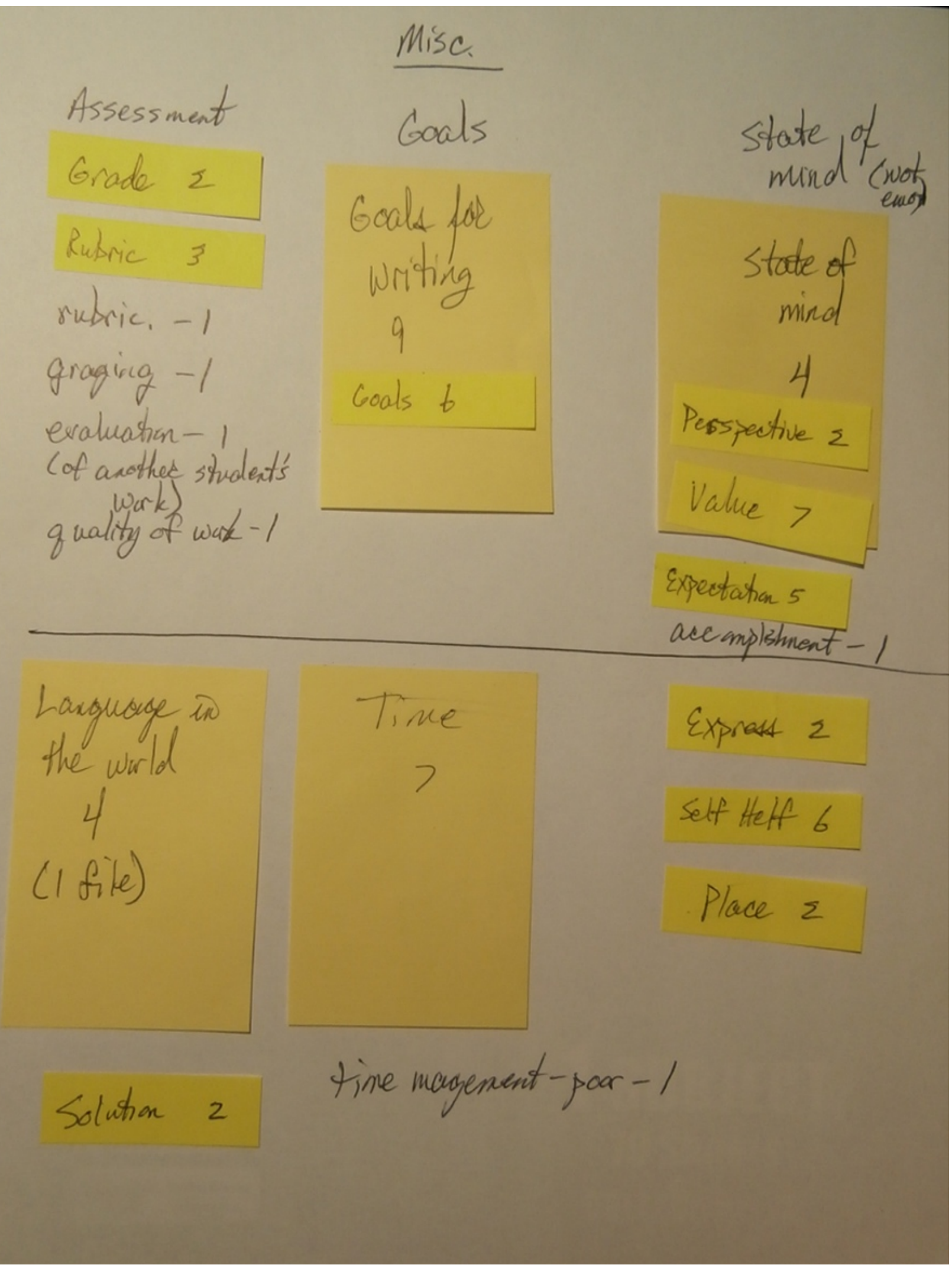


Wrating Invages

- Dog eyeing treat - doy interested in food, Quinn intedated in weitung, willing to learx more abont wreting

- Dog tearing us box - Joyce compaces love of do weitug to love of dog todx-up box repesents prustratiox with writng

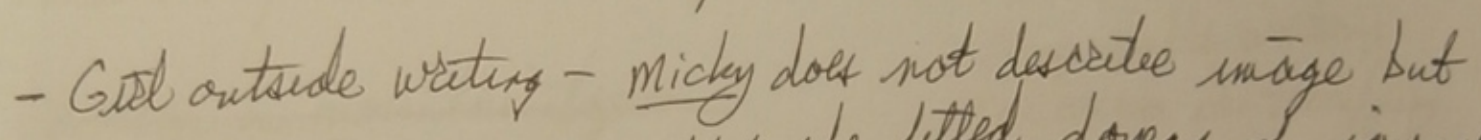
Also, persor or montantos says she fitted doyges of jorsuals,

Regresents succests, whicto she says is her purpose foc any "topic, prigect, o" to wont to be a writes, Writury puts her "at ease."

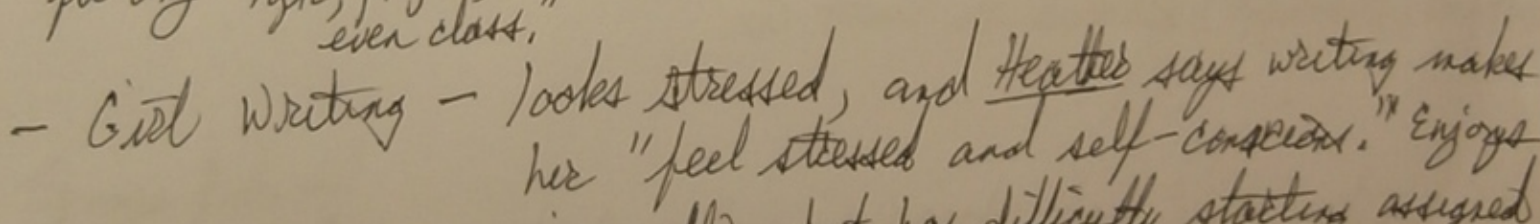
jorrialling but hat difficitty stactury astigned werting.

- Girl Warting - Writug is essape and a way of findurg (cactora image) solutions to problens. Relotes wirtury to finding her "true self" but also says it allowt lei to "Whoreved [she] wants to be withort anyore judging" hed. - Janio

207 
aht bulls - Heacey descriter wating as "challeaging"

- Cand gears inside but says that fong getting ideas a head) is "like wer a a lighttulb goes off in your head when you thint of [then]."

- Thanglet bubble - Repsesents both "creaturty and optuan" creaturety and "the difficutty of being stuch"

Adam (Dubble is empsty).

Relotes compiotence to creatuity.

- Roller coaster Jany calls writing "extuting or terdifying"

- Piano (keyboad-partion)- Lindsey sees a strong connectecer betwea wateng and the piano, most of whict she discusses in terins of ematrac (expresting enstows).

Sponge Bob -

Zaintoro, "Inagnatios" - Ber suggests theat inagiration is a brutge between the weter and his or ber tosio.

Sponge Bob - Helen says ler wating "stasts off with a gleat istea" but that she ofter changes et, and the pequect beconess a complete and utter mest."

208 
Test-Epreat Yonstelf - Black and whte letteing -

Wreting desicted as a meant of communicatio withat judgread.

stacey also uses" "withing to xelievo [hes] steast.

No Inage - Margie doscribes writug at a neans of communicatia communicatise and expressian of enotese creaturly and thangltt. She seefes to "more" an audience and approcher wetorg weto" patience, crestivety and an fer mind."

Wreturg smage - Descisptax self-exprastion - 3 Strest Reteof - 2

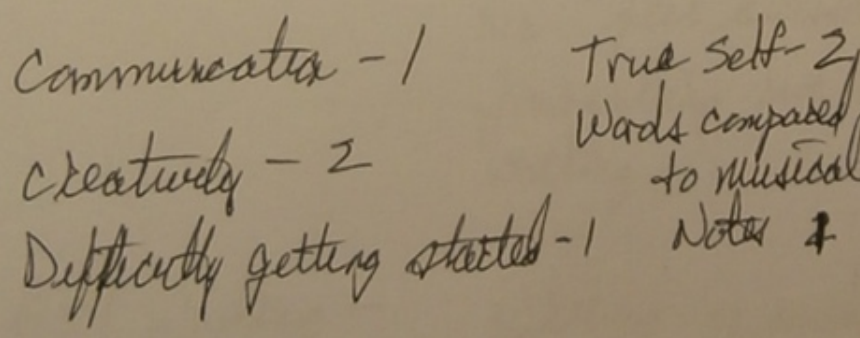

Escage

Frustatia I

Imaginatra,

True self- 2 Lore of Wietring I Wads compased Messy Procest I Light Bulb Misnentt I self-confidence I Succest

1 Thought and Enotus I Willingness

Writing as satelestery

209 